\title{
ANALYSIS OF TRUNK MUSCLE EMG DURING ROTATIONAL MOTION
}

by

\author{
Nika Zolfaghari \\ B. Eng., Ryerson University, Toronto, Ontario, Canada, 2012
}

\author{
A thesis \\ presented to Ryerson University \\ in partial fulfillment of the \\ requirements for the degree of \\ Master of Applied Science \\ in the Program of \\ Electrical and Computer Engineering
}

Toronto, Ontario, Canada, 2015

(C) Nika Zolfaghari 2015 


\section{AUTHOR'S DECLARATION FOR ELECTRONIC SUBMISSION OF A THESIS}

I hereby declare that I am the sole author of this thesis. This is a true copy of the thesis, including any required final revisions, as accepted by my examiners.

I authorize Ryerson University to lend this thesis to other institutions or individuals for the purpose of scholarly research

I further authorize Ryerson University to reproduce this thesis by photocopying or by other means, in total or in part, at the request of other institutions or individuals for the purpose of scholarly research.

I understand that my thesis may be made electronically available to the public. 


\title{
Abstract
}

\section{ANALYSIS OF TRUNK MUSCLE EMG DURING ROTATIONAL MOTION}

\author{
Nika Zolfaghari, B. Eng \\ Department of Electrical and Computer Engineering \\ Ryerson University, 2015
}

The study of seated balance, specifically for the application of wheelchair users, has been an area of interest for quite some time. Unfortunately, most of the available studies to date have focused on upper limb and shoulder muscles, and little has been done analyzing the activity of trunk muscles (abdominal and back). For the purpose of this study, motorized rotational motion in the forward and backward directions at \pm 45 degrees was simulated, and the corresponding trunk muscle activity of nine healthy subjects was recorded by surface electromyography (EMG) for eight muscles, including an analysis on the effect of holding on to a harness for support, coupled with the presence of a visual input. The collected raw data was filtered, and the produced results illustrated that the muscle activity was greatest in the forward rotational direction, when the subject was holding on to a harness for support, with visuals present. 


\section{Acknowledgements}

I would like to start off by thanking my supervisor, Dr. Kristiina McConville for being a mentor and for all of your guidance, encouragement, and patience during this process. I always felt calmed down after talking things through with you.

Thank you to my family for their unconditional love and support. Mom and Dad, I truly could not have done any of this without your wise words and encouragement. To my sister, Nojan, thank you for always managing a way to make me laugh during stressful times, when all I wanted to do was cry.

To my very special friends whom I've grown up with, thank you for your constant encouragement, and for showing me the meaning of true friendship.

A special thank you goes out to my lab partner and friend, Shahini Sirikantharajah, for all of your help throughout the process, especially during data collection. We spent many long tedious hours in the lab wondering if we were ever going to finish, but knowing that we were on this journey together. Also, thank you to Mohsen Shafeie for showing me the process as to how things were done.

Thank you to all of my colleagues and friends in the FEAS Dean's Office for your continual understanding and support throughout this process, and for making my time at Ryerson truly unforgettable.

Last but certainly not least, thank you to my committee members for taking the time out of your very busy schedules to accommodate me, and provide your feedback throughout this process. 


\section{Table of Contents}

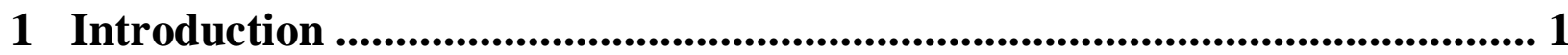

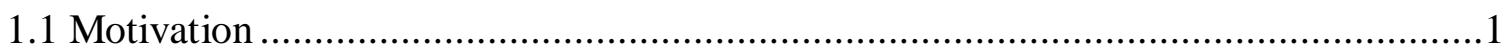

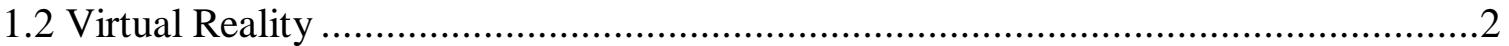

1.3 Rotational Angle in Real-World Applications .......................................................

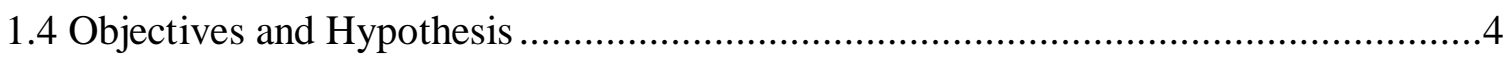

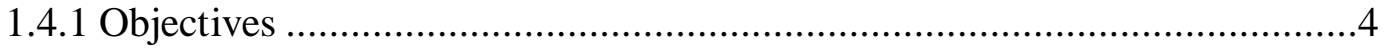

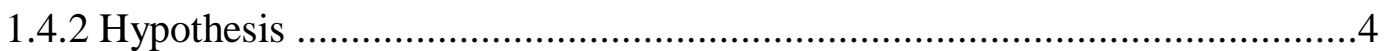

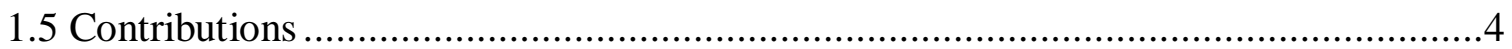

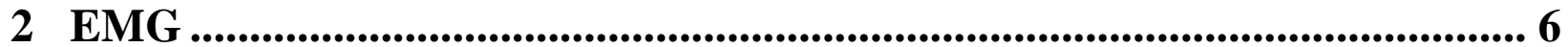

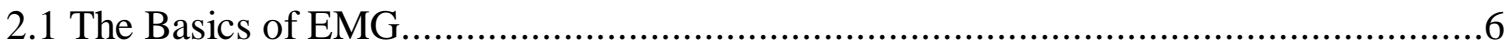

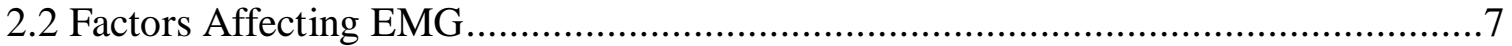

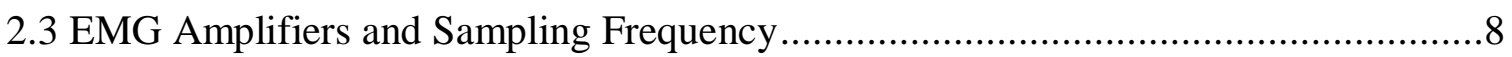

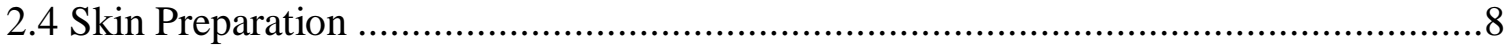

2.5 Surface Electrodes and Their Placement ..............................................................

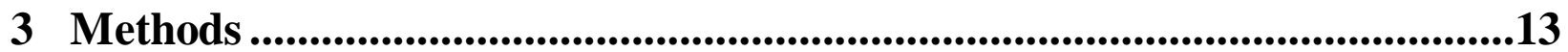

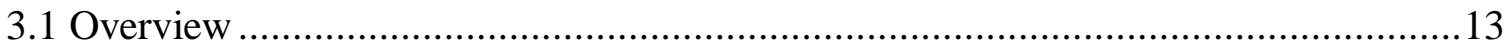

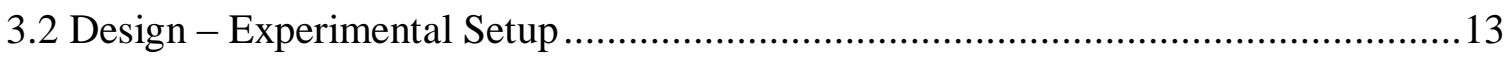

3.2.1 MaxFlight Motion Simulator .....................................................................13

3.2.1.1 System Specifications ………………………...........................13

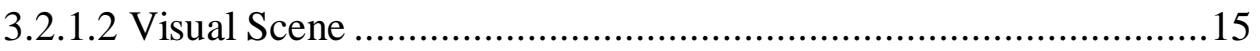

3.2.1.3 Safety Precautions ......................................................................16

3.2.2 CleveMed Bioradio 150 Acquisition System …………………................16

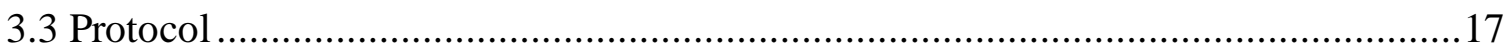

3.3.1 Subjects..........................................................................................

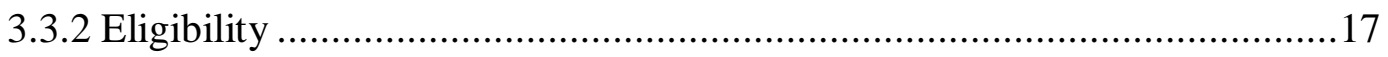

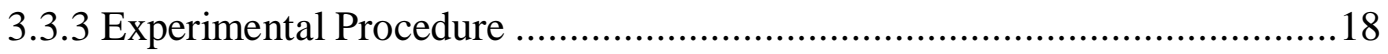


4 Signal Processing ...............................................................................................21

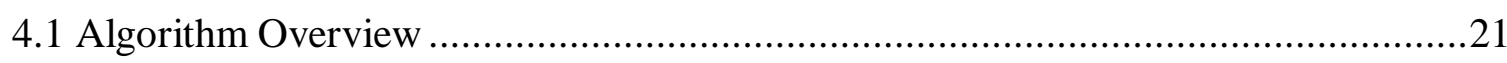

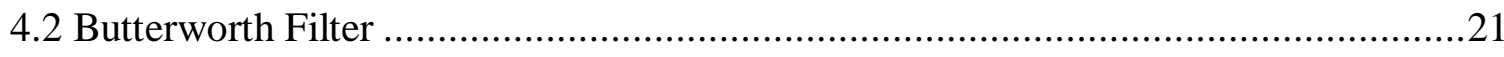

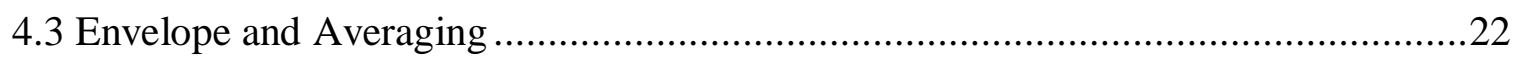

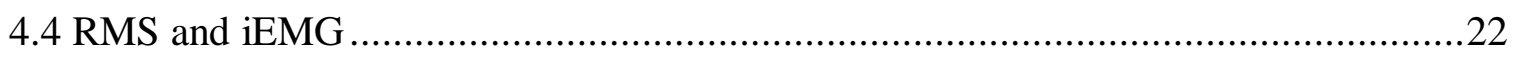

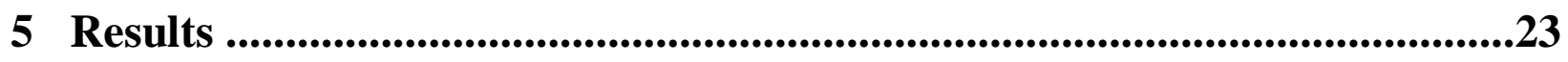

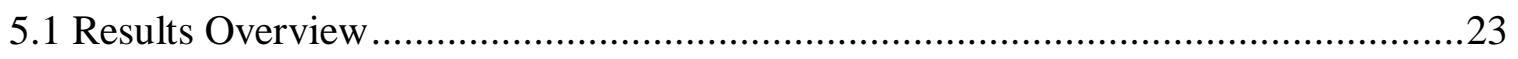

5.2 Sample Signal Processing Results ......................................................................24

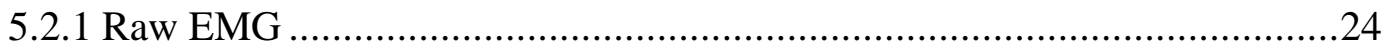

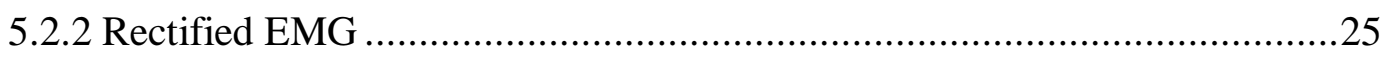

5.2.3 Butterworth Filtered EMG..................................................................25

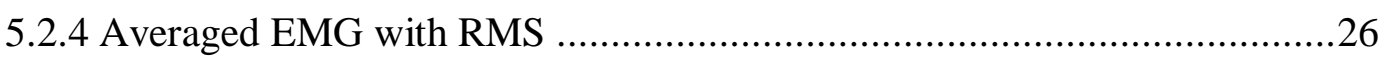

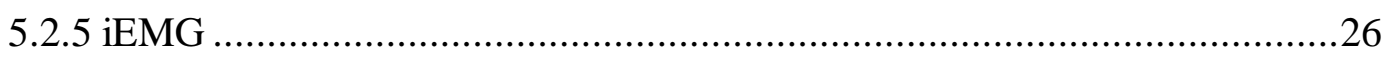

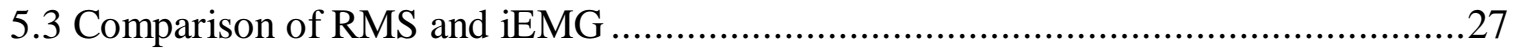

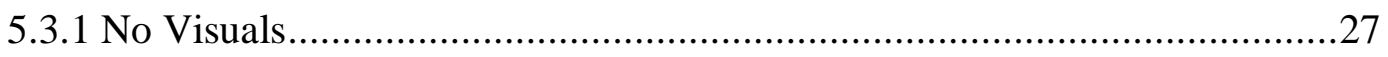

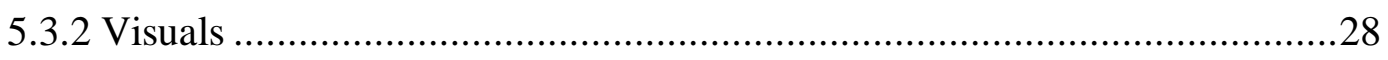

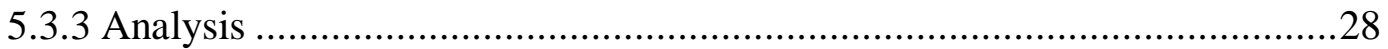

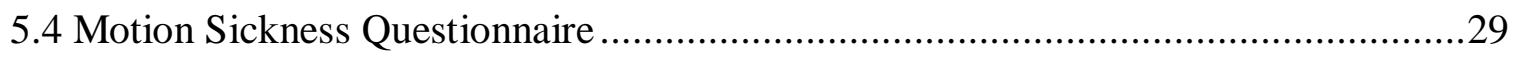

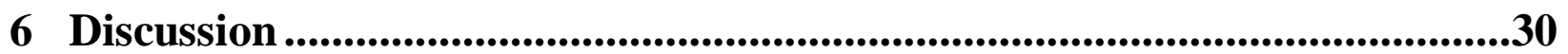

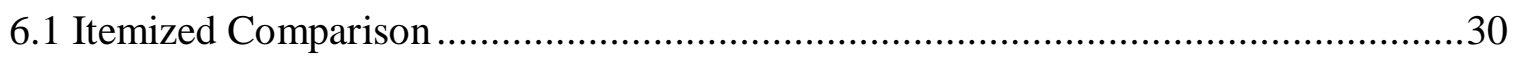

6.1.1 Amplitude and Overall Response..............................................................30

6.1.2 RMS and iEMG................................................................................. 30

7 Conclusion ..................................................................................................................34 


\section{List of Tables}

Table 1: Ohm Test Across Electrodes to Ensure Sufficient Skin Impedance [34] .....................9

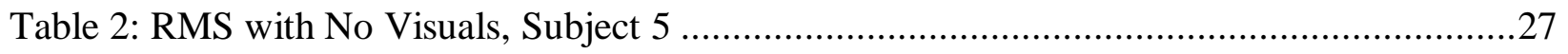

Table 3: iEMG with No Visuals, Subject 5 ..............................................................27

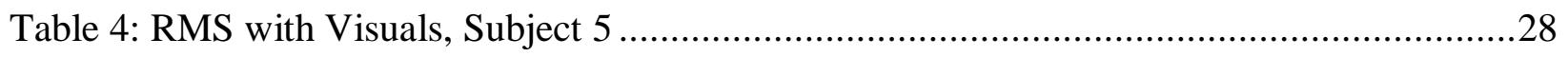

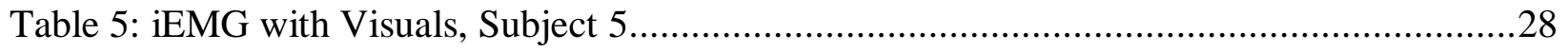




\section{List of Figures}

Figure 1: Process of Signals Picked Up by the EMG Electrodes [34] .....................................6

Figure 2: Shape of a Raw EMG Signal Consisting of Three Contractions [34]..........................

Figure 3: 3M Red Dot Surface Electrodes Used in This Study ...............................................

Figure 4: Upper Body Anatomical Landmarks in Relation to Electrode Placement [34].............10

Figure 5: Frontal View of Muscles Which Can Use Surface and Needle Electrodes [34] ...........11

Figure 6: Dorsal View of Muscles Which Can Use Surface and Needle Electrodes [34] ............12

Figure 7: MaxFlight Simulator in the Resting Position, Closed Cockpit ...................................14

Figure 8: MaxFlight Simulator with an Open Cockpit ..........................................................

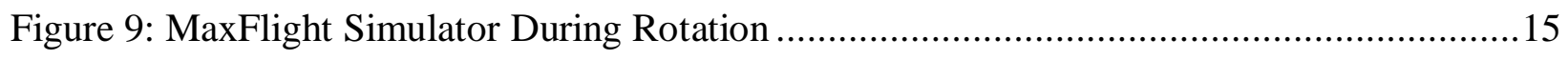

Figure 10: Position of Selected Trunk Muscles in Relation to the Human Body [38] .................18

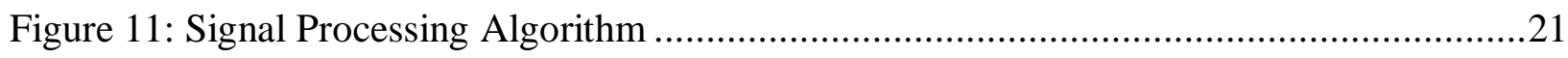

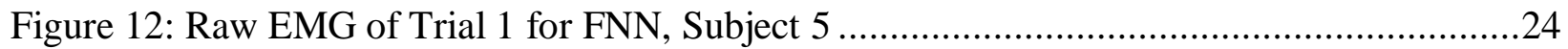

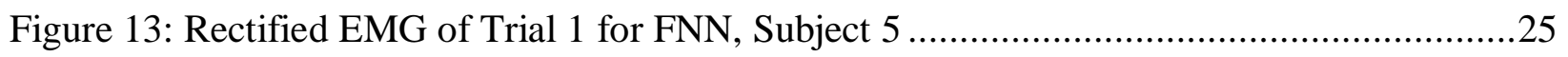

Figure 14: Butterworth Filtered EMG of Trial 1 for FNN, Subject 5 ....................................25

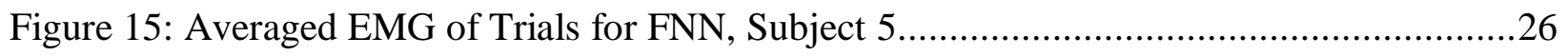

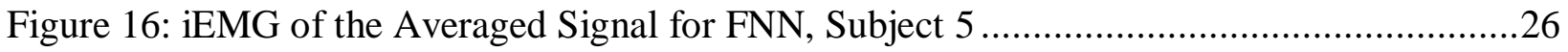




\section{List of Appendices}

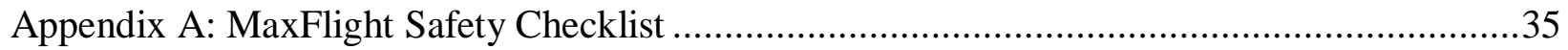

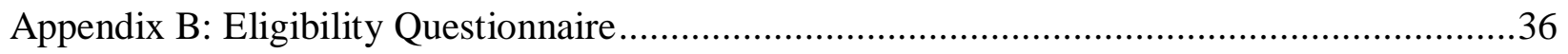

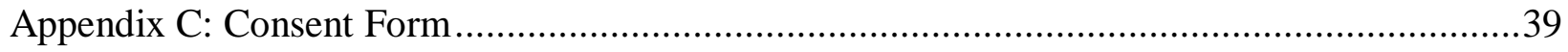

Appendix D: Motion Sickness Questionnaire ..............................................................46

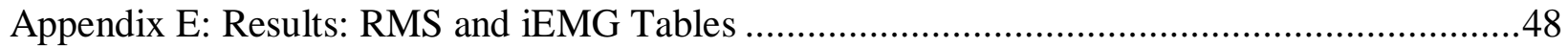

Appendix F: Results: Averaged EMG Figures ..........................................................66 


\section{Chapter 1}

\section{Introduction}

\subsection{Motivation}

The study of seated balance and postural control has become an area of increased interest in the field of biomedical engineering, specifically rehabilitation research. This area of research has a wide array of applications including, but not limited to, spinal cord injury, stroke, and Parkinson's patients. Understanding the factors which affect seated balance is especially important when it comes to dealing with individuals in wheelchairs. For these patients, regaining their mobility, and most importantly, their independence holds high priority. Furthermore, it has been found that since sitting is a major activity in the daily lives of wheelchair users, their seated balance can play a large role in their level of independence. ${ }^{[1]}$ It can be argued that wheelchairs have accomplished these goals to a certain extent. However, they may also have serious drawbacks, as prolonged use has been shown to cause injuries and lead to discomfort. ${ }^{[2]}$ These injuries include carpal tunnel syndrome ${ }^{1}$, joint pain, back pain, and tendonitis ${ }^{2}$, all of which can be caused when the wheelchair goes over uneven surfaces and/or ramps. ${ }^{[2-7]}$ Wheelchair users commonly experience vibrations when utilizing ramps for accessibility purposes, travelling over uneven surfaces when using sidewalks, or crossing the street. When these users ascend or descend ramps, they lean forwards and backwards in the opposite direction of motion in order to reduce tipping, in turn shifting their centre of mass. ${ }^{[8,9]}$ Previous studies have shown a link between the amount of directional leaning back and forth, and the strength of abdominal muscles. ${ }^{[3]}$ It is important to note that the degree to which these patients can stabilize their bodies upright is dependent on the strength of their abdominal muscles, and many of these users have weak abdominal muscles due to either atrophy ${ }^{3}$ or spinal cord injury itself. ${ }^{[10]}$ Furthermore, it

\footnotetext{
${ }^{1}$ Compression of a major nerve in the hand or fingers caused by repetitive motions over a long period of time, leading to a sensation of tingling, numbness, and pain.

${ }^{2}$ Overuse of a tendon, leading to inflammation.

${ }^{3}$ Wasting away, or decline in effectiveness due to the degeneration of cells.
} 
becomes essential to evaluate the reaction of abdominal muscles during motion in order to perform further analysis in this field.

In terms of previous studies which have been done assessing muscle contractions while in motion, specifically during wheelchair propulsion, the majority have studied upper limb and shoulder muscles, and very few have focused on abdominal and trunk muscles. ${ }^{[11,12]}$ In fact, it has been suggested that in order to maintain a controlled upright posture during forward wheelchair propulsion, the strength of the lower trunk and abdominal muscles surrounding the spinal cord play a key role. ${ }^{[13,14]}$ In studies performed by Yang et $\mathrm{al}^{[13]}$ and Howarth et al ${ }^{[15]}$, examining abdominal and lower back muscles via electromyography (EMG) during forward wheelchair propulsion, it was found that muscle activity was highest at the initial stages of motion. ${ }^{[13,15]}$ Moreover, most studies to date have been done in relation to manual wheelchair propulsion, and on even surfaces. However, motorized wheelchairs and scooters are being used more commonly in today's society, and as previously mentioned, wheelchairs usually go over uneven surfaces. Therefore, the starting focus of this study is to further evaluate the effect of motorized wheelchair movement on trunk muscles.

\subsection{Virtual Reality}

One of the best ways to test the link between visuals and physical movement is via virtual reality, as it allows for the study of the interaction between perception and behaviour ${ }^{[16]}$, as well as the opportunity to recreate the complexity of the world in a controlled lab setting. ${ }^{[17,18]}$ A lot of the time, the individual's perception of the world is enhanced when accompanied by visuals, as it provides an additional dimension and depth perception to interpret the surrounding environment. ${ }^{[19]}$ Virtual reality is a synthetic version of the real world, in turn, allowing for isolated and customized control over physical variables, while recording the kinematic and

psychological response of the subject. ${ }^{[20,21]}$ As a study by Wilson et al pointed out, virtual reality can be used as a reliable method for rehabilitation training. ${ }^{[22]}$ It is important to note that the most effective virtual reality condition is one in which the visuals and real world environments are synced. Furthermore, when it comes to maintaining balance, visuals play an important role; especially in the case that other sensory inputs such as proprioceptive and vestibular senses are 
deficient. ${ }^{[23]}$ Although virtual reality has been extensively studied for the purpose of training and rehabilitation, little has been done in the field to date in regards to seated balance for wheelchair

users. ${ }^{[24-26]}$ However, when testing during rotational motion, the chances of experiencing motion sickness increase according to the sensory conflict theory. This theory states that when there are conflicting visual and vestibular inputs, disequilibrium occurs, resulting in motion sickness. ${ }^{[27,28]}$

\subsection{Rotational Angle in Real-World Applications}

It is important to determine an appropriate rotational angle which relates back to its real world applications for SCI patients or other individuals in wheelchairs. Garg et al $^{[29]}$ performed studies which illustrated that when patients are transferred from a bed to a wheelchair, or from a shower chair to a wheelchair, their bodies are subjected to 25 degrees of motion. Forslund et al ${ }^{[30]}$ performed a similar study, in which patients were transferred from a table onto a wheelchair. They found that females experience rotational angles of 42 degrees, and men experience rotational angles of 31 degrees. Thus, if our study were to utilizes a rotational angle of 45 degrees, it would account for all of those movements. Moreover, when an individual in a wheelchair is being pushed over a curb, their rotational angle is close to 45 degrees as well. Furthermore, previous studies done in this area, such as the ones by Chow et al, ${ }^{[8]}$ and Howarth et $\mathrm{al},{ }^{[15]}$ only focus on very minimal rotational angles of 12 degrees, making our study more encompassing.

It should also be noted that when a wheelchair user is manually propelling or controlling the wheelchair themselves, they can better anticipate the road conditions ahead of them, such as an uneven sidewalk or small pot hole/ditch. However, when they are being advanced by another individual, they may not be paying as much attention to the upcoming road conditions. Our study resembles this condition, as the subjects were not in control of the upcoming motion, and thus could not mentally or physically prepare their bodies. 


\subsection{Objectives and Hypothesis}

\subsubsection{Objectives}

For the purpose of this study, seated motorized rotary motion at \pm 45 degrees will be assessed in the forward and backward pitch directions on abdominal and back muscle contractions as obtained by surface EMG. Additional aspects which will be evaluated include the effects that holding on to a harness for support, as well as the presence of a visual stimulus have on the muscles. The specific muscles which will be studied include the Rectus Abdominis (RA), External Oblique (EO), Thoracic Erector Spinae (TE), and Lumbar Erector Spinae (LE), which are similar to the trunk muscles used in comparable studies. ${ }^{[13,15,31]}$

\subsubsection{Hypothesis}

It is hypothesized that the muscles' response to the forward and backward motions will be relatively equal as they are being subjected to the same rotational angle. It is further hypothesized that the presence of a visual stimulus will have an effect on the muscles' response as it will affect the brain's perception of motion, which will translate to the muscle fibers. Moreover, it is hypothesized that the muscle activity will be greater when the subjects are not holding on to the harness for support, as their trunk muscles will be the sole body parts responsible for stabilization.

\subsection{Contributions}

This thesis originated from a pilot study in which in which the same eight muscles were analyzed during pitch and roll rotations on a different motion simulator, known as the Space Ball. This motion simulator is similar to the MaxFlight motion simulator, which was used as part of this thesis, except it does not contain an enclosed cockpit, thus it is not a fully immersive virtual reality experience. The pilot study was performed on two subjects, and the results were published in two peer-reviewed publications. ${ }^{[18,19]}$ For this thesis, the scope of the study was to be expanded, thus approval from the Ryerson University Research Ethics Board was sought after, 
which would allow us to use the fully immersive MaxFlight motion simulator on a larger population size.

While approval from the Research Ethics Board was pending, another small study was performed in which the effectiveness of dry versus wet electrodes for the purpose of signal acquisition from the human body was assessed. Those results were also published in peerreviewed publications, including a journal. ${ }^{[32,33]}$

One approval from the Research Ethics Board was granted, eligible subjects were recruited, and the required data was acquired. Next, a MATLAB code was written which filtered the raw data in preparation for analysis. Detailed descriptions of each step in the process will be described in the coming chapters, including an analysis of the results. 


\section{Chapter 2}

\section{EMG}

\subsection{The Basics of EMG}

EMG deals with the analysis of myoelectric signals, which are given from muscle fibers when there are variations in their physiological state ${ }^{[34]} \mathrm{EMG}$ is becoming a widely used tool in many areas including sports training, physiotherapy, rehabilitation, and research. Reasons for its wide use stem from its many benefits. For example, it detects muscle response to various external and internal stimuli, helps patients effectively train muscles, improves sport activities, and aids in the decision making process before and after surgery. ${ }^{[34]}$ In turn, the EMG signal is based on the action potentials in the muscles, as it picks up the potential difference between two electrodes, as shown in Figure 1.

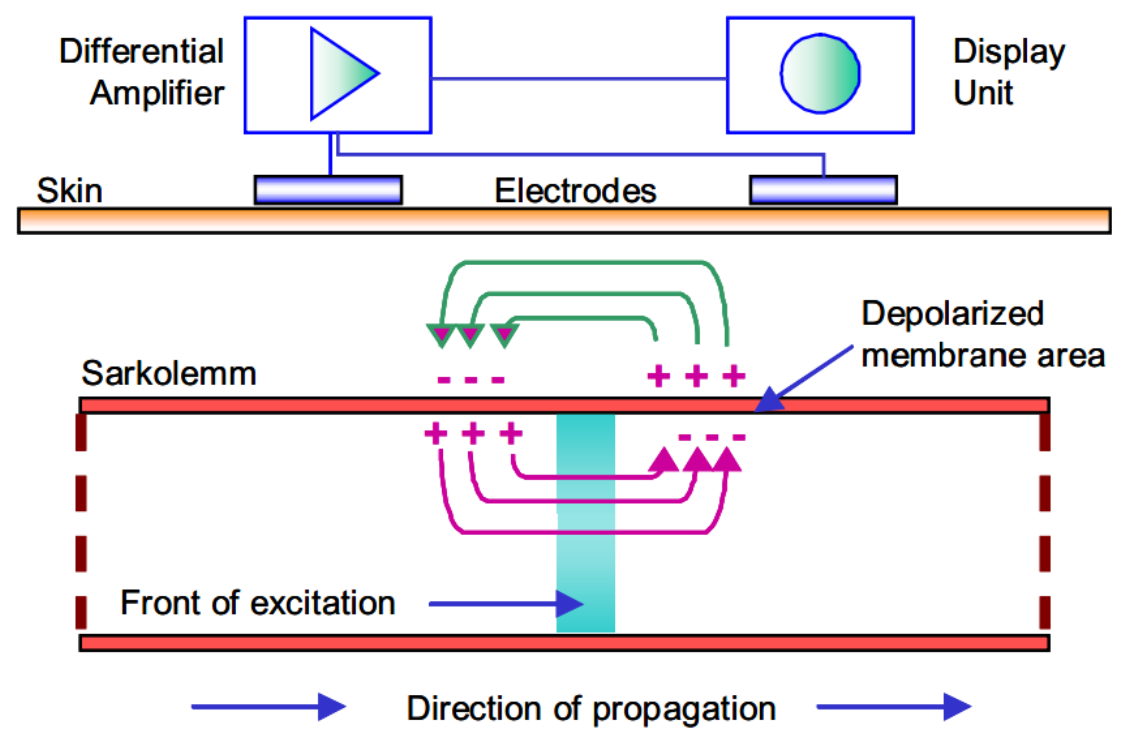

Figure 1: Process of Signals Picked Up by the EMG Electrodes [34]

Whereas other signals acquired from the body, such as electrocardiogram (ECG), are generally uniform in their shape and structure, unfiltered raw EMG signals have more of a random shape by nature, as illustrated in Figure 2. This means that a raw EMG spike is not reproducible. This 
occurs because the set of motor units which are used to fire up the muscle constantly changes. ${ }^{[34]}$ Moreover, if two or more motor units are charged at the same time, they produce a large spike in the signal. This effect can be minimized by filtering.

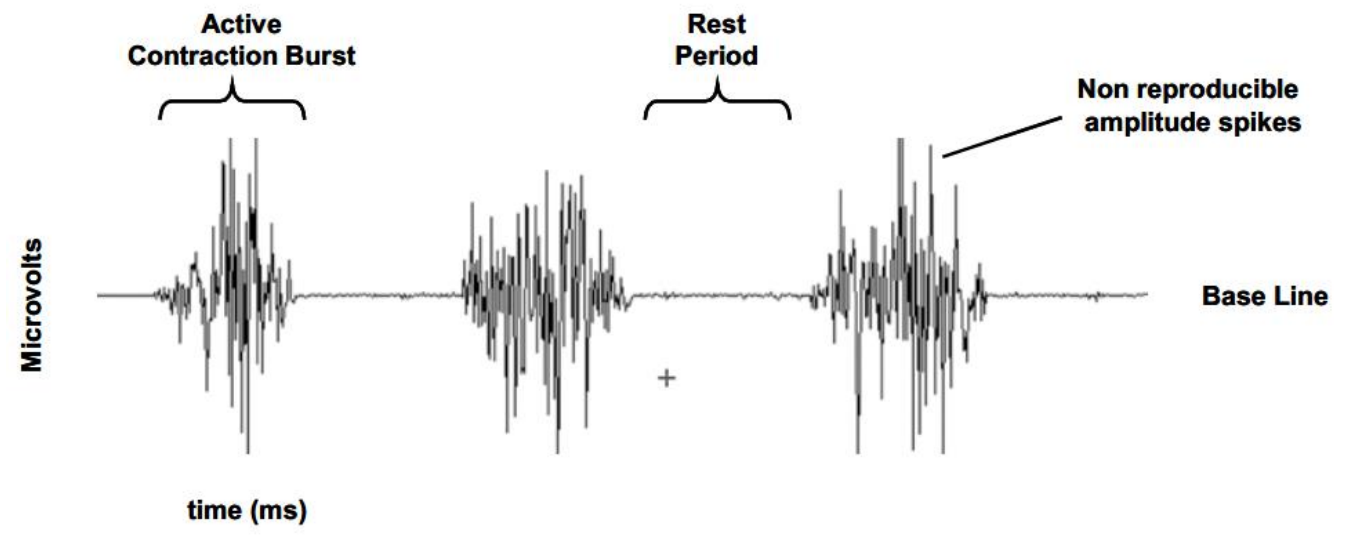

Figure 2: Shape of a Raw EMG Signal Consisting of Three Contractions [34]

\subsection{Factors Affecting EMG}

Once data is collected from the surface EMG, it needs to be processed. Since the layers of skin and underlying tissue act a low pass filter between the signal and the electrodes, the obtained data does not represent the characteristics of the desired original signal. ${ }^{[34]}$ The EMG signal can be influenced by the following factors which affect the characteristics and shape of the signal ${ }^{[34,}$ 35]:

External Noise: this can be caused by either incorrect grounding, or by being placed in close proximity of other electrical devices.

Physiological Cross Talk: based on the location of the electrodes, it is possible for them to pickup muscle activity from other nearby muscles. Therefore, it is very important to make sure that electrode placement is as precise as possible.

Amplifiers and Electrodes: The quality of the chosen electrodes may add noise to the signal. In addition, if amplifier specifications are not properly carried out, they may also result in unwanted noise. 
Tissue Characteristics: It may be difficult to directly compare an EMG of one person to that of another since everyone has their own unique tissue type, characteristics, and thickness which all affect the recorded signal.

Geometrical Changes between Electrode and Muscle Placement: Particularly in cases where an EMG is recorded during motion, the altered placement of the electrode as compared to initial placement may affect the quality of the signal.

\subsection{EMG Amplifiers and Sampling Frequency}

The main purpose of amplifiers in EMG applications is to eliminate artifacts. This is done as the amplifier detects the potential difference between the electrodes and rejects external interferences. ${ }^{[34]}$ When dealing with EMG amplifiers, the term common mode rejection ratio (CMRR) is crucial in determining the quality of an amplification technique, as it represents the difference between differential and common mode gain. ${ }^{[34]}$ In order to eliminate noise caused by external signals, it is desirable to have the CMRR as high as possible (greater than $95 \mathrm{~dB}) .{ }^{[34]}$ It is also important to note than before a recorded signal can be analyzed on a computer, it needs to be converted from analog to digital via A/D conversion. To that extent, it is important to select an appropriate sampling frequency according to the Nyquist sampling theorem, which states that the sampling frequency must be at least twice that of the maximum expected frequency. ${ }^{[34]}$ According to this theorem, to avoid signal loss for an EMG signal with an amplifier setting between 10 and $500 \mathrm{~Hz}$, a sampling frequency of at least 1000 or $1500 \mathrm{~Hz}$ must be used. ${ }^{\text {[34] }}$

\subsection{Skin Preparation}

For ideal placement of the electrodes, the electrode should come in contact with low skin impedance. In order for this to occur, the skin needs to first be prepped, usually by cleaning the contact area with alcohol. This will remove any dead skin cells, sweat, and dirt, and result in high impedance (the skin will in most cases be a light red colour). ${ }^{[34]}$ If alcohol is not available, sand paper or various cleaning creams may be used to accomplish the same task. If there is hair in the contact area, it should be removed prior to alcohol cleaning. 
In order to verify good skin impedance conditions, the Ohm test can be performed between two electrodes. Table 1 can be used as a guide to ensure that proper conditions for a clean signal are met:

\begin{tabular}{|c|c|}
\hline $\begin{array}{c}\text { Impedance range } \\
(\mathrm{KOhm})\end{array}$ & Recommendation \\
\hline $\mathbf{1 - 5}$ & -very good condition \\
\hline $\mathbf{5}-\mathbf{1 0}$ & - good and recommended if feasible \\
\hline $\mathbf{1 0}-\mathbf{3 0}$ & - acceptable for easy conditions \\
\hline $\mathbf{3 0 - 5 0}$ & - less good, attention is needed (see next chapter) \\
\hline$>50$ & - should be avoided or requires a second cleaning run \\
\hline
\end{tabular}

Table 1: Ohm Test Across Electrodes to Ensure Sufficient Skin Impedance [34]

\subsection{Surface Electrodes and Their Placement}

In the case that surface muscles are being analyzed, surface electrodes suffice, and are rather easier to use. However, should the desired muscles be deeper (either below the bone or covered by surface muscles), needle electrodes will have to be utilized. The most common kind of surface electrodes used are $\mathrm{Ag} / \mathrm{Ag} \mathrm{Cl}$ (silver/silver chloride) electrodes, with a diameter of approximately $1 \mathrm{~cm}$, specifically, wet gel electrodes deliver the highest impedance. ${ }^{[34]}$ Figure 3 illustrates the surface electrodes used in this study. It is also important to note that the smaller the electrode, the higher the impedance value. A rule of thumb in applying two electrodes to a muscle is to aim to maintain a $2 \mathrm{~cm}$ inter-electrode distance, which is from the centre of one electrode to the centre of the next; electrodes measuring the same muscle should be applied in parallel. $^{[34]}$

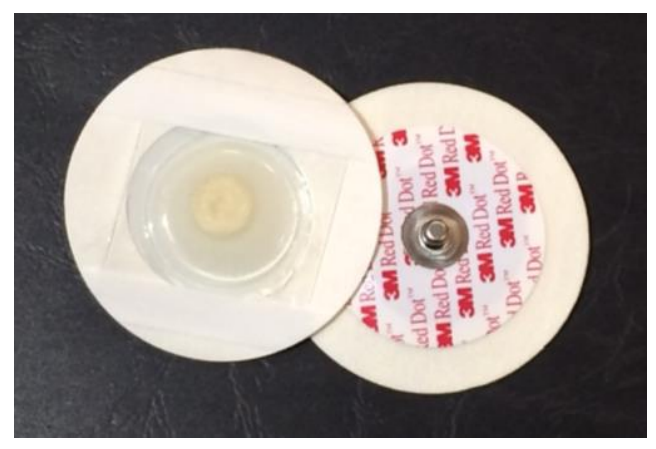

Figure 3: 3M Red Dot Surface Electrodes Used in This Study 
In order to determine electrode placement, most of the time documents will refer to the distance an electrode has to be from an anatomical landmark. Figure 4 illustrates some universal anatomical landmarks which many documents refer to in order to direct proper electrode placement. For the purpose of this study, the main landmarks which will be used are the umbilicus, and spinosus.
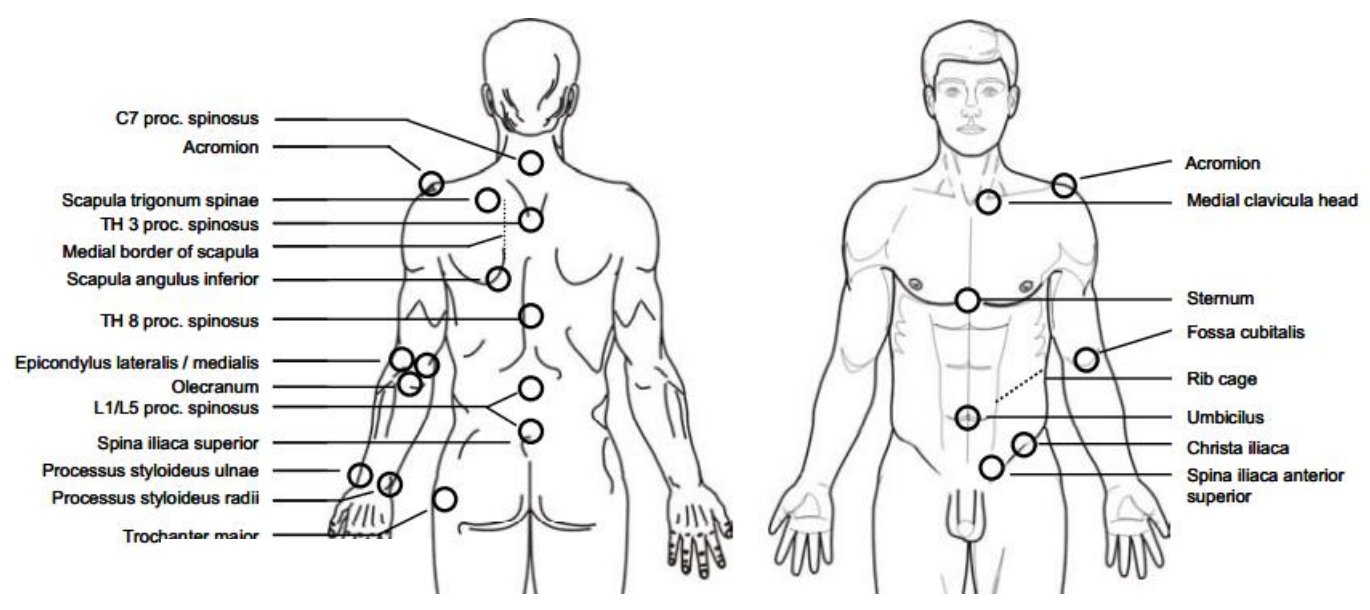

\section{Figure 4: Upper Body Anatomical Landmarks in Relation to Electrode Placement [34]}

If electrodes are going to be placed on an area of high motion, such as the stomach muscles, it is important to ensure that the electrodes are secure, and to keep in mind that they may move around as the skin in that area may stretch in motion, causing the electrodes to detach from the skin. ${ }^{[34,36]}$ In such dynamic experiments, it is a good idea to secure the electrodes and cables to the body in order to avoid the electrodes being pulled off of the skin. The cables and electrodes can be secured using basic tape, elastics, or bandages, keeping in mind that they should not be secured too tightly, to allow for movement.

In order to determine which muscles can use surface electrodes, and which ones require needle electrodes, the diagram in Figures 5 and 6 can be used as a guide: 
Fine Wire Sites:

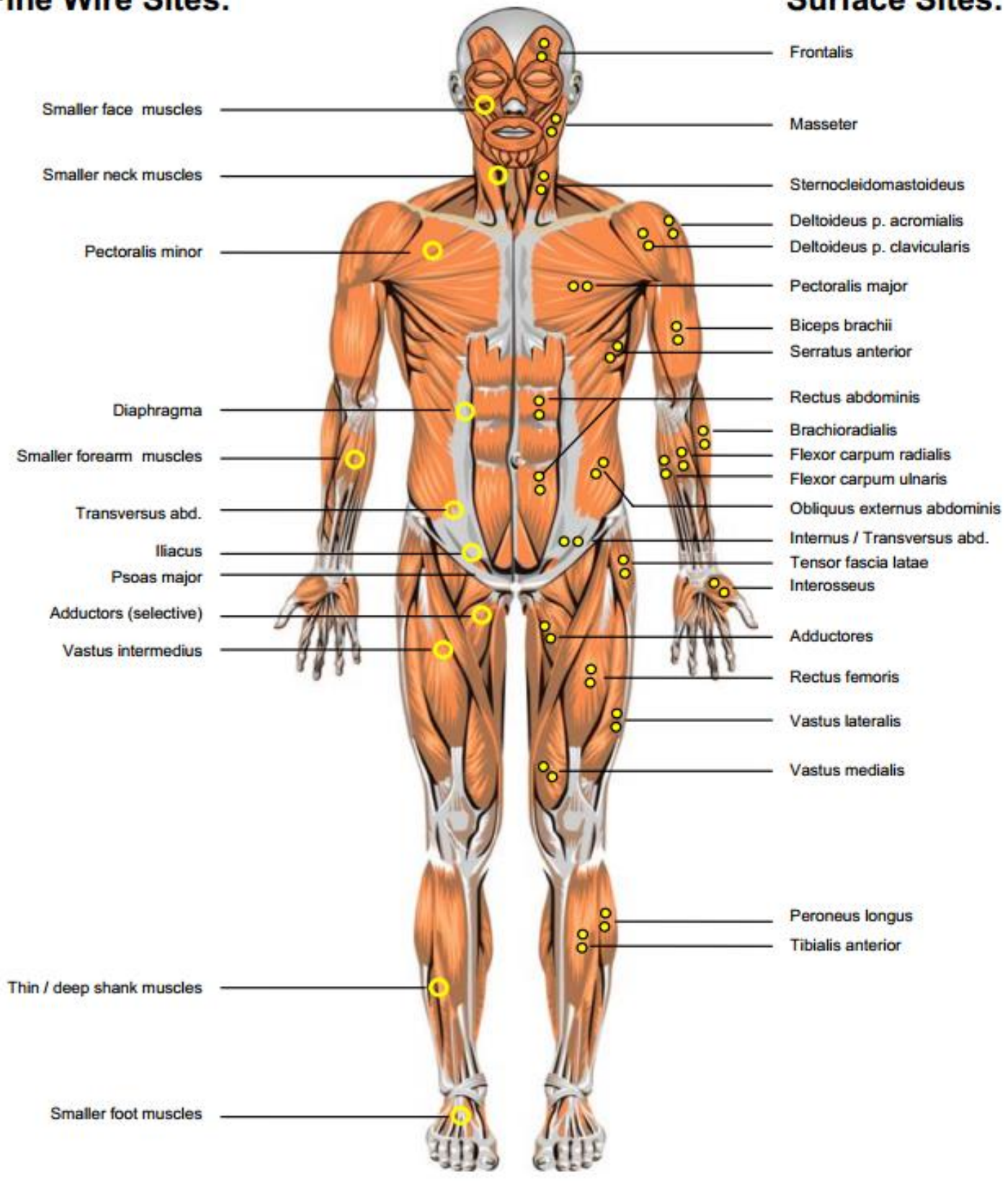

Figure 5: Frontal View of Muscles Which Can Use Surface and Needle Electrodes [34] 


\section{Fine Wire Sites:}

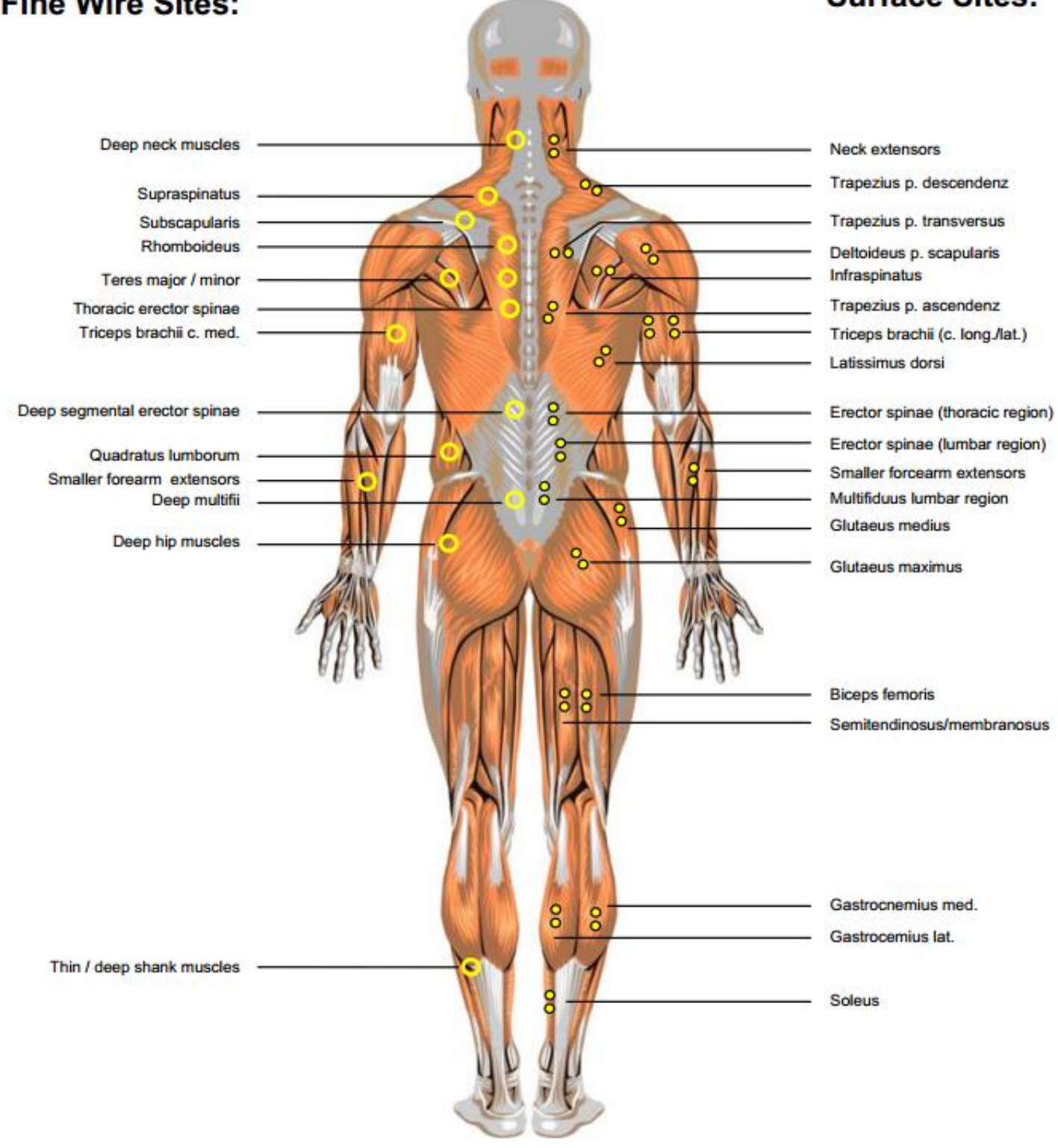

\section{Figure 6: Dorsal View of Muscles Which Can Use Surface and Needle Electrodes [34]}

When obtaining EMG signals, it is important that a reference, or ground, electrode be placed as well. This will set a baseline when analyzing EMG signals, and should be placed close to the other electrodes, but far enough away that it will not be affected by movement. ${ }^{[34]}$ Common placements for reference electrodes are at joints, such as the elbow. 


\section{Chapter 3}

\section{Methods}

\subsection{Overview}

This study has been examined and approved by the Research Ethics Board at Ryerson University prior to the commencement of data collection. In order to reach the objective, electrodes were attached to the target muscles of the subjects from a wireless acquisition device, and the subjects were securely seated in the MaxFlight FS-VC Dual System motion simulator. The simulator was then rotated forwards and backwards 45 degrees, three times in each direction under a variety of circumstances, while the acquisition system recorded the muscles' EMG. This was then repeated with the screen turned off so that no visuals were playing. In between the recordings, the subjects were given a short break, during which they filled out a motion sickness questionnaire to ensure that they are capable of continuing in the study. A detailed explanation of the procedure can be found in section 3.3 Protocol.

\subsection{Design - Experimental Setup}

\subsubsection{MaxFlight Motion Simulator}

\subsubsection{System Specifications}

The MaxFlight FS-VC Dual System motion simulator, Figure 7, is the only 360 degrees pitch and roll simulator in the world. It seats two passengers side-by-side, as shown in Figure 8, and there is a large screen directly in front of them. The simulator comes with two pre-programmed modes: rollercoaster and flight simulator. In each mode, the simulator's motion corresponds to the visuals playing on the screen via a projector, creating a fully immersive experience. 


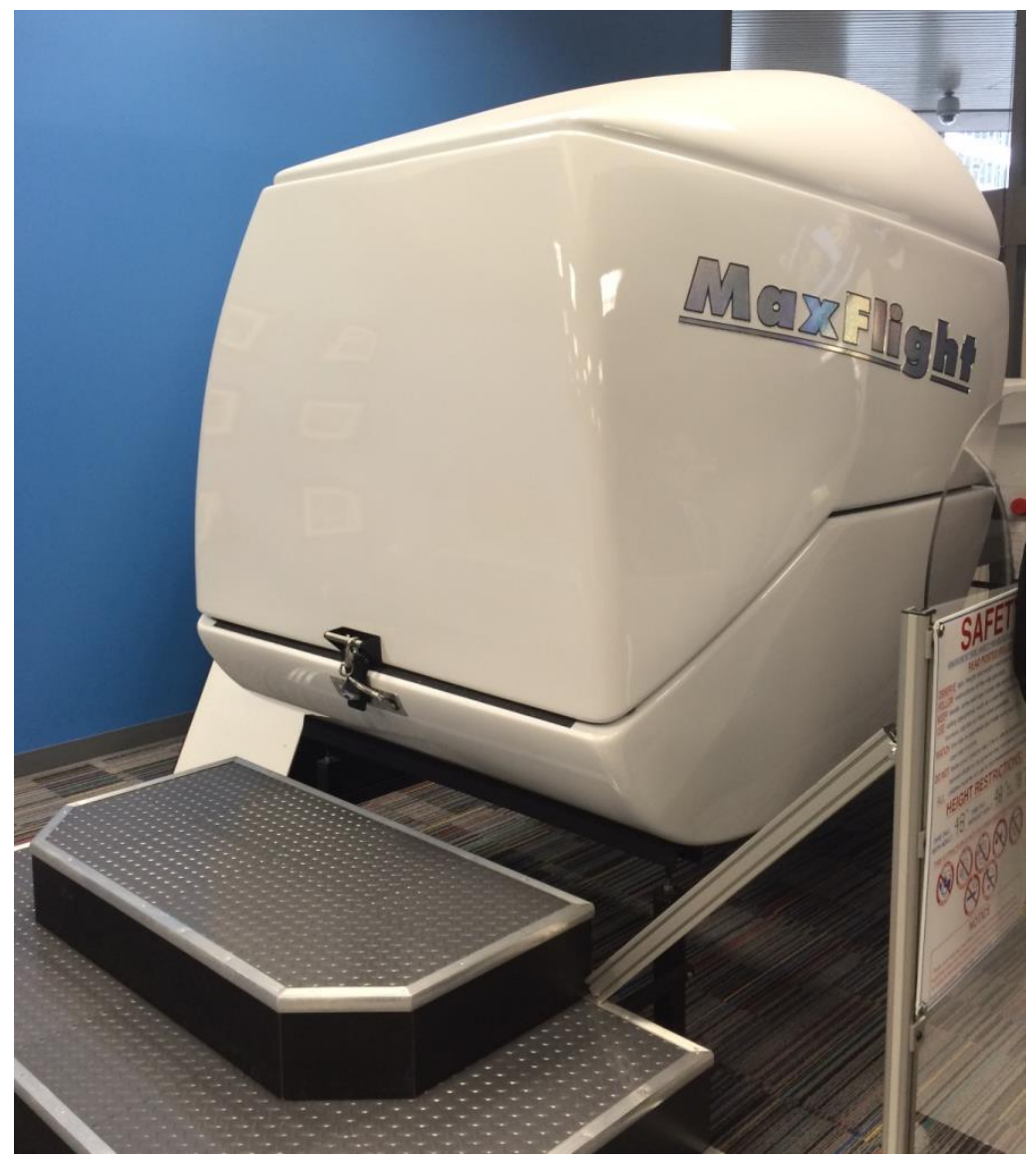

Figure 7: MaxFlight Simulator in the Resting Position, Closed Cockpit

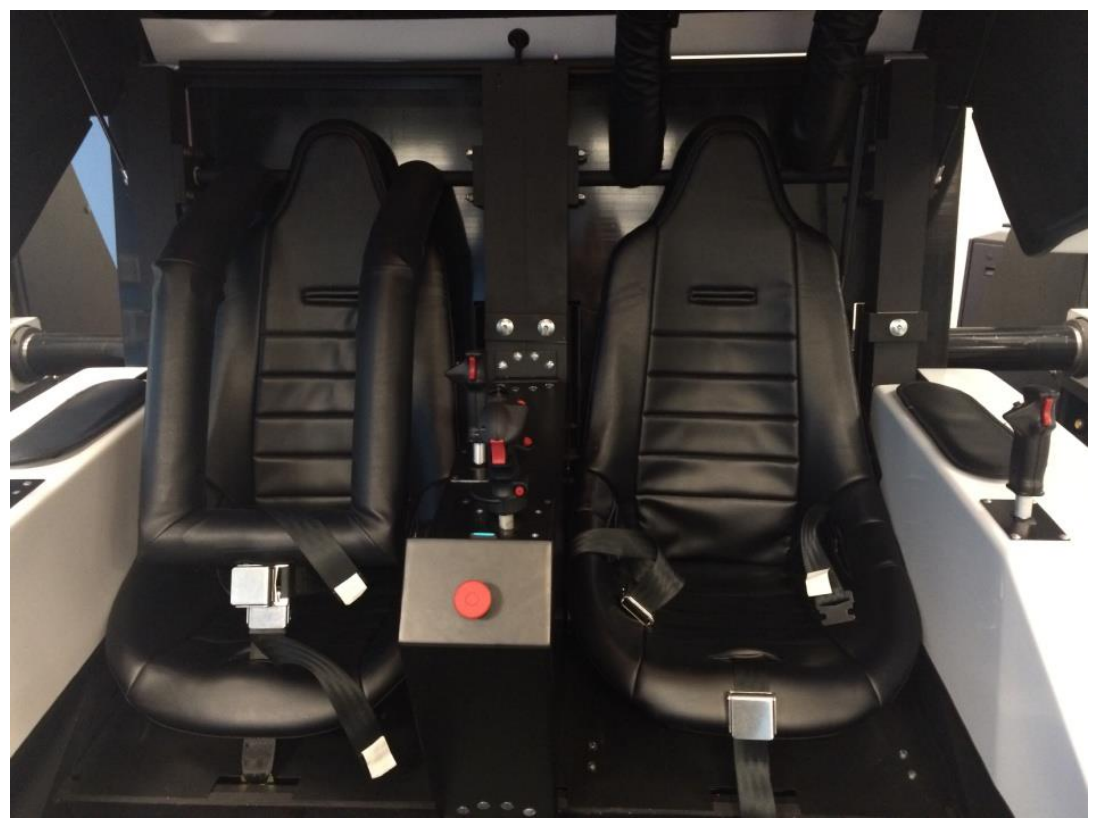

Figure 8: MaxFlight Simulator with an Open Cockpit 
In addition to the pre-programmed modes, there is also the option of manually controlling the angle of rotation in either the pitch or roll direction. Again, the angle of rotation can be set anywhere between 0 and 360 degrees in either the forward or backward direction, as illustrated by Figure 9. When manually controlling the motion, the projector can be turned on, and will play a short repetitive clip which gives the user a sense of forward and backward motion.

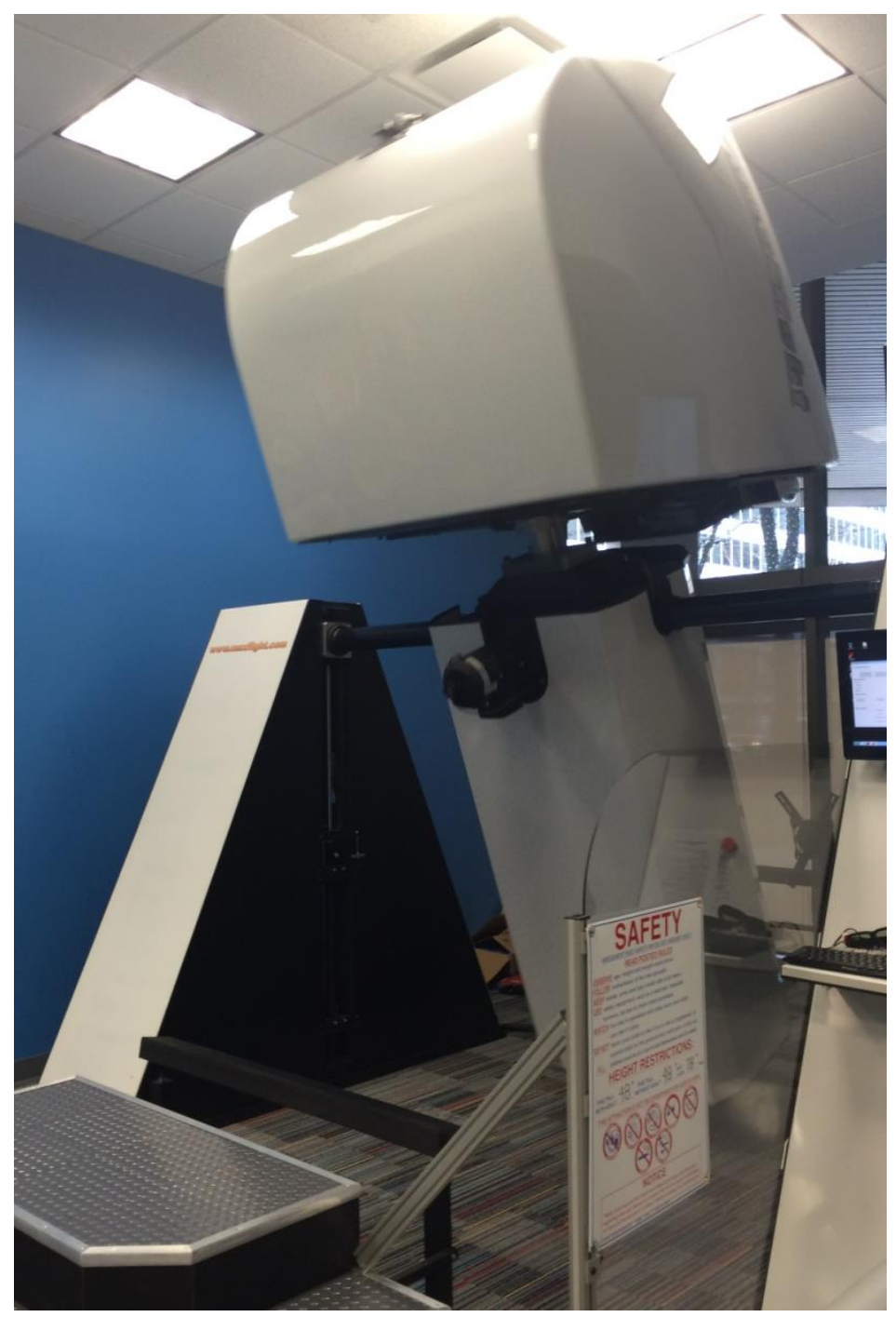

\section{Figure 9: MaxFlight Simulator During Rotation}

\subsubsection{Visual Scene}

As previously mentioned, the visuals displayed on the screen when the simulator is in one of the pre-programmed modes, such as the rollercoaster mode, are completely in sync and matched with the motion profile of the simulator. However, when the motion of the simulator is managed 
manually, such as the case for this study, then the only option for the visual scene was a dynamic screen saver. This screen saver was set it a dark stone tunnel, with the words "MaxFlight Simulator" in a 3D yellow font rotating in the yaw direction up and down the tunnel. In essence, since the cockpit was dark when it was closed, looking at the screen gave the user a sense of vection and the perception that they were moving forward and backwards in the tunnel.

\subsubsection{Safety Precautions}

The device itself has minimal objective travel displacement, speed, and acceleration. In an unlikely case, the compartment could become stuck in an inverted position due to power failure or other malfunction, therefore there are always two trained operators present, and manual recovery procedures will be carried out. There is a stop button within arm's reach within the compartment to enable the occupant to return the compartment to an upright position and stop the experience at any time. The operator remains at the controls at all times and can stop the movement immediately in any position, or terminate the cycle and return in minimal time to the neutral position. A Ryerson University technical officer has overall oversight of device maintenance, and all trained operators have a safety checklist which is followed before any participants are loaded (this checklist can be seen in Appendix A). The investigators fasten the seatbelts and harness, and make sure that everything is secured. They also perform a test run of the motion without any passengers boarded to ensure that everything is running as it should. If the seatbelts are not fastened, or the door is not closed securely, an error message shows up on the computer control screen, and the simulator will not move until the errors have been cleared. In addition, the floor of the facility was reinforced to meet or exceed the manufacturer's specifications for floor loading, and there are fire extinguishers in the facility in the case of a fire.

\subsubsection{CleveMed Bioradio 150 Acquisition System}

Surface EMG of the abdominal and lower back muscles were recorded by placing two $\mathrm{Ag} / \mathrm{AgCl}$ electrodes (3M $\mathrm{M}^{\mathrm{TM}}$ Red Dot ${ }^{\mathrm{TM}}$ Monitoring Electrodes) on each muscle, with an approximate interelectrode distance of $3 \mathrm{~cm}$. The electrodes were then connected to snap-leads which were hooked up to the CleveMed Bioradio 150 data acquisition system, which was in turn connected to a computer by a wireless receiver. The wireless CleveMed Bioradio 150 data acquisition 
system is capable of displaying and recording physiological signals through eight channels, allowing us to record from up to eight muscles. It consists of a user unit, which easily clips on to the subject's clothes allowing for mobility, and a USB receiver, which wirelessly receives the signals from the user unit and transfers them to a computer for viewing and analysis. ${ }^{[37]}$

\subsection{Protocol}

\subsubsection{Subjects}

Nine subjects were used in this study for data acquisition; seven females and two males, between 20 and 30 years of age. As the purpose of the study was to set the baseline for how healthy muscles should be contracting, only healthy subjects were used.

\subsubsection{Eligibility}

Subjects were asked to fill out an eligibility questionnaire (Appendix B), which was used to determine their eligibility for the study. Subjects were excluded from participation if they had any previous injuries or pre-existing medical conditions as outlined in the eligibility questionnaire, including a history of motion sickness. If they were eligible, they continued on the same day. In addition, there were three balance tests: In the first test, they were asked to achieve and maintain balance on a balance board. The second test was a static posture test, the "Romberg" test; they stood with both feet together and hands by their side with eyes closed as the evaluator examined their swaying for a full minute. In the third test, they were asked to stand on one foot with eyes closed. Their performance on these tests was timed (one minute each), and they must have passed all the tests in order to be eligible for the study.

The eligibility questionnaire consists of three parts. For part 1, answering "No" to question 3 and/or "Yes" to questions 4-12 would have made a participant ineligible for the study. Also, for the second part of the questionnaire $(\mathrm{ABC})$ if the participant reported less than $50 \%$ on a majority of the questions, they were ineligible. If they reported $50 \%$ or higher on a majority of the questions, but scored less than $50 \%$ on any of the questions, the Romberg and other physical balance tests were used to determine eligibility. If a participant performed poorly on the balance 
tests, then they were ineligible (the results of the physical balance tests should correlate with the results of the $\mathrm{ABC}$ eligibility test). Finally, for the third part of the questionnaire, answering "Yes" to any of these questions would have made the participant ineligible.

\subsubsection{Experimental Procedure}

Once a subject has met the eligibility requirements and signed the consent form (Appendix C), their muscles were wiped with alcohol swabs in preparation for electrode attachment. Two $\mathrm{Ag} / \mathrm{AgCl}$ electrodes (3MTM Red $\operatorname{Dot}^{\mathrm{TM}}$ Monitoring Electrodes) were placed on each of the following trunk muscles with an approximate interelectrode distance of $3 \mathrm{~cm}$ : Rectus Abdominis (RA) $-3 \mathrm{~cm}$ lateral to the umbilicus (belly button), External Oblique (EO) $-5 \mathrm{~cm}$ lateral to the rectus abdominis, Thoracic Erector Spinae (TE) $-5 \mathrm{~cm}$ lateral to the T9 spinal disk, and Lumbar Erector Spinae (LE) $-3 \mathrm{~cm}$ lateral to the L4 spinal disk. As previously mentioned, these muscles play a key role in seated balance, and were chosen for that reason. Figure 10 illustrates the position of these muscles within the human body.
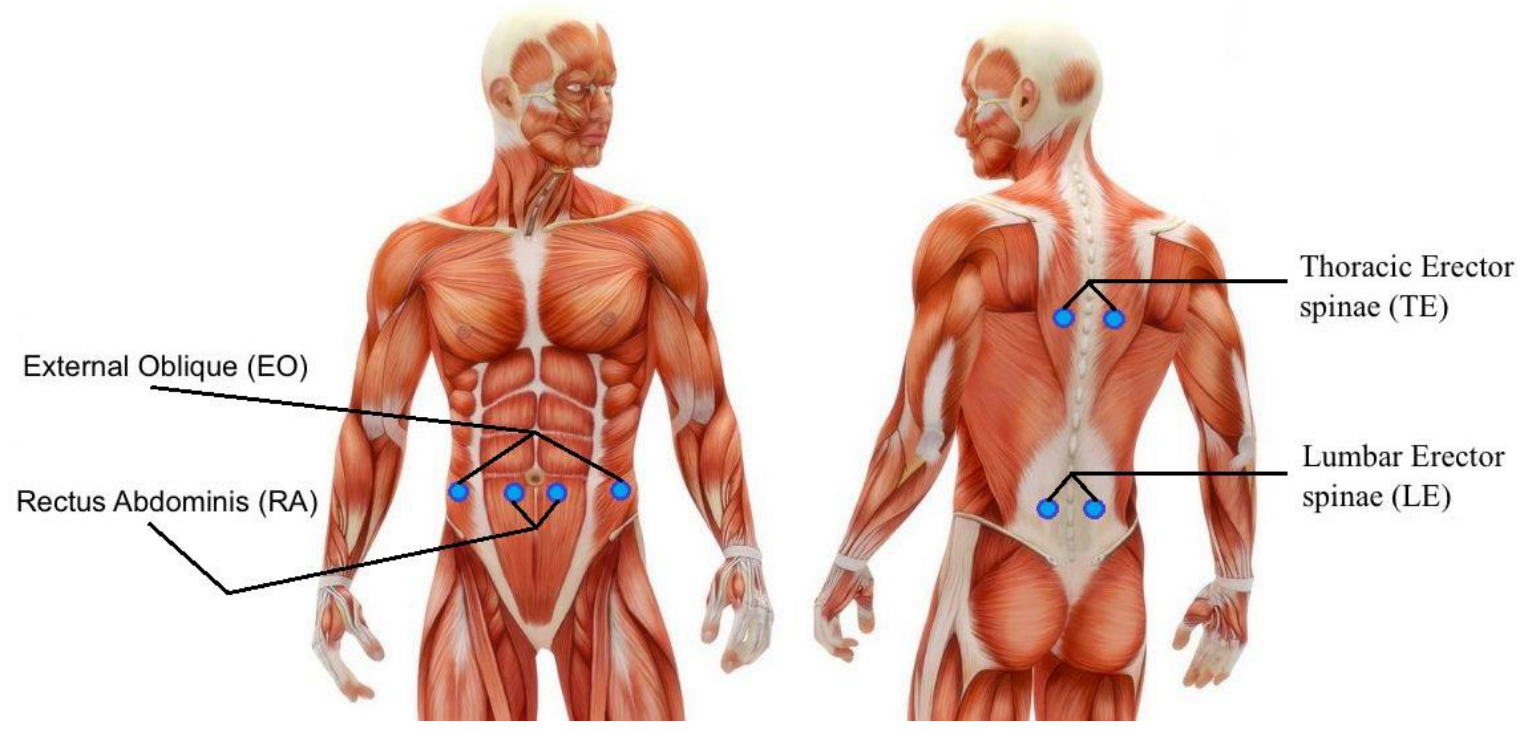

Figure 10: Position of Selected Trunk Muscles in Relation to the Human Body [38]

The electrodes were then connected to snap-leads which were hooked up to the CleveMed Bioradio 150 data acquisition system, which was in turn connected to a computer by a wireless receiver. The subject was then seated and securely fastened into the motion simulator and was informed about some important safety features and emergency responses. 
A series of tests were done where the subjects were subjected to rotational motion. Four tests were done in the forward direction, and four tests were done in the backwards direction, each resulting in a rotation of 45 degrees (it takes one second to reach this angle). Half of these tests were done while a visual was playing on the screen in front of the subjects. Specifically, the four tests in each direction included:

- Holding onto the harness without any visuals on the screen

- Holding onto the harness with visuals playing on the screen

- Placing hands on lap without any visuals on the screen

- Placing hands on lap with visuals playing on the screen

This resulted in a total of eight tests:

- Backwards direction, holding onto the harness with no visuals on the screen (BHN)

- Forwards direction, holding onto the harness with no visuals on the screen (FHN)

- Backwards direction, holding onto the harness with visuals playing on the screen (BHV)

- Forwards direction, holding onto the harness with visuals playing on the screen (FHV)

- Backwards direction, not holding on with no visuals on the screen (BNN)

- Forwards direction, not holding on with no visuals on the screen (FNN)

- Backwards direction, not holding on with visuals on the screen (BNV)

- Forwards direction, not holding on with visuals on the screen (FNV)

Essentially, in each direction we were testing to see if there was a difference in the trunk muscles' response between holding onto the harness, and not holding in conjunction with the presence of visuals on the screen.

For accuracy purposes, the trials were randomized. First, the test with the visual scene present were performed. The subjects were told hold on to the harness, but were not told whether they would be travelling in the forward or backwards directions (three trials were performed in each direction, randomized). Next, the subjects were told to not hold on to the harness, but were not told whether they would be travelling in the forward or backwards directions (three trials were performed in each direction, randomized). The subjects were then given a ten minute break where they were asked to complete the motion sickness questionnaire (Appendix D). If the 
results of the motion sickness questionnaire showed that the subject was experiencing motion sickness, they were given the option of either taking a longer break or coming back to record the rest of the data on another day. After the break, the exact same procedures were performed again, but this time with no visuals present. At the end of the experiments, the subjects were asked to complete a motion sickness questionnaire again. As there were three trials for each test, in total, there were twenty-four trials per subject.

All of the acquired data was stored on a computer for further analysis. 


\section{Chapter 4}

\section{Signal Processing}

\subsection{Algorithm Overview}

Data acquisition was done at a sampling frequency of $960 \mathrm{~Hz}$. Once data collection was complete, the signals needed to be filtered before proper analysis could be done. As only the onset of motion was analyzed, the data before and after the main motion were removed. Figure 11 illustrates the signal processing techniques used.

\section{Raw EMG}

Figure 11: Signal Processing Algorithm

\subsection{Butterworth Filter}

Once the signals were rectified, the noise needed to be reduced, therefore, they were passed through a $4^{\text {th }}$ order low-pass Butterworth filter with a cut-off frequency of $6 \mathrm{~Hz}$, as it was found that this frequency produced the best results, and resulted in the cleanest signal without losing any of the important signal properties. The magnitude-squared frequency response shown in equation (1) characterizes the filter.

$$
|H(\Omega)|^{2}=\frac{1}{1+\left(\Omega / \Omega_{c}\right)^{2 N}}=\frac{1}{1+\varepsilon^{2}\left(\Omega / \Omega_{P}\right)^{2 N}}
$$


Where $\mathrm{N}$ is the order of filter, $\Omega \mathrm{c}$ is the cut-off frequency, $\Omega \mathrm{p}$ is the pass-band edge frequency, and $1 /(1+\varepsilon 2)$ is the band edge value of $|H(\Omega)| 2$.

\subsection{Envelope and Averaging}

Once the signals were passed through a Butterworth filter, their envelopes were obtained, which serve as a good representation of the overall shape and activity of the muscle.

For this study, three trials were performed for every component of data collection. Not all of the trials produced identical signals due to biological and external factors during data acquisition, which resulted in slightly different muscle responses. For example, the electrodes may have shifted during motion, or the muscles may have experienced an unexpected spasm. Therefore, averaging the three trials for each testing condition not only helped in reducing some of the random noise, but it resulted in a single signal which embodied the key factors which were desired, such as amplitude and duration. In turn, this method accounted for the slight deviations which naturally occurred during data acquisition.

\subsection{RMS and iEMG}

The amount of muscle activity was calculated by finding the root mean square (RMS) of the averaged signal. RMS is a common statistical measure of the magnitude of a changing quantity. In this context, the RMS represents the strength of the contraction. It is essentially the square root of the average of the squares of a set of numbers, as illustrated in equation (2).

$$
x_{r m s}=\sqrt{\frac{1}{n}\left(x_{1}^{2}+x_{2}^{2}+x_{3}^{2}+\cdots+x_{n}^{2}\right)}
$$

Furthermore, the work done by the muscle, or the amount of contractions, can be identified by finding the integral of the signal (iEMG), i.e. the area under the curve, as represented by equation (3).

$$
i E M G=\int_{0}^{t} E M G d t
$$




\section{Chapter 5}

\section{Results}

\subsection{Results Overview}

All of the calculations and figures were performed and obtained using MATLAB. Since there were eight muscles being evaluated for nine subjects, under four conditions, a plethora of figures were produced. For the purpose of this section, a small representative sample of the results will be displayed, and the full set can be found in Appendices E and F. Upon analysis of the results, it was found that subject 5 had the most representative results overall in the different categories, and thus their data will be shown in this section as a sample.

As previously mentioned, data was acquired during a rotational angle of \pm 45 degrees, in both the forward and backwards pitch motions. Furthermore, each condition was accompanied by either the presence or absence of visuals, with the subject either holding on to the harness or not holding on at all. In total, this gave us 8 conditions under which data was acquired.

Furthermore, each of the eight channels represents a different muscle as according to the following:

Ch.1: Right Rectus Abdominis (RA)

Ch.2: Left Rectus Abdominis (RA)

Ch.3: Right External Oblique (EO)

Ch.4: Left External Oblique (EO)

Ch.5: Right Lumbar Erector Spinae (LE)

Ch.6: Left Lumbar Erector Spinae (LE)

Ch.7: Right Thoracic Erector Spinae (TE)

Ch.8: Left Thoracic Erector Spinae (TE) 


\subsection{Sample Signal Processing Results}

The following figures serve as a visual representation of the signals (FNN used as an example) as they go through the signal processing algorithm shown in Figure 11 for subject 5.

\subsubsection{Raw EMG}

As it can be seen in Figure 12, the raw EMG signals were quite noisy, so it was essential that filtering techniques be used before any analysis could take place. Furthermore, some of the muscle responses were in the positive direction, whereas others were in the negative direction. This could have been due to the electrode placement, or the nature of the muscle's response, therefore, the graphs were all rectified.

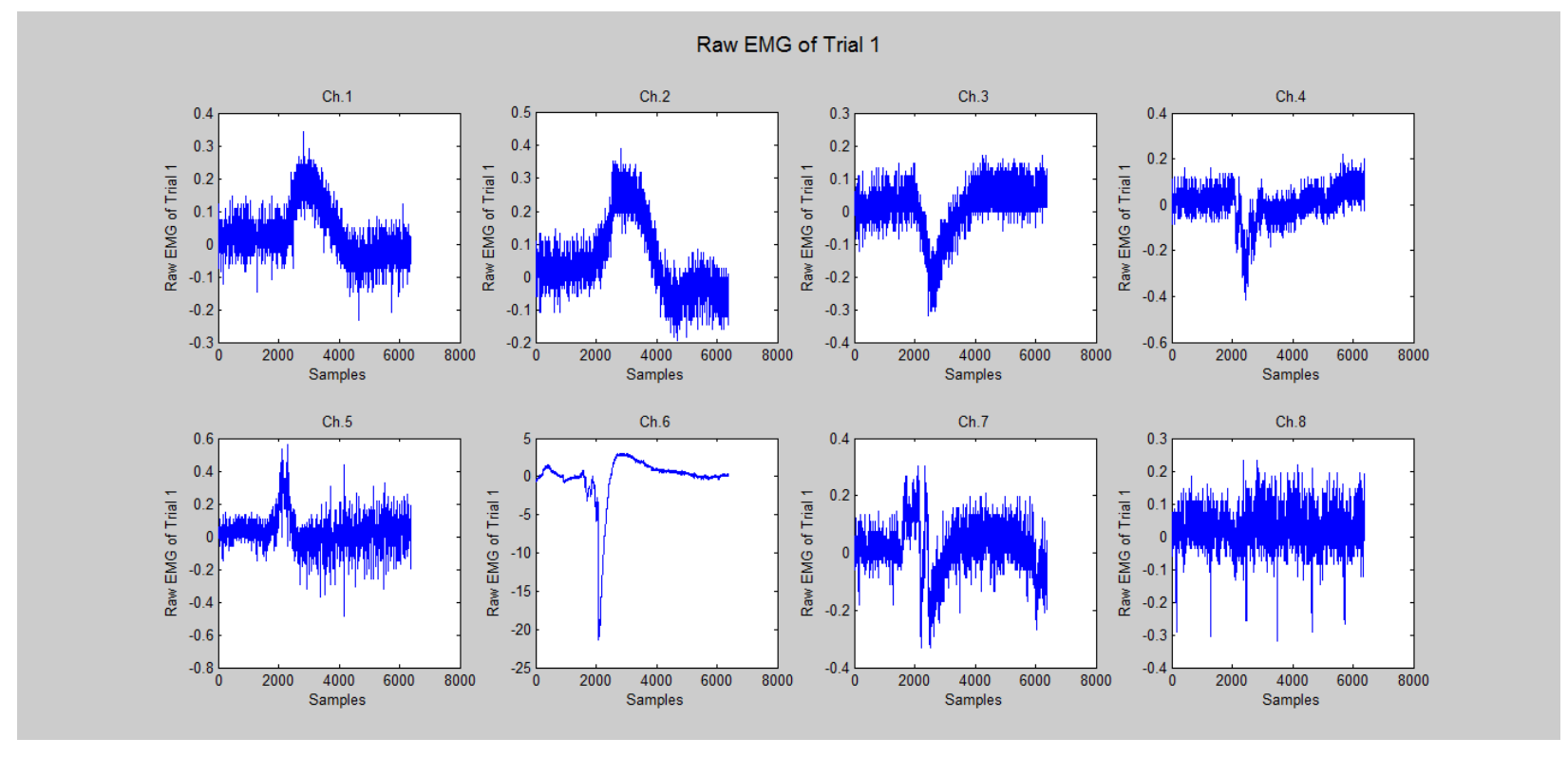

Figure 12: Raw EMG of Trial 1 for FNN, Subject 5 


\subsubsection{Rectified EMG}

Figure 13 represents the rectified version of the signal, which will make it easier for amplitude analysis.

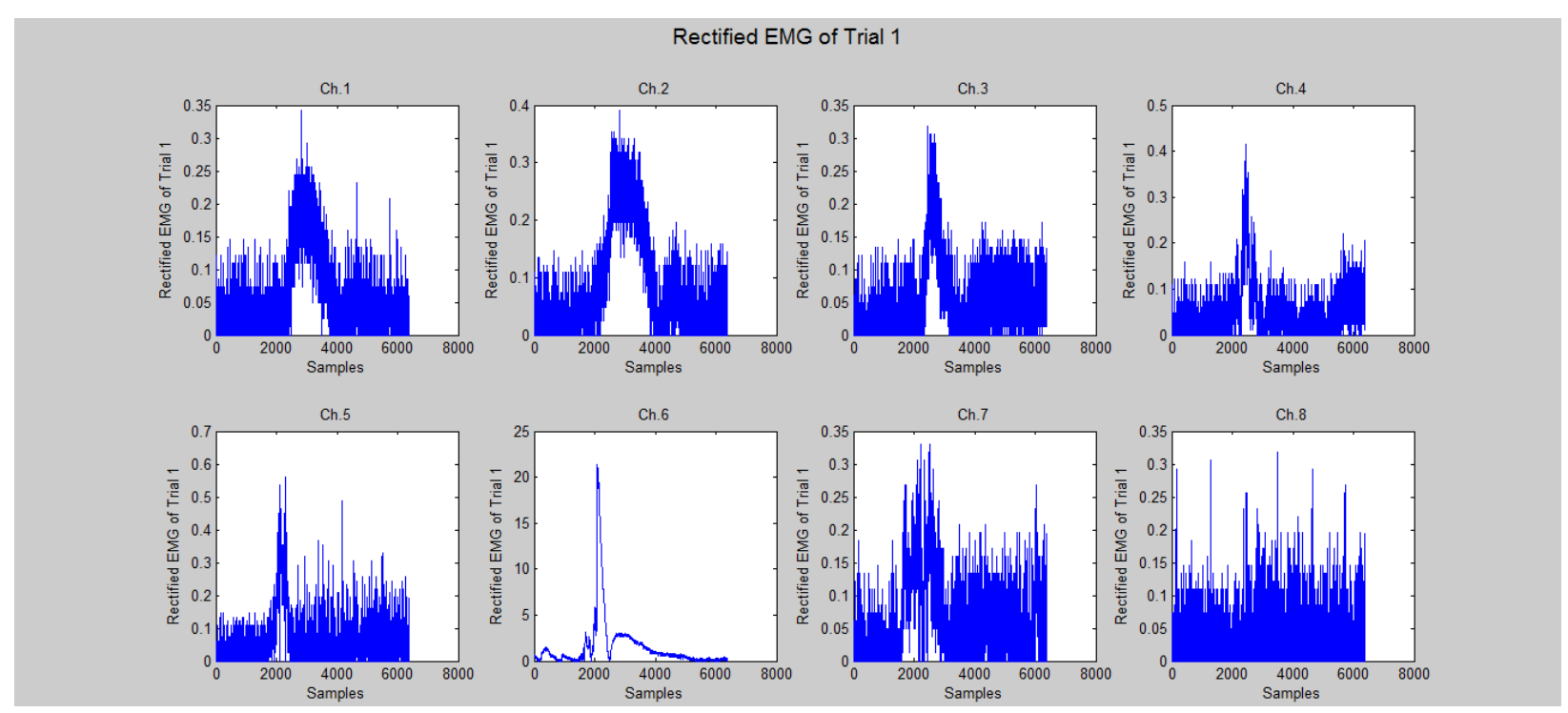

Figure 13: Rectified EMG of Trial 1 for FNN, Subject 5

\subsubsection{Butterworth Filtered EMG}

As it can evidently be seen from Figure 14, once the Butterworth filter was applied, a majority of the noise was reduced, and resulted in a much cleaner signal.

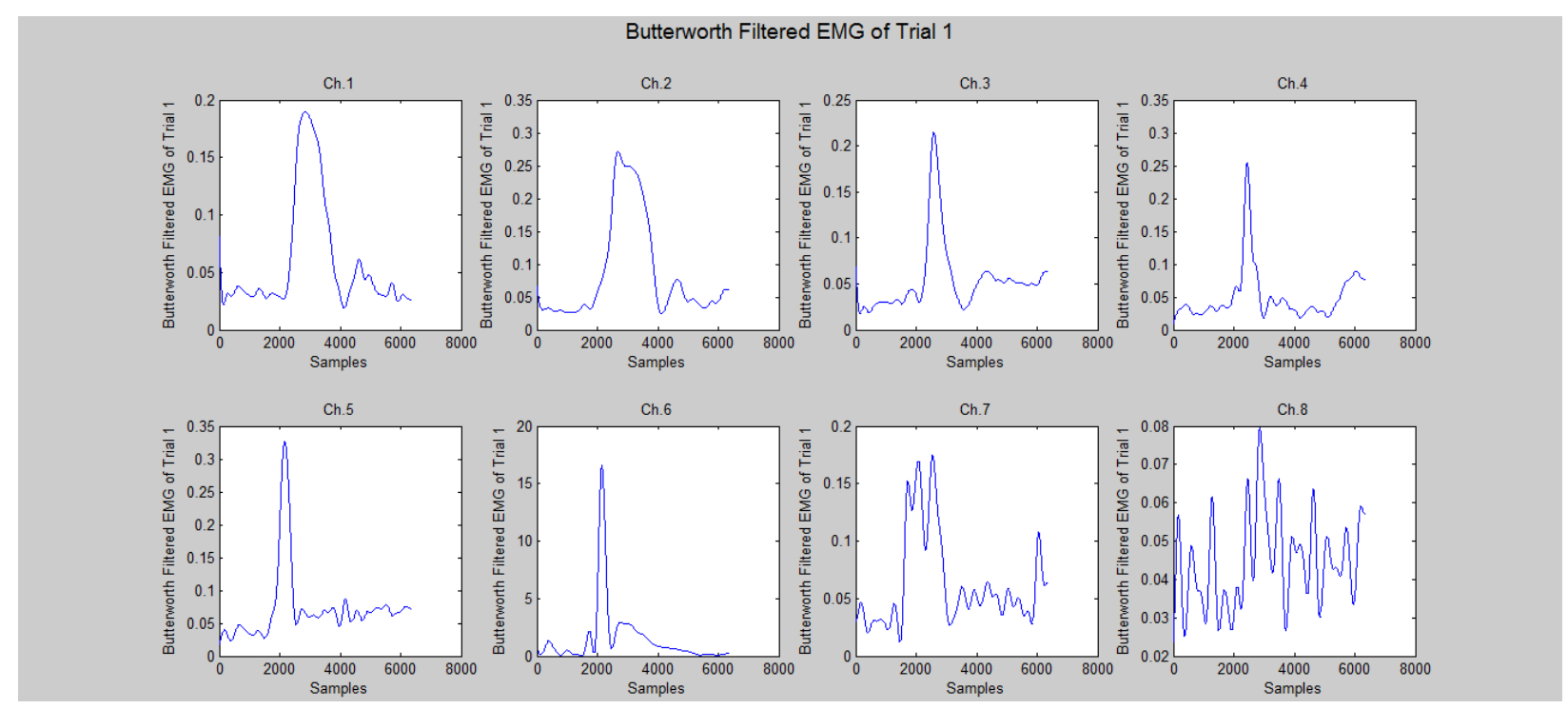

Figure 14: Butterworth Filtered EMG of Trial 1 for FNN, Subject 5 


\subsubsection{Averaged EMG with RMS}

Since there were three trials per condition, the average was taken per subject in order to account for slight deviations due to biological factors during data acquisition for each trial. The RMS was also calculated and displayed on the same graph, as shown in Figure 15.

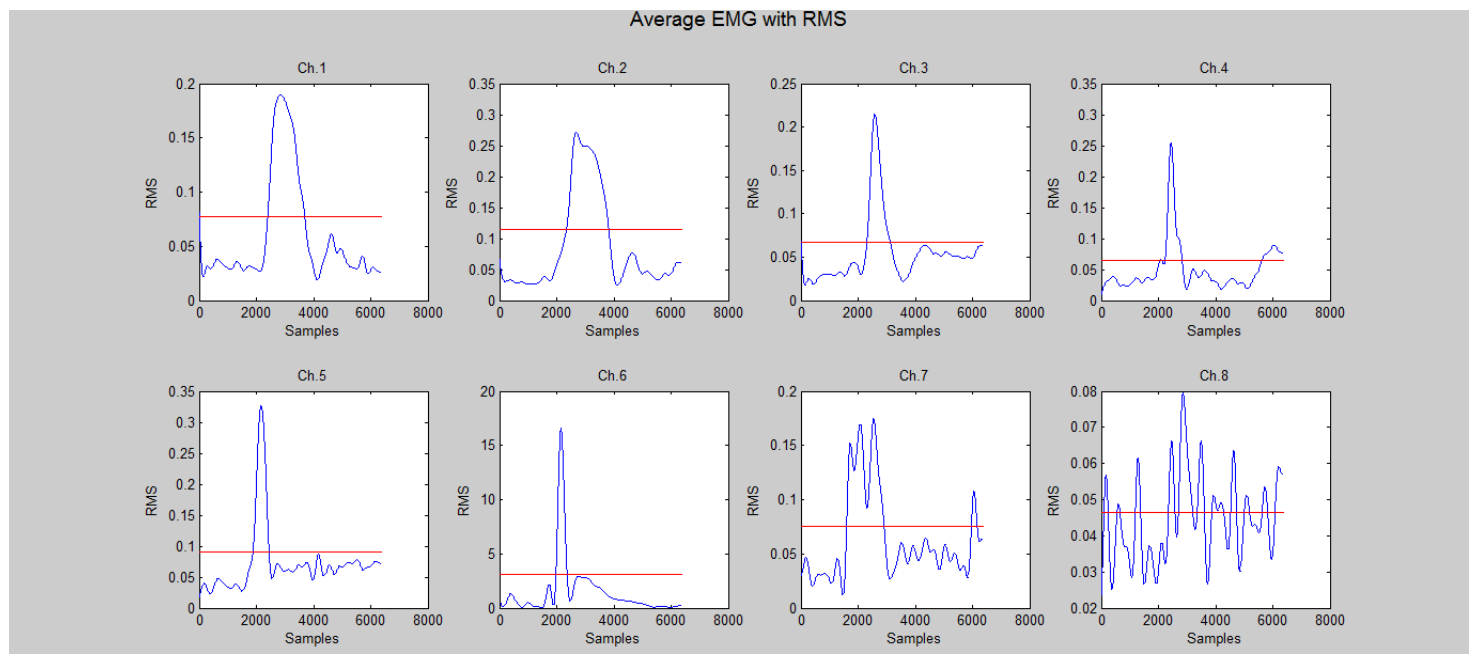

Figure 15: Averaged EMG of Trials for FNN, Subject 5

\subsection{5 iEMG}

Figure 16 represents the cumulative iEMG of the averaged signals, which represents the amount of work done by the muscles. As the iEMG represents the area under the EMG curve, whenever there is a steep positive slope, it correlates with the spike of the contraction in the EMG graphs shown in Figure 15.
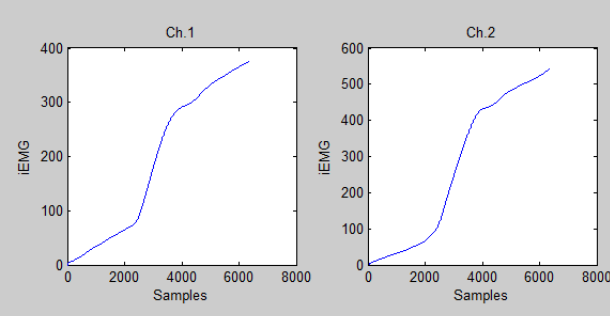

iEMG
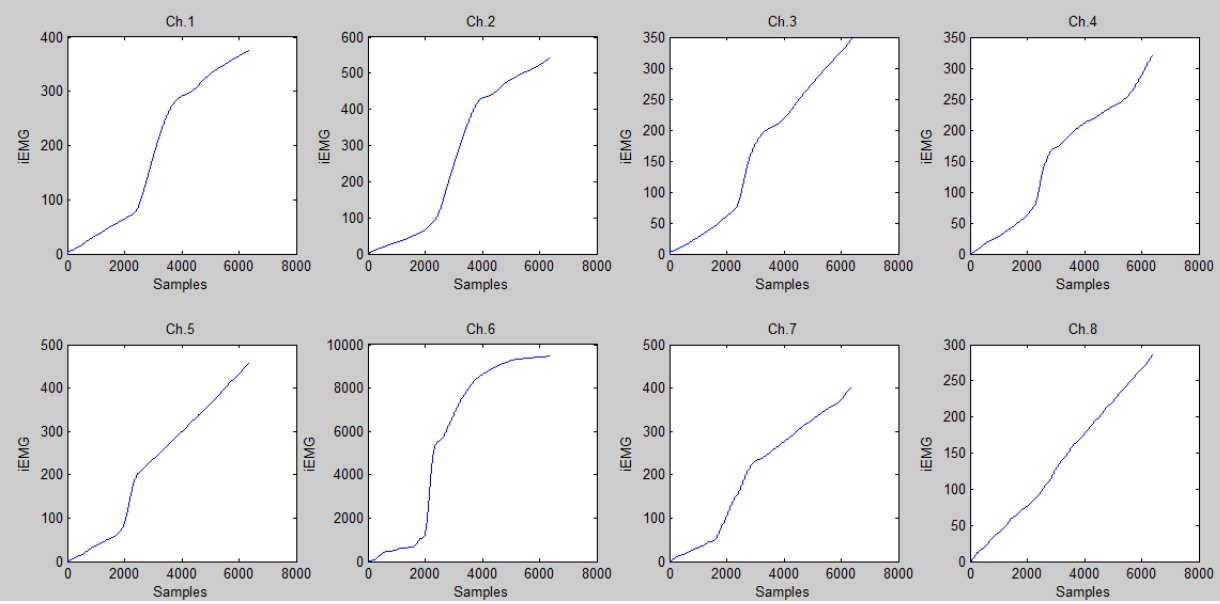

Ch.7
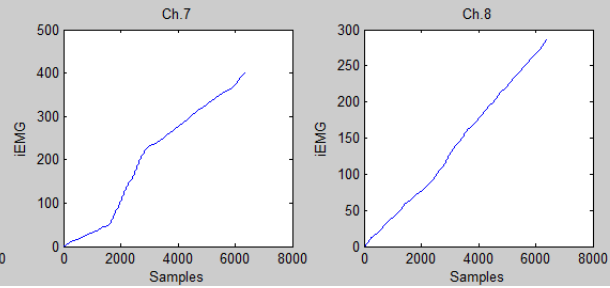

Figure 16: iEMG of the Averaged Signal for FNN, Subject 5 


\subsection{Comparison of RMS and iEMG}

Since the RMS and iEMG represent the strength and amount of work done by the muscles during contraction, their values will be compared under the various conditions. As described in section 5.1 Results Overview, Ch. 1 - 4 represent the abdominal muscles, and Ch. 5 - 8 represent eh back muscles. All of the mentioned values in the RMS tables are in $\mathrm{mV}$, and in the iEMG tables are $(\mathrm{mV})(\mathrm{s})$.

\subsubsection{No Visuals}

\begin{tabular}{|c|c|c|c|c|c|c|c|c|}
\hline & Ch.1 & Ch.2 & Ch.3 & Ch.4 & Ch.5 & Ch.6 & Ch.7 & Ch.8 \\
& Right RA & Left RA & Right EO & Left RA & Right LE & Left LE & Right TE & Left TE \\
\hline BHN & 0.0291 & 0.0299 & 0.0298 & 0.0299 & 0.0645 & 0.1736 & 0.1075 & 0.0468 \\
\hline BNN & 0.0331 & 0.0368 & 0.0301 & 0.0390 & 0.1967 & 1.1833 & 0.7194 & 0.4084 \\
\hline FHN & 0.0343 & 0.0347 & 0.0398 & 0.0349 & 0.0620 & 0.1084 & 0.0979 & 0.0584 \\
\hline FNN & 0.0774 & 0.1154 & 0.0670 & 0.0649 & 0.0910 & 3.1084 & 0.0749 & 0.0464 \\
\hline
\end{tabular}

\section{Table 2: RMS with No Visuals, Subject 5}

\begin{tabular}{|c|c|c|c|c|c|c|c|c|}
\hline & $\begin{array}{c}\text { Ch.1 } \\
\text { Right RA }\end{array}$ & $\begin{array}{c}\text { Ch.2 } \\
\text { Left RA }\end{array}$ & $\begin{array}{c}\text { Ch.3 } \\
\text { Right EO }\end{array}$ & $\begin{array}{c}\text { Ch.4 } \\
\text { Left RA }\end{array}$ & $\begin{array}{c}\text { Ch.5 } \\
\text { Right LE }\end{array}$ & $\begin{array}{c}\text { Ch.6 } \\
\text { Left LE }\end{array}$ & $\begin{array}{c}\text { Ch.7 } \\
\text { Right TE }\end{array}$ & Ch.8 \\
Left TE \\
\hline BHN & 59.4 & 60.5 & 60.0 & 61.3 & 92.3 & 309.8 & 124.2 & 86.4 \\
\hline BNN & 186.8 & 199.4 & 172.2 & 205.0 & 597.9 & 4817.0 & 2165.7 & 1387.8 \\
\hline FHN & 125.1 & 133.1 & 143.9 & 131.3 & 204.5 & 277.2 & 253.9 & 207.5 \\
\hline FNN & 375.9 & 544.6 & 348.8 & 321.7 & 460.5 & 9486.3 & 402.4 & 286.9 \\
\hline
\end{tabular}

Table 3: iEMG with No Visuals, Subject 5 


\subsubsection{Visuals}

\begin{tabular}{|c|c|c|c|c|c|c|c|c|}
\hline & $\begin{array}{c}\text { Ch.1 } \\
\text { Right RA }\end{array}$ & $\begin{array}{c}\text { Ch.2 } \\
\text { Left RA }\end{array}$ & $\begin{array}{c}\text { Ch.3 } \\
\text { Right EO }\end{array}$ & $\begin{array}{c}\text { Ch.4 } \\
\text { Left RA }\end{array}$ & $\begin{array}{c}\text { Ch.5 } \\
\text { Right LE }\end{array}$ & $\begin{array}{c}\text { Ch.6 } \\
\text { Left LE }\end{array}$ & $\begin{array}{c}\text { Ch.7 } \\
\text { Right TE }\end{array}$ & Ch.8 \\
\hline BHV & 0.0336 & 0.0394 & 0.0334 & 0.0662 & 0.0887 & 0.0716 & 0.0740 & 0.0414 \\
\hline BNV & 0.0303 & 0.0302 & 0.0284 & 0.0347 & 0.0358 & 0.1105 & 0.0351 & 0.0401 \\
\hline & & & & & & & & \\
\hline FHV & 0.0501 & 0.0287 & 0.0282 & 0.0674 & 0.0582 & 0.8973 & 0.0556 & 0.0667 \\
\hline FNV & 0.0380 & 0.0316 & 0.0294 & 0.0348 & 0.0470 & 0.4690 & 0.0464 & 0.0460 \\
\hline
\end{tabular}

Table 4: RMS with Visuals, Subject 5

\begin{tabular}{|c|c|c|c|c|c|c|c|c|}
\hline & Ch.1 & Ch.2 & Ch.3 & Ch.4 & Ch.5 & Ch.6 & Ch.7 & Ch.8 \\
& Right RA & Left RA & Right EO & Left RA & Right LE & Left LE & Right TE & Left TE \\
\hline BHV & 148.3 & 173.7 & 147.0 & 225.5 & 289.1 & 285.1 & 280.3 & 175.7 \\
\hline BNV & 77.9 & 77.1 & 73.1 & 83.2 & 90.0 & 235.1 & 89.3 & 100.8 \\
\hline & & & & & & & & \\
\hline FHV & 188.2 & 138.6 & 138.1 & 259.2 & 247.5 & 2936.9 & 262.2 & 307.4 \\
\hline FNV & 175.4 & 159.7 & 149.0 & 160.4 & 225.8 & 1431.7 & 219.7 & 228.9 \\
\hline
\end{tabular}

\section{Table 5: iEMG with Visuals, Subject 5}

\subsubsection{Analysis}

As it can be seen from the results in sections 5.3.1 No Visuals and 5.3.2 Visuals, there does not seem to be a significant difference between when the subject is holding on to harness, and when they are not holding on (hands in their laps) in either direction. It can also be seen that the results follow the same pattern under the various conditions, except for the iEMG when there are no visuals. In this case, the iEMG values are higher when the subject is not holding on, signifying that the muscles are doing more work during that period. Furthermore, both the RMS and iEMG values of the back muscles (Ch.5-8) are higher than those of the abdominal muscles (Ch.1-4) 
under all of the conditions. A detailed analysis of these results, and their explanations will be discussed further in Chapter 6: Discussion.

\subsection{Motion Sickness Questionnaire}

As previously mentioned, the subjects were asked to complete a motion sickness questionnaire (Appendix D) both during the 10 minute break between trials, as well as at the end of the study. If the results of the questionnaire showed that the subjects had answered "Moderate" or "Severe" for any of the questions, they would have either been asked to take a longer break until their symptoms subside, or to complete the study on another day. Subjects were also asked to fill in the same questionnaire at the end of the study so that we could track any changed. Fortunately, none of the subjects reported any concerning motion sickness symptoms during the 10 minute break, and their results of the questionnaire after the study were very similar to their results during the 10 minute break. As mentioned in section 1.2 Virtual Reality, when there are conflicting visual and vestibular inputs, disequilibrium occurs, resulting in motion sickness. ${ }^{[27,38]}$ Since none of the subjects experienced motion sickness, this suggests that the visual input, although not completely synced with the motion, followed the direction of motion closely enough for representative results. 


\section{Chapter 6}

\section{Discussion}

\subsection{Itemized Comparison}

\subsubsection{Amplitude and Overall Response}

When looking at the graphs in Appendix F, it can be seen that the overall muscle response and shape is very similar from one condition to another for the same subject. This is to be expected, as although each individual's muscle response is unique, it is consistent. Furthermore, when analyzing the various conditions, there was no clear trend in the amplitude response. For example, when looking at the conditions with no visuals present, BNN had generally lower amplitudes than BHN, whereas there was not much of a difference between the amplitudes of FHN and FNN. Moreover, the other conditions with visuals present (BHV, BNV, and FHV, FNV) did not have a consistent pattern amongst all of the subjects, as for some subjects the amplitude response was higher when they were holding on to the harness, and for others is was higher when they were not holding on to the harness.

It is also important to note that in the raw data, the muscles contract at the initial and final jolts of the motion, and do not have any activity in between, suggesting that the muscles are most active during acceleration and deceleration, and that postural adjustment is not required in the middle of motion.

\subsubsection{RMS and iEMG}

When looking at the RMS and iEMG tables in Appendix E, a few trends can be seen. First of all, the RMS values of the back muscles (Ch.5-8) are consistently higher than those of the abdominal muscles (Ch.1-4). This is a significant finding as it illustrates that it in fact the posterior back muscles that play a larger role in stabilization as compared to the anterior trunk muscles. When referring back to Figure 10, it can be seen that the back muscles are much larger than the 
abdominal muscles, which could be a reason as to why they play a more significant role in balance.

Furthermore, when comparing the muscle groups individually, it can be seen that for the abdominal muscles, in the backwards direction, the left Rectus Abdominis (Ch.2) had higher muscle activity than the right Rectus Abdominis (Ch.1), whereas the right and left External Obliques (Ch.3 and Ch.4) had relatively similar muscle activity. Similarly, in the forwards direction, the left Rectus Abdominis (Ch.2) had higher muscle activity than the right Rectus Abdominis (Ch.1), however, the right External Oblique (Ch.3) had higher muscle activity than the left External Oblique (Ch.4). It is interesting to note that the left Rectus Abdominis (Ch.2) consistently has higher muscle activity as compared to the right Rectus Abdominis (Ch.1) regardless of the direction of motion. One possible explanation for this could be that since the subjects were seated in the seat to the left of the screen, their bodies could have been leaning right, towards the centre of the simulator as the focal point of the visuals was in the centre of the simulator cockpit. As a result, the left side of their bodies could have potentially tried to compensate for that directional tipping, and activated the left muscles in order to straighten their bodies. This would support the findings by Chow et al ${ }^{[8]}$ and Milosevic et al ${ }^{[9]}$ which stated that when the body is tipping in a certain direction, it compensates by leaning in the opposite direction of motion in order to maintain balance.

Moreover, when analyzing the response of the back muscles, in the backwards direction, the right Lumbar Erector Spinae (Ch.5) has more muscle activity than the left Lumbar Erector Spinae (Ch.6), whereas, the right and left Thoracic Erector Spinae (Ch.7 and Ch.8) have very similar muscle activity. On the contrary, in the forwards direction, all of the back muscles (Ch.58) had very similar levels of muscle activity. This could suggest that when travelling in the forwards direction, the back muscles (which are larger than the abdominal muscles) act together uniformly, however, when travelling in the backwards direction, the right Lumbar Erector Spinae (Ch.5) has more muscle activity than the left Lumbar Erector Spinae (Ch.6).

The second major trend is that the muscles show slightly higher RMS and iEMG values when the subject is holding on to the harness as to compared to when they are not holding on, and have their hands on their laps. This goes against the common thinking that if the subject is holding on to the harness, they are more secure, and thus their muscles put in less work to stabilize. A 
possible explanation for this finding could be that if the subject is holding on to the harness with their hands, their upper limbs, such as their arms, are doing a lot of muscular work to stabilize. This causes the trunk muscles to do more work than they normally would in order to meet the work being done by the upper limbs in an effort to uniformly stabilize the body. Moreover, when the subject is not holding on to the harness, their body muscles all contract uniformly together so that no one muscle group is exerting excess work.

The third visible trend is that the RMS and iEMG values of the muscles tend to be higher when the subject is traveling in the forward direction as opposed to backwards. A possible explanation for this could be that when the subject is rotating in the backwards direction in the motion simulator, they are leaning against the back of the seat, so their muscles do not have to put in a lot of work to balance. However, when the motion simulator is traveling in the forwards direction, there is nothing in place to support the controlled motion of the body, so the muscles have to work harder to stabilize and maintain balance. This difference in muscle activity based on direction is further supported by a study performed by Masani et al, ${ }^{[39]}$ where they looked at the effect of horizontal perturbations on trunk muscles in different directions of motion. They also concluded that the muscles showed a varied response dependent on the direction of motion.

The fourth and final trend is that the RMS and iEMG values of the muscles tend to be higher when visuals were playing on the screen as opposed to when the screen was turned off. This was expected, as when the visuals are playing on the screen, it gives the subject the feeling that they are travelling/displaying more than they actually are. If the subject perceives their fall to be steeper, their muscles will work harder to stabilize the body, resulting in higher RMS and iEMG values. Moreover, when the screen was turned off, it was pitch black inside of the motion simulator cabin, so the subject was not able to place themselves in relation to the surrounding environment, and likewise, their muscles did not feel as though they had to work as hard to stabilize balance. An article by Szabo et $\mathrm{al}^{[40]}$ stated that when it comes to an visual scenery, a focal point plays an important role. Although our visual scenery may not have been completed synced with the motion of the simulator (the visual scene was moving forward into a tunnel, even when the motion simulator was moving backwards), it did have an obvious focal point, and produced reliable results. Furthermore, the results obtained by the initial pilot studies in the Space Ball ${ }^{[19]}$, as mentioned in section 1.5 Contributions, also showed that the presence of 
visuals had an effect on the trunk muscles' response, as it affected the subject's perception of their motion.

Combining all of these findings, it can be concluded that the FHV (forward direction, holding on to the harness, visuals present) motion had the highest RMS and iEMG values, meaning it produced the highest muscle activity. A similar study by Zedka et al ${ }^{[41]}$ also found that rotational movement in the forward direction resulted in slightly higher muscle activity. However, in their study they found the difference to be negligible in some cases. This is understandable as their study only had a rotational angle of 20 degrees, less than half of the rotational angle in our study, leading us to infer that at higher rotational angles, the difference in muscle response becomes more prominent. Their study also had fewer subjects than ours, which could also account for the difference in findings. Furthermore, it should be noted that the subjects in their study were blindfolded, which is comparable to our condition in which there are no visuals. Moreover, we found that when visuals are present, muscle activity is higher, which also lends a hand to our theory that the presence of visuals gives the user a higher sense of vection ${ }^{4}$, which translates to the activity of the muscles used for balance. When considering that the forward direction had the highest muscle activity, and it was the back muscles that also had the higher activity, then it validates what Chow et $\mathrm{al}^{[8]}$ and Milosevic et $\mathrm{al}^{[9]}$ found; when the body is tipping in a certain direction, it compensates by leaning in the opposite direction of motion in order to maintain balance. So, when the subjects were traveling in the forward direction, the body's natural response was to use the back muscles to lean back and stabilize balance in an attempt to prevent the subject from falling forward.

\footnotetext{
${ }^{4}$ The sensation of motion, even though the individual is stationary
} 


\section{Chapter 7}

\section{Conclusion}

This study has proven to be a complete and successful research study from conception to completion. A sufficient number of healthy subjects were recruited and enrolled into the study, and appropriate safeguards were assessed at various checkpoints. Furthermore, the signal processing techniques applied to the raw data significantly removed the noise from the signal, and allowed for clear analysis.

When summarizing all of the findings, it can be seen that the FHV (forward direction, holding on to the harness, visuals present) motion had the highest RMS and iEMG values, meaning that the muscles, specifically the posterior back muscles, had higher contractile activity and exerted more work. It should be noted that the muscular response is related to the perception of the surrounding environment, and the anticipation of upcoming motions.

This study served as a platform for training and rehabilitation for individuals with weakened muscles, as it can mimic the conditions of the outside world through virtual reality. Moreover, Cooper et al,${ }^{[42]}$ Harison et al, ${ }^{[43]}$ Mahajan et al,${ }^{[44]}$ and Erren-Wolters et al ${ }^{[45]}$ all conducted studies in regards to virtual reality of wheelchair users, and they all also found it to be a reliable means for rehabilitation training. Furthermore, we have found that this study has functioned as the benchmark for evaluating the response of a healthy person's trunk muscles during rotational motion. Now that this benchmark has been set, the next step would be to expand this study to incorporate wheelchair users as subjects in order to obtain fully encompassing results. 


\section{Appendix A: MaxFlight Safety Checklist}

MaxFlight Corporation

I Executive Drive, Toms River, NJ 08755

Phone: (732) 281-2007 Fax: (732)281-2009

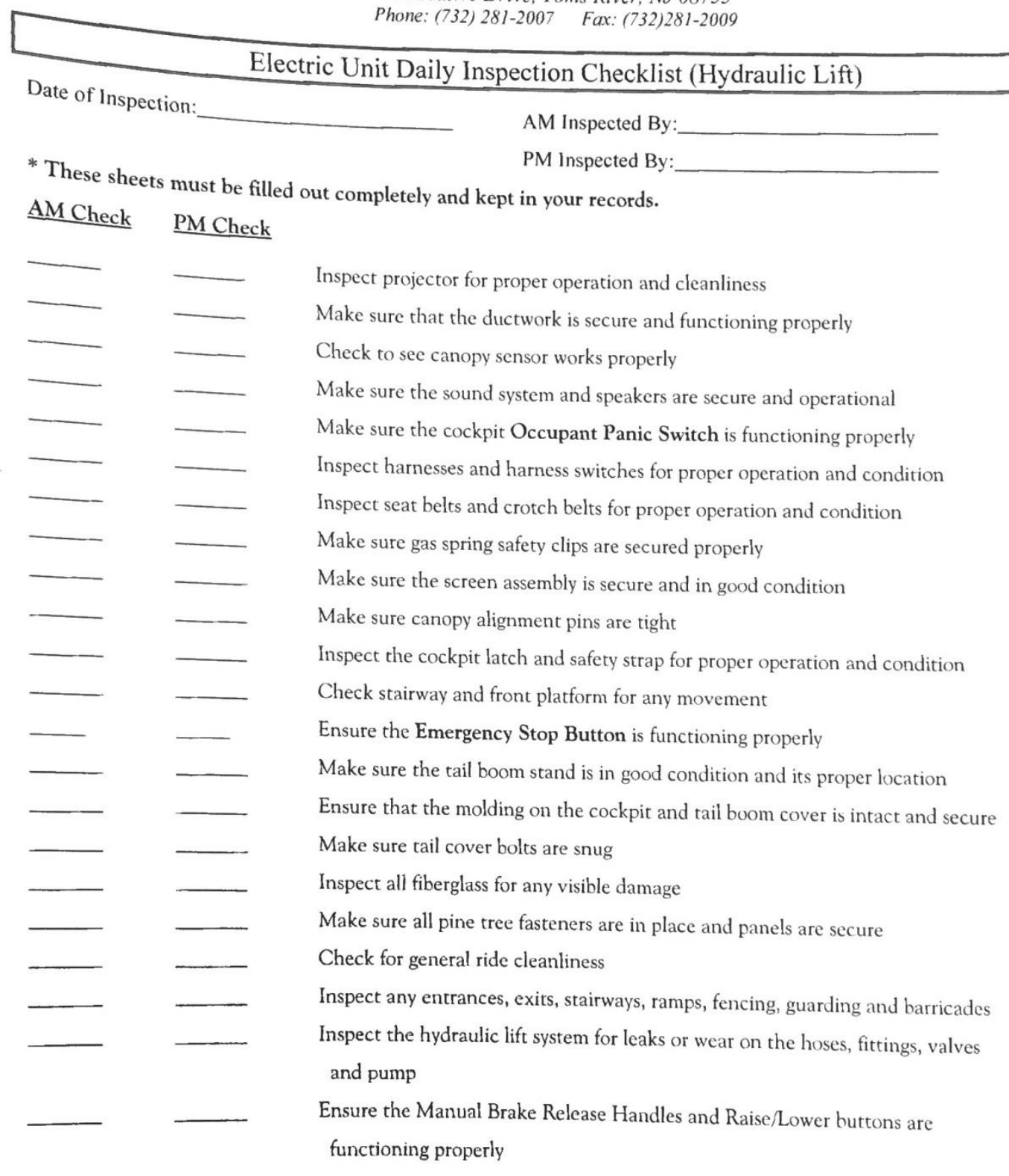

NOTE: When inspection is completed, run one full ride cycle to ensure all system components function properly. 


\section{Appendix B: Eligibility Questionnaire}

\section{To be completed only at the beginning of the study.}

1. Height: __ Feet__ Inches

2.Weight: _ l lbs

3. Do you considered yourself to have "relatively good health"? YES NO

4. Have you fallen more than once in the past year? YES NO

5. Do you feel dizzy or unsteady if you make sudden changes in movement such as bending down or quickly turning? YES NO

6. Do you have black-outs or seizures? YES NO

7. Have you experienced a stroke or other neurological problem that has affected your balance? YES NO

8. Do you experience numbness or loss of sensation in your legs and/or feet?

\section{YES NO}

9. Are you inactive? (Answer yes if you do not participate in a regular form of exercise, such as walking or exercising 20-30 minutes at least three times a week.) YES NO

10. Do you feel unsteady when you are walking, climbing stairs? YES NO

11. Do you have difficulty sitting down or rising from a seated or lying position?

\section{YES NO}

12. Do you belong to a special population that could affect your informed consent or put you in a risky situation during viewing of a visual display and making arm, head and body motions, or maintaining your balance, such as but not limited to (pregnant women, and cognitively or physically impaired individuals) ? YES NO

Source: www.BalanceandMobility.com 


\section{To be completed at the beginning and end of the study}

\section{The Activities-specific Balance Confidence (ABC) Scale (Modified)}

For each of the following activities, please indicate your level of self-confidence by choosing a corresponding number from the following rating scale:

$$
\begin{array}{lllllllllll}
0 \% & 10 & 20 & 30 & 40 & 50 & 60 & 70 & 80 & 90 & 100 \% \\
\text { no confidence } & & & & & & & & \text { completely confident }
\end{array}
$$

"How confident are you that you will not lose your balance or become unsteady when you...

...walk up or down stairs? _ $\%$

...bend and reach?

...stand on your tiptoes and reach for something above your head? __ $\%$

...stand on a chair and reach for something? __ $\%$

....are bumped into by people as you walk through the mall? ___ $\%$

... step onto or off an escalator while you are holding onto a railing? __ $\%$

... step onto or off an escalator while holding onto parcels such that you cannot hold onto the railing?__ $\%$

$\ldots$ walk outside on icy sidewalks?

Source: Powell, LE \& Myers AM. The Activities-specific Balance Confidence (ABC) Scale. $J$ Gerontol Med Sci 1995; 50(1): M28-34 
3. To be completed at the beginning of the study.

1. Are you under the influence of alcohol or any other type of drugs? YES NO

2. Are you pregnant? YES NO

3. Do you suffer from motion sickness or claustrophobia? YES NO

4. Do you suffer from heart conditions, back or neck ailments, or other serious disabilities? YES NO

5. Are you epileptic? YES NO

Source: Manufacturer: MaxFlight Corporation 


\section{Appendix C: Consent Form}

The Response of Abdominal and Back Muscles During Rotational Motion

\section{Research Ethics Board \\ Ryerson University}

Before you give your consent to be a volunteer in this study, it is important that you read the following information and ask as many questions as necessary to be sure you understand what you will be asked to do.

\section{Investigators:}

Dr. Kristiina McConville: Ph.D., P.Eng., Associate Professor, Ryerson University

Nika Zolfaghari: M.A.Sc. Student (II year, Electrical Engineering, Ryerson University)

\section{Purpose of the Study:}

The study will analyze the human body's muscular response to rotational motion in the forward and backward directions, and its effect on balance. This study is being conducted as partial fulfilment of a graduate thesis.

\section{Description of the Study:}

The eligibility criteria for the study are that subjects will be between the ages of 18-50, healthy, without any history of falls, or impairment that could affect balance. Twenty subjects will be recruited.

- Eligibility: You will be asked to fill out a questionnaire, which will be used to determine your eligibility for the study. This will not take more than fifteen minutes. If you are eligible, you will continue on the same day (if you are not part of the Ryerson community, or are not on campus, the eligibility questionnaire can be filled out over the phone, and you may come in on another day to record data). 
- Balance Tests: There will be three balance tests: In the first test, you will be asked to achieve and maintain balance on a balance board. The second test is a static posture test: the "Romberg" test. In this you will stand with both feet together and hands by your side with your eyes closed as the evaluator will examine your swaying for a full minute. In the third test, you will be asked to stand on one foot with eyes closed. Your performance on these tests will be timed.

- Preparation for Data Collection: Electrodes will then be attached to your abdomen, chest, and back muscles, and you will be securely fastened into the MaxFlight motion simulator seat. The EMG and ECG recording will involve adhesion of several pregelled electrodes. These electrodes passively record the electrical activity naturally present within your body and do not conduct any electrical current or voltage to you. You will not feel any sort of pain or discomfort from these electrodes.

- Data Collection: Before any testing is to begin, the examiners will show you some of the safety features of the simulator and instruct you on what to do during an emergency situation, or if you feel like you would like to stop the motion at any time. A series of tests will be done where you will be subjected to rotational motion. Four tests will be done in the forward direction, and four tests will be done in the backwards direction, each resulting in a rotation of $45^{\circ}$ (it takes 1 second to reach this angle). Some of these tests will be done while a visual is playing on the screen in front of you. Specifically, the four tests in each direction will include:

Holding onto the harness without any visuals on the screen

$>$ Holding onto the harness with visuals playing on the screen

$>$ Placing your hands on your lap without any visuals on the screen

$>$ Placing your hands on your lap with visuals playing on the screen

Once the four tests are done in one direction (forward or backward), the participants will be given a 10 minute break before performing the four tests in the opposite direction. During this break, participants will be asked to complete a motion sickness questionnaire. If the results of the motion sickness questionnaire show that the participant is experiencing motion sickness, they will be given the option of either taking a longer break or coming back to record the rest of the data on another day. The investigators strongly discourage participants from continuing while they feel motion sickness coming on. As always, participants will have the option of discontinuing the study if they wish to do so. 
- Repeat of Balance Tests and Questionnaire: The same balance tests that were conducted prior to the experiment, will be conducted once again at the end along with a motion sickness questionnaire.

The entire study is expected to take approximately an hour.

During the experiment, another trained graduate student will be present to help carry out the safety procedures and assist in the unlikely case of an emergency.

The experiments may be video recorded or photographed for analysis at a later time, but should a participant not want to be recorded, they can indicate so on this consent form by not signing the corresponding section. These tapes will be used only for quantitative assessment and confirmation of performance during training and testing.

\section{What is Experimental in this Study:}

The major aim of this study is to gather of information for the purpose of analysis. The experimental procedure of the study is to evaluate how healthy muscles respond to rotational motion, and its effects on balance.

\section{Risks or Discomforts:}

The potential risks with the experiment are: 1. loss of balance, 2. simulator sickness, which is similar to motion sickness. The risks are considered minimal as 1 . only healthy subjects will be used with minimal challenge to balance, and you will have a bar to grab onto for support if you lose your balance during the balance testing, 2. the simulator is a popular ride used in many entertainment facilities, so it's safety standards have been approved. Should you feel sick during the motion, there is an emergency stop button located next to your seat which you can press at any time. You are free to discontinue participation at any time.

\section{Benefits of the Study:}

This study will benefit a large amount of population: elderly, people who are at risk of falling, or anyone who is in a wheelchair and is subject to forward and backwards tipping while going over ramps or uneven surfaces. The data collected will give an insight into how healthy muscles contract during these motions so that they can be compared to how the muscles of unhealthy individuals contract in the future. There are no benefits as such for the subjects who participate in the study. 


\section{Confidentiality:}

No names of the participants will be disclosed in any publication. Subjects will be referred to by an assigned number during analysis and publication of results. The researchers will have the only access to data. It will be stored on Ryerson computers accessible by user ID and password authentication, and any paper copies will be locked in the researcher's office. The graduate student researcher will only have access to data for the period of their study. The supervisor (K. McConville) will keep the data for 5 years after which it will be destroyed. The trials may be video-taped. These tapes will be used only for quantitative assessment and confirmation of performance during training and testing. Only the researchers (supervisor and graduate student) will have access to these. The subjects will not be able to review or edit the tapes prior to any publication. The recordings may be shown referencing subjects only by number code during presentations of the data (the subject's name will never be shared). Video recordings of the actual subjects will never be shown to anyone other than the stated researchers without separate written consent by the subject.

\section{Incentives to Participate:}

The participants will be paid an honorarium of $\$ 10$ at the completion of this study.

\section{Costs and/or Compensation for Participation:}

There are no costs (other than travel to and from the University) or compensation other than the incentive described above associated with the participation.

\section{Compensation for Injury:}

It is unlikely that participation in this project will result in harm to participants. If any complications arise, we will assist you in obtaining appropriate attention. We will provide transportation to a medical facility in the case of injury. While every measure will be taken to avoid any possible injury or risk of injury, if any should occur, the researchers will refer the participant to any necessary medical care, such as the Occupational Health Clinic at Ryerson University, the local hospital or physician.

\section{Voluntary Nature of Participation:}

Participation in this study is voluntary. Your choice of whether or not to participate will not 
influence your future relations with Ryerson University. If you decide to participate, you are free to withdraw your consent and to stop your participation at any time.

At any particular point in the study, you may refuse to answer any particular question or stop participation altogether.

\title{
Questions about the Study:
}

If you have any questions about the research now, please ask. If you have questions later about the research, you may contact.

\author{
Kristiina McConville \\ Ryerson University \\ kmcconvi@ee.ryerson.ca
}

(416) 979-5000 ext. 6085

If you have questions regarding your rights as a human subject and participant in this study, you may contact the Ryerson University Research Ethics Board for information.

\author{
Research Ethics Board \\ c/o Office of the Associate Vice President, Academic \\ Ryerson University \\ 350 Victoria Street \\ Toronto, ON M5B 2K3 \\ 416-979-5042
}

\section{Agreement:}

Your signature below indicates that you have read the information in this agreement and have had a chance to ask any questions you have about the study. Your signature also indicates that you agree to be in the study and have been told that you can change your mind and withdraw your consent to participate at any time. You have been given a copy of this agreement.

You have been told that by signing this consent agreement you are not giving up any of your legal rights. 
Name of Participant (please print)

Signature of Participant

Date

Signature of Investigator

Date

\section{Agreement to be videotaped:}

Your signature below indicates that you agree to be videotaped during the study. These video recordings will be used for quantitative assessment by the researchers only, for example to validate the data obtained through head movement or muscle or foot pressure recordings. This agreement is voluntary and does not affect your participation in the study.

Name of Participant (please print)

Signature of Participant

Date

Signature of Investigator

Date 


\section{Agreement for videotape being shown:}

Your signature below indicates that you agree that videotapes taken of you during the study may be shown during research presentations or for educational purposes. This agreement is voluntary and does not affect your participation in the study.

Name of Participant (please print)

Signature of Participant

Date

Signature of Investigator

Date 


\section{Appendix D: Motion Sickness Questionnaire}

4. To be completed during the $\mathbf{1 0}$ minute break and at the end of each training session.

\section{Simulator Sickness Questionnaire}

Please indicate the degree to which you are experiencing the following symptoms:

General discomfort

Fatigue

Headache

Eyestrain

Difficulty focusing

Increased salivation

Sweating

Nausea
None

Slight

Moderate

Severe

None Slight Moderate

Severe

Non

Slight

Moderate

Severe

None

Slight

Moderate

Severe

None Slight Moderate Severe

None Slight Moderate Severe

None

Slight

Moderate

Severe

None

Slight

Moderate

Severe 


$\begin{array}{lllll}\text { Difficulty concentrating } & \text { None } & \text { Slight } & \text { Moderate } & \text { Severe } \\ \text { Fullness of head } & & & & \\ & \text { None } & \text { Slight } & \text { Moderate } & \text { Severe } \\ \text { Blurred vision } & \text { None } & \text { Slight } & \text { Moderate } & \text { Severe } \\ \text { Dizzy (eyes open) } & \text { None } & \text { Slight } & \text { Moderate } & \text { Severe } \\ & & & & \\ \text { Dizzy (eyes closed) } & \text { None } & \text { Slight } & \text { Moderate } & \text { Severe } \\ \text { Vertigo } 2 & & & & \\ & \text { None } & \text { Slight } & \text { Moderate } & \text { Severe } \\ \text { Stomach awareness } & & & & \\ & \text { None } & \text { Slight } & \text { Moderate } & \text { Severe } \\ \text { Burping } & & & & \\ & \text { None } & \text { Slight } & \text { Moderate } & \text { Severe }\end{array}$




\section{Appendix E: Results: RMS and iEMG Tables}

*Please note that all RMS values are in $m V$, and all iEMG values are in $(\mathrm{mV})(\mathrm{s})$

\section{$\underline{\text { Subject } 1}$}

No Visuals

\begin{tabular}{|c|c|c|c|c|c|c|c|c|}
\hline & $\begin{array}{c}\text { Ch.1 } \\
\text { Right RA }\end{array}$ & $\begin{array}{c}\text { Ch.2 } \\
\text { Left RA }\end{array}$ & $\begin{array}{c}\text { Ch.3 } \\
\text { Right EO }\end{array}$ & $\begin{array}{c}\text { Ch.4 } \\
\text { Left RA }\end{array}$ & $\begin{array}{c}\text { Ch.5 } \\
\text { Right LE }\end{array}$ & $\begin{array}{c}\text { Ch.6 } \\
\text { Left LE }\end{array}$ & $\begin{array}{c}\text { Ch.7 } \\
\text { Right TE }\end{array}$ & $\begin{array}{c}\text { Ch.8 } \\
\text { Left TE }\end{array}$ \\
\hline BHN & 0.0015 & 0.0222 & 0.0056 & 0.0423 & 0.0452 & 0.0203 & 0.0230 & 0.0266 \\
\hline BNN & 0.0327 & 0.0294 & 0.0291 & 0.0305 & 0.0337 & 0.0283 & 0.0361 & 0.0365 \\
\hline & & & & & & & & \\
\hline FHN & - & - & - & - & - & - & - & - \\
\hline FNN & - & - & - & - & - & - & - & - \\
\hline
\end{tabular}

Table 1: RMS with No Visuals, Subject 1

\begin{tabular}{|c|c|c|c|c|c|c|c|c|}
\hline & $\begin{array}{c}\text { Ch.1 } \\
\text { Right RA }\end{array}$ & $\begin{array}{c}\text { Ch.2 } \\
\text { Left RA }\end{array}$ & $\begin{array}{c}\text { Ch.3 } \\
\text { Right EO }\end{array}$ & $\begin{array}{c}\text { Ch.4 } \\
\text { Left RA }\end{array}$ & $\begin{array}{c}\text { Ch.5 } \\
\text { Right LE }\end{array}$ & $\begin{array}{c}\text { Ch.6 } \\
\text { Left LE }\end{array}$ & $\begin{array}{c}\text { Ch.7 } \\
\text { Right TE }\end{array}$ & $\begin{array}{c}\text { Ch.8 } \\
\text { Left TE }\end{array}$ \\
\hline BHN & 0.1 & 2.0 & 0.5 & 3.8 & 4.0 & 0.0 & 0.0 & 2.4 \\
\hline BNN & 20.7 & 19.8 & 19.3 & 20.4 & 22.4 & 19.1 & 23.6 & 24.6 \\
\hline & & & & & & & & \\
\hline FHN & - & - & - & - & - & - & - & - \\
\hline FNN & - & - & - & - & - & - & - & - \\
\hline
\end{tabular}

Table 2: iEMG with No Visuals, Subject 1 
Visuals

\begin{tabular}{|c|c|c|c|c|c|c|c|c|}
\hline & $\begin{array}{c}\text { Ch.1 } \\
\text { Right RA }\end{array}$ & $\begin{array}{c}\text { Ch.2 } \\
\text { Left RA }\end{array}$ & $\begin{array}{c}\text { Ch.3 } \\
\text { Right EO }\end{array}$ & $\begin{array}{c}\text { Ch.4 } \\
\text { Left RA }\end{array}$ & $\begin{array}{c}\text { Ch.5 } \\
\text { Right LE }\end{array}$ & $\begin{array}{c}\text { Ch.6 } \\
\text { Left LE }\end{array}$ & $\begin{array}{c}\text { Ch.7 } \\
\text { Right TE }\end{array}$ & $\begin{array}{c}\text { Ch.8 } \\
\text { Left TE }\end{array}$ \\
\hline BHV & 0.0297 & 0.0308 & 0.0295 & 0.0283 & 0.0286 & 0.0319 & 0.0319 & 0.0377 \\
\hline BNV & 0.0221 & 0.0478 & 0.0598 & 0.0365 & 0.0245 & 0.0821 & 0.0446 & 0.1122 \\
\hline & & & & & & & & \\
\hline FHV & - & - & - & - & - & - & - & - \\
\hline FNV & 0.0367 & 0.0300 & 0.0253 & 0.0286 & 0.0305 & 1.0494 & 0.0326 & 0.0320 \\
\hline
\end{tabular}

Table 3: RMS with Visuals, Subject 1

\begin{tabular}{|c|c|c|c|c|c|c|c|c|}
\hline & $\begin{array}{c}\text { Ch.1 } \\
\text { Right RA }\end{array}$ & $\begin{array}{c}\text { Ch.2 } \\
\text { Left RA }\end{array}$ & $\begin{array}{c}\text { Ch.3 } \\
\text { Right EO }\end{array}$ & $\begin{array}{c}\text { Ch.4 } \\
\text { Left RA }\end{array}$ & $\begin{array}{c}\text { Ch.5 } \\
\text { Right LE }\end{array}$ & $\begin{array}{c}\text { Ch.6 } \\
\text { Left LE }\end{array}$ & $\begin{array}{c}\text { Ch.7 } \\
\text { Right TE }\end{array}$ & $\begin{array}{c}\text { Ch.8 } \\
\text { Left TE }\end{array}$ \\
\hline BHV & 101.5 & 105.2 & 100.6 & 96.2 & 97.6 & 97.6 & 108.5 & 124.9 \\
\hline BNV & 0.0 & 2.3 & 2.9 & 1.8 & 1.2 & 4.0 & 0.0 & 0.0 \\
\hline & & & & & & & & \\
\hline FHV & - & - & - & - & - & - & - & - \\
\hline FNV & 54.9 & 48.2 & 41.0 & 47.2 & 50.4 & 1530.2 & 53.6 & 52.3 \\
\hline
\end{tabular}

Table 4: iEMG with Visuals, Subject 1 


\section{Subject 2}

No Visuals

\begin{tabular}{|c|c|c|c|c|c|c|c|c|}
\hline & $\begin{array}{c}\text { Ch.1 } \\
\text { Right RA }\end{array}$ & $\begin{array}{c}\text { Ch.2 } \\
\text { Left RA }\end{array}$ & $\begin{array}{c}\text { Ch.3 } \\
\text { Right EO }\end{array}$ & $\begin{array}{c}\text { Ch.4 } \\
\text { Left RA }\end{array}$ & $\begin{array}{c}\text { Ch.5 } \\
\text { Right LE }\end{array}$ & $\begin{array}{c}\text { Ch.6 } \\
\text { Left LE }\end{array}$ & $\begin{array}{c}\text { Ch.7 } \\
\text { Right TE }\end{array}$ & $\begin{array}{c}\text { Ch.8 } \\
\text { Left TE }\end{array}$ \\
\hline BHN & 0.0344 & 0.0344 & 0.0293 & 0.0409 & 0.0333 & 0.0268 & 0.2751 & 0.0698 \\
\hline BNN & 0.0381 & 0.0477 & 0.0484 & 0.0436 & 0.0753 & 0.0285 & 0.6543 & 0.2189 \\
\hline & & & & & & & & \\
\hline FHN & 0.3335 & 0.0258 & 0.9302 & 0.0307 & 0.3098 & 0.0965 & 0.0720 & 0.0479 \\
\hline FNN & 0.0627 & 0.0255 & 0.0246 & 0.0284 & 0.0654 & 0.0334 & 0.0550 & 0.0506 \\
\hline
\end{tabular}

Table 1: RMS with No Visuals, Subject 2

\begin{tabular}{|c|c|c|c|c|c|c|c|c|}
\hline & Ch.1 & Ch.2 & Ch.3 & Ch.4 & Ch.5 & Ch.6 & Ch.7 & Ch.8 \\
& Right RA & Left RA & Right EO & Left RA & Right LE & Left LE & Right TE & Left TE \\
\hline BHN & 17.0 & 16.5 & 14.5 & 19.4 & 15.8 & 13.8 & 121.3 & 32.3 \\
\hline BNN & 22.5 & 26.8 & 26.7 & 25.4 & 42.7 & 17.1 & 340.5 & 116.5 \\
\hline & & & & & & & & \\
\hline FHN & 474.1 & 50.0 & 1280.9 & 60.5 & 433.5 & 130.8 & 138.8 & 91.8 \\
\hline FNN & 113.7 & 45.6 & 44.7 & 51.7 & 117.9 & 61.0 & 99.4 & 92.1 \\
\hline
\end{tabular}

Table 2: iEMG with No Visuals, Subject 2 
Visuals

\begin{tabular}{|c|c|c|c|c|c|c|c|c|}
\hline & $\begin{array}{c}\text { Ch.1 } \\
\text { Right RA }\end{array}$ & $\begin{array}{c}\text { Ch.2 } \\
\text { Left RA }\end{array}$ & $\begin{array}{c}\text { Ch.3 } \\
\text { Right EO }\end{array}$ & $\begin{array}{c}\text { Ch.4 } \\
\text { Left RA }\end{array}$ & $\begin{array}{c}\text { Ch.5 } \\
\text { Right LE }\end{array}$ & $\begin{array}{c}\text { Ch.6 } \\
\text { Left LE }\end{array}$ & $\begin{array}{c}\text { Ch.7 } \\
\text { Right TE }\end{array}$ & $\begin{array}{c}\text { Ch.8 } \\
\text { Left TE }\end{array}$ \\
\hline BHV & 0.0289 & 0.0348 & 0.0375 & 0.0288 & 0.5654 & 0.0684 & 0.0862 & 0.0666 \\
\hline BNV & 0.0273 & 0.0277 & 0.0335 & 0.0295 & 0.0316 & 0.0270 & 0.0405 & 0.0406 \\
\hline & & & & & & & & \\
\hline FHV & 0.0549 & 0.2376 & 0.4505 & 0.0309 & 0.2391 & 0.1755 & 0.1092 & 0.0554 \\
\hline FNV & 0.0349 & 0.0451 & 0.1374 & 0.0330 & 0.1884 & 0.0798 & 0.0623 & 0.0445 \\
\hline
\end{tabular}

Table 3: RMS with Visuals, Subject 2

\begin{tabular}{|c|c|c|c|c|c|c|c|c|}
\hline & $\begin{array}{c}\text { Ch.1 } \\
\text { Right RA }\end{array}$ & $\begin{array}{c}\text { Ch.2 } \\
\text { Left RA }\end{array}$ & $\begin{array}{c}\text { Ch.3 } \\
\text { Right EO }\end{array}$ & $\begin{array}{c}\text { Ch.4 } \\
\text { Left RA }\end{array}$ & $\begin{array}{c}\text { Ch.5 } \\
\text { Right LE }\end{array}$ & $\begin{array}{c}\text { Ch.6 } \\
\text { Left LE }\end{array}$ & $\begin{array}{c}\text { Ch.7 } \\
\text { Right TE }\end{array}$ & $\begin{array}{c}\text { Ch.8 } \\
\text { Left TE }\end{array}$ \\
\hline BHV & 63.0 & 76.0 & 80.0 & 62.9 & 881.7 & 121.7 & 151.5 & 115.0 \\
\hline BNV & 50.1 & 51.0 & 60.3 & 53.3 & 58.0 & 49.6 & 73.6 & 73.3 \\
\hline & & & & & & & & \\
\hline FHV & 98.5 & 309.3 & 521.2 & 63.3 & 375.4 & 292.6 & 199.6 & 102.4 \\
\hline FNV & 140.3 & 157.0 & 410.5 & 132.7 & 426.7 & 270.6 & 239.7 & 177.3 \\
\hline
\end{tabular}

Table 4: iEMG with Visuals, Subject 2 


\section{$\underline{\text { Subject } 3}$}

No Visuals

\begin{tabular}{|c|c|c|c|c|c|c|c|c|}
\hline & $\begin{array}{c}\text { Ch.1 } \\
\text { Right RA }\end{array}$ & $\begin{array}{c}\text { Ch.2 } \\
\text { Left RA }\end{array}$ & $\begin{array}{c}\text { Ch.3 } \\
\text { Right EO }\end{array}$ & $\begin{array}{c}\text { Ch.4 } \\
\text { Left RA }\end{array}$ & $\begin{array}{c}\text { Ch.5 } \\
\text { Right LE }\end{array}$ & $\begin{array}{c}\text { Ch.6 } \\
\text { Left LE }\end{array}$ & $\begin{array}{c}\text { Ch.7 } \\
\text { Right TE }\end{array}$ & $\begin{array}{c}\text { Ch.8 } \\
\text { Left TE }\end{array}$ \\
\hline BHN & 0.0616 & 0.1457 & 0.0289 & 0.0339 & 0.0567 & 0.3511 & 0.1959 & 0.0492 \\
\hline BNN & 0.0340 & 0.0803 & 0.0470 & 0.0307 & 0.3316 & 0.5396 & 0.2085 & 0.1350 \\
\hline & & & & & & & & \\
\hline FHN & 0.0754 & 0.1926 & 0.0398 & 0.0287 & 0.0407 & 0.2398 & 0.0484 & 0.0754 \\
\hline FNN & 0.0534 & 0.2375 & 0.0681 & 0.0284 & 0.0460 & 0.2841 & 0.0700 & 0.0767 \\
\hline
\end{tabular}

Table 1: RMS with No Visuals, Subject 3

\begin{tabular}{|c|c|c|c|c|c|c|c|c|}
\hline & $\begin{array}{c}\text { Ch.1 } \\
\text { Right RA }\end{array}$ & $\begin{array}{c}\text { Ch.2 } \\
\text { Left RA }\end{array}$ & $\begin{array}{c}\text { Ch.3 } \\
\text { Right EO }\end{array}$ & $\begin{array}{c}\text { Ch.4 } \\
\text { Left RA }\end{array}$ & $\begin{array}{c}\text { Ch.5 } \\
\text { Right LE }\end{array}$ & $\begin{array}{c}\text { Ch.6 } \\
\text { Left LE }\end{array}$ & $\begin{array}{c}\text { Ch.7 } \\
\text { Right TE }\end{array}$ & $\begin{array}{c}\text { Ch.8 } \\
\text { Left TE }\end{array}$ \\
\hline BHN & 258.3 & 391.8 & 147.0 & 168.3 & 236.2 & 1024.8 & 522.1 & 242.1 \\
\hline BNN & 149.9 & 301.7 & 204.8 & 140.3 & 112.1 & 127.7 & 662.4 & 457.4 \\
\hline & & & & & & & & \\
\hline FHN & 320.2 & 777.7 & 227.4 & 166.9 & 235.3 & 622.8 & 254.9 & 346.9 \\
\hline FNN & 198.9 & 647.9 & 232.1 & 119.3 & 186.6 & 602.0 & 236.1 & 269.7 \\
\hline
\end{tabular}

Table 2: iEMG with No Visuals, Subject 3 
Visuals

\begin{tabular}{|c|c|c|c|c|c|c|c|c|}
\hline & $\begin{array}{c}\text { Ch.1 } \\
\text { Right RA }\end{array}$ & $\begin{array}{c}\text { Ch.2 } \\
\text { Left RA }\end{array}$ & $\begin{array}{c}\text { Ch.3 } \\
\text { Right EO }\end{array}$ & $\begin{array}{c}\text { Ch.4 } \\
\text { Left RA }\end{array}$ & $\begin{array}{c}\text { Ch.5 } \\
\text { Right LE }\end{array}$ & $\begin{array}{c}\text { Ch.6 } \\
\text { Left LE }\end{array}$ & $\begin{array}{c}\text { Ch.7 } \\
\text { Right TE }\end{array}$ & $\begin{array}{c}\text { Ch.8 } \\
\text { Left TE }\end{array}$ \\
\hline BHV & 0.0507 & 0.3953 & 0.0358 & 0.1216 & 0.1220 & 0.0691 & 0.0991 & 0.0560 \\
\hline BNV & 0.1213 & 0.3414 & 0.1214 & 0.1338 & 0.0011 & 0.0352 & 0.0600 & 0.0239 \\
\hline & & & & & & & & \\
\hline FHV & 0.1414 & 0.3428 & 0.0356 & 0.0535 & 0.0470 & 0.1610 & 0.0542 & 0.0709 \\
\hline FNV & 0.2038 & 0.4658 & 0.0751 & 0.0722 & 0.0539 & 0.2377 & 0.0593 & 0.0656 \\
\hline
\end{tabular}

Table 3: RMS with Visuals, Subject 3

\begin{tabular}{|c|c|c|c|c|c|c|c|c|}
\hline & $\begin{array}{c}\text { Ch.1 } \\
\text { Right RA }\end{array}$ & $\begin{array}{c}\text { Ch.2 } \\
\text { Left RA }\end{array}$ & $\begin{array}{c}\text { Ch.3 } \\
\text { Right EO }\end{array}$ & $\begin{array}{c}\text { Ch.4 } \\
\text { Left RA }\end{array}$ & $\begin{array}{c}\text { Ch.5 } \\
\text { Right LE }\end{array}$ & $\begin{array}{c}\text { Ch.6 } \\
\text { Left LE }\end{array}$ & $\begin{array}{c}\text { Ch.7 } \\
\text { Right TE }\end{array}$ & $\begin{array}{c}\text { Ch.8 } \\
\text { Left TE }\end{array}$ \\
\hline BHV & 213.4 & 1279.2 & 162.2 & 352.5 & 377.7 & 246.2 & 346.8 & 251.6 \\
\hline BNV & 2.3 & 6.5 & 2.3 & 2.5 & 0.0 & 0.0 & 0.0 & 0.0 \\
\hline & & & & & & & & \\
\hline FHV & 483.5 & 1275.5 & 178.5 & 235.0 & 212.2 & 445.1 & 229.0 & 293.4 \\
\hline FNV & 464.5 & 1471.0 & 257.7 & 221.6 & 201.6 & 419.1 & 204.3 & 227.2 \\
\hline
\end{tabular}

Table 4: iEMG with Visuals, Subject 3 


\section{$\underline{\text { Subject } 4}$}

No Visuals

\begin{tabular}{|c|c|c|c|c|c|c|c|c|}
\hline & $\begin{array}{c}\text { Ch.1 } \\
\text { Right RA }\end{array}$ & $\begin{array}{c}\text { Ch.2 } \\
\text { Left RA }\end{array}$ & $\begin{array}{c}\text { Ch.3 } \\
\text { Right EO }\end{array}$ & $\begin{array}{c}\text { Ch.4 } \\
\text { Left RA }\end{array}$ & $\begin{array}{c}\text { Ch.5 } \\
\text { Right LE }\end{array}$ & $\begin{array}{c}\text { Ch.6 } \\
\text { Left LE }\end{array}$ & $\begin{array}{c}\text { Ch.7 } \\
\text { Right TE }\end{array}$ & $\begin{array}{c}\text { Ch.8 } \\
\text { Left TE }\end{array}$ \\
\hline BHN & 0.0393 & 0.0388 & 0.0373 & 0.0384 & 0.0785 & 0.2657 & 0.1590 & 0.1276 \\
\hline BNN & 0.0123 & 0.0271 & 0.0059 & 0.0071 & 0.0169 & 0.0104 & 0.0170 & 0.0085 \\
\hline & & & & & & & & \\
\hline FHN & 0.0343 & 0.0347 & 0.0398 & 0.0349 & 0.0620 & 0.1084 & 0.0979 & 0.0584 \\
\hline FNN & 0.0360 & 0.0392 & 0.0423 & 0.0314 & 0.0421 & 0.0498 & 0.0508 & 0.0637 \\
\hline
\end{tabular}

Table 1: RMS with No Visuals, Subject 4

\begin{tabular}{|c|c|c|c|c|c|c|c|c|}
\hline & Ch.1 & Ch.2 & Ch.3 & Ch.4 & Ch.5 & Ch.6 & Ch.7 & Ch.8 \\
& Right RA & Left RA & Right EO & Left RA & Right LE & Left LE & Right TE & Left TE \\
\hline BHN & 140.1 & 136.9 & 132.0 & 130.0 & 219.3 & 627.6 & 403.8 & 349.6 \\
\hline BNN & 1.8 & 4.0 & 0.0 & 0.9 & 2.5 & 1.5 & 2.5 & 1.0 \\
\hline FHN & 125.1 & 133.1 & 143.9 & 131.3 & 204.5 & 277.2 & 253.9 & 207.5 \\
\hline FNN & 63.3 & 69.6 & 66.8 & 56.0 & 72.6 & 89.7 & 91.4 & 104.7 \\
\hline
\end{tabular}

Table 2: iEMG with No Visuals, Subject 4 
Visuals

\begin{tabular}{|c|c|c|c|c|c|c|c|c|}
\hline & $\begin{array}{c}\text { Ch.1 } \\
\text { Right RA }\end{array}$ & $\begin{array}{c}\text { Ch.2 } \\
\text { Left RA }\end{array}$ & $\begin{array}{c}\text { Ch.3 } \\
\text { Right EO }\end{array}$ & $\begin{array}{c}\text { Ch.4 } \\
\text { Left RA }\end{array}$ & $\begin{array}{c}\text { Ch.5 } \\
\text { Right LE }\end{array}$ & $\begin{array}{c}\text { Ch.6 } \\
\text { Left LE }\end{array}$ & $\begin{array}{c}\text { Ch.7 } \\
\text { Right TE }\end{array}$ & $\begin{array}{c}\text { Ch.8 } \\
\text { Left TE }\end{array}$ \\
\hline BHV & 0.0398 & 0.0395 & 0.0365 & 0.0333 & 0.2861 & 0.2160 & 0.1267 & 0.2523 \\
\hline BNV & 0.0343 & 0.0369 & 0.0277 & 0.0314 & 0.0459 & 0.1037 & 0.0344 & 0.0455 \\
\hline & & & & & & & & \\
\hline FHV & 0.0405 & 0.0369 & 0.0313 & 0.0274 & 11.1606 & 0.0810 & 0.0558 & 0.2482 \\
\hline FNV & 0.0315 & 0.0338 & 0.0305 & 0.0298 & 0.0424 & 0.0284 & 0.0399 & 0.0445 \\
\hline
\end{tabular}

Table 3: RMS with Visuals, Subject 4

\begin{tabular}{|c|c|c|c|c|c|c|c|c|}
\hline & $\begin{array}{c}\text { Ch.1 } \\
\text { Right RA }\end{array}$ & $\begin{array}{c}\text { Ch.2 } \\
\text { Left RA }\end{array}$ & $\begin{array}{c}\text { Ch.3 } \\
\text { Right EO }\end{array}$ & $\begin{array}{c}\text { Ch.4 } \\
\text { Left RA }\end{array}$ & $\begin{array}{c}\text { Ch.5 } \\
\text { Right LE }\end{array}$ & $\begin{array}{c}\text { Ch.6 } \\
\text { Left LE }\end{array}$ & $\begin{array}{c}\text { Ch.7 } \\
\text { Right TE }\end{array}$ & $\begin{array}{c}\text { Ch.8 } \\
\text { Left TE }\end{array}$ \\
\hline BHV & 178.4 & 175.1 & 162.3 & 149.7 & 753.0 & 662.8 & 405.0 & 793.6 \\
\hline BNV & 16.0 & 17.2 & 12.8 & 14.0 & 20.9 & 47.8 & 15.8 & 20.2 \\
\hline & & & & & & & & \\
\hline FHV & 126.0 & 117.0 & 101.0 & 88.0 & 27822.0 & 228.0 & 174.0 & 527.0 \\
\hline FNV & 44.5 & 48.0 & 43.7 & 42.2 & 61.3 & 40.1 & 57.0 & 63.2 \\
\hline
\end{tabular}

Table 4: iEMG with Visuals, Subject 4 


\section{$\underline{\text { Subject } 5}$}

No Visuals

\begin{tabular}{|c|c|c|c|c|c|c|c|c|}
\hline & $\begin{array}{c}\text { Ch.1 } \\
\text { Right RA }\end{array}$ & $\begin{array}{c}\text { Ch.2 } \\
\text { Left RA }\end{array}$ & $\begin{array}{c}\text { Ch.3 } \\
\text { Right EO }\end{array}$ & $\begin{array}{c}\text { Ch.4 } \\
\text { Left RA }\end{array}$ & $\begin{array}{c}\text { Ch.5 } \\
\text { Right LE }\end{array}$ & $\begin{array}{c}\text { Ch.6 } \\
\text { Left LE }\end{array}$ & $\begin{array}{c}\text { Ch.7 } \\
\text { Right TE }\end{array}$ & $\begin{array}{c}\text { Ch.8 } \\
\text { Left TE }\end{array}$ \\
\hline BHN & 0.0291 & 0.0299 & 0.0298 & 0.0299 & 0.0645 & 0.1736 & 0.1075 & 0.0468 \\
\hline BNN & 0.0331 & 0.0368 & 0.0301 & 0.0390 & 0.1967 & 1.1833 & 0.7194 & 0.4084 \\
\hline & & & & & & & & \\
\hline FHN & 0.0343 & 0.0347 & 0.0398 & 0.0349 & 0.0620 & 0.1084 & 0.0979 & 0.0584 \\
\hline FNN & 0.0774 & 0.1154 & 0.0670 & 0.0649 & 0.0910 & 3.1084 & 0.0749 & 0.0464 \\
\hline
\end{tabular}

Table 1: RMS with No Visuals, Subject 5

\begin{tabular}{|c|c|c|c|c|c|c|c|c|}
\hline & $\begin{array}{c}\text { Ch.1 } \\
\text { Right RA }\end{array}$ & $\begin{array}{c}\text { Ch.2 } \\
\text { Left RA }\end{array}$ & $\begin{array}{c}\text { Ch.3 } \\
\text { Right EO }\end{array}$ & $\begin{array}{c}\text { Ch.4 } \\
\text { Left RA }\end{array}$ & $\begin{array}{c}\text { Ch.5 } \\
\text { Right LE }\end{array}$ & $\begin{array}{c}\text { Ch.6 } \\
\text { Left LE }\end{array}$ & $\begin{array}{c}\text { Ch.7 } \\
\text { Right TE }\end{array}$ & $\begin{array}{c}\text { Ch.8 } \\
\text { Left TE }\end{array}$ \\
\hline BHN & 59.4 & 60.5 & 60.0 & 61.3 & 92.3 & 309.8 & 124.2 & 86.4 \\
\hline BNN & 186.8 & 199.4 & 172.2 & 205.0 & 597.9 & 4817.0 & 2165.7 & 1387.8 \\
\hline & & & & & & & & \\
\hline FHN & 125.1 & 133.1 & 143.9 & 131.3 & 204.5 & 277.2 & 253.9 & 207.5 \\
\hline FNN & 375.9 & 544.6 & 348.8 & 321.7 & 460.5 & 9486.3 & 402.4 & 286.9 \\
\hline
\end{tabular}

Table 2: iEMG with No Visuals, Subject 5 
Visuals

\begin{tabular}{|c|c|c|c|c|c|c|c|c|}
\hline & $\begin{array}{c}\text { Ch.1 } \\
\text { Right RA }\end{array}$ & $\begin{array}{c}\text { Ch.2 } \\
\text { Left RA }\end{array}$ & $\begin{array}{c}\text { Ch.3 } \\
\text { Right EO }\end{array}$ & $\begin{array}{c}\text { Ch.4 } \\
\text { Left RA }\end{array}$ & $\begin{array}{c}\text { Ch.5 } \\
\text { Right LE }\end{array}$ & $\begin{array}{c}\text { Ch.6 } \\
\text { Left LE }\end{array}$ & $\begin{array}{c}\text { Ch.7 } \\
\text { Right TE }\end{array}$ & $\begin{array}{c}\text { Ch.8 } \\
\text { Left TE }\end{array}$ \\
\hline BHV & 0.0336 & 0.0394 & 0.0334 & 0.0662 & 0.0887 & 0.0716 & 0.0740 & 0.0414 \\
\hline BNV & 0.0303 & 0.0302 & 0.0284 & 0.0347 & 0.0358 & 0.1105 & 0.0351 & 0.0401 \\
\hline & & & & & & & & \\
\hline FHV & 0.0501 & 0.0287 & 0.0282 & 0.0674 & 0.0582 & 0.8973 & 0.0556 & 0.0667 \\
\hline FNV & 0.0380 & 0.0316 & 0.0294 & 0.0348 & 0.0470 & 0.4690 & 0.0464 & 0.0460 \\
\hline
\end{tabular}

Table 3: RMS with Visuals, Subject 5

\begin{tabular}{|c|c|c|c|c|c|c|c|c|}
\hline & $\begin{array}{c}\text { Ch.1 } \\
\text { Right RA }\end{array}$ & $\begin{array}{c}\text { Ch.2 } \\
\text { Left RA }\end{array}$ & $\begin{array}{c}\text { Ch.3 } \\
\text { Right EO }\end{array}$ & $\begin{array}{c}\text { Ch.4 } \\
\text { Left RA }\end{array}$ & $\begin{array}{c}\text { Ch.5 } \\
\text { Right LE }\end{array}$ & $\begin{array}{c}\text { Ch.6 } \\
\text { Left LE }\end{array}$ & $\begin{array}{c}\text { Ch.7 } \\
\text { Right TE }\end{array}$ & $\begin{array}{c}\text { Ch.8 } \\
\text { Left TE }\end{array}$ \\
\hline BHV & 148.3 & 173.7 & 147.0 & 225.5 & 289.1 & 285.1 & 280.3 & 175.7 \\
\hline BNV & 77.9 & 77.1 & 73.1 & 83.2 & 90.0 & 235.1 & 89.3 & 100.8 \\
\hline & & & & & & & & \\
\hline FHV & 188.2 & 138.6 & 138.1 & 259.2 & 247.5 & 2936.9 & 262.2 & 307.4 \\
\hline FNV & 175.4 & 159.7 & 149.0 & 160.4 & 225.8 & 1431.7 & 219.7 & 228.9 \\
\hline
\end{tabular}

Table 4: iEMG with Visuals, Subject 5 


\section{$\underline{\text { Subject } 6}$}

No Visuals

\begin{tabular}{|c|c|c|c|c|c|c|c|c|}
\hline & Ch.1 & Ch.2 & Ch.3 & Ch.4 & Ch.5 & Ch.6 & Ch.7 & Ch.8 \\
& Right RA & Left RA & Right EO & Left RA & Right LE & Left LE & Right TE & Left TE \\
\hline BHN & 0.1201 & 0.0406 & 0.0420 & 0.0668 & 0.0400 & 0.0758 & 0.0485 & 0.0595 \\
\hline BNN & 0.5141 & 0.0389 & 0.4663 & 0.0700 & 0.1033 & 0.0413 & 0.0351 & 0.0391 \\
\hline & & & & & & & & \\
\hline FHN & - & - & - & - & - & - & - & - \\
\hline FNN & - & - & - & - & - & - & - & - \\
\hline
\end{tabular}

Table 1: RMS with No Visuals, Subject 6

\begin{tabular}{|c|c|c|c|c|c|c|c|c|}
\hline & $\begin{array}{c}\text { Ch.1 } \\
\text { Right RA }\end{array}$ & $\begin{array}{c}\text { Ch.2 } \\
\text { Left RA }\end{array}$ & $\begin{array}{c}\text { Ch.3 } \\
\text { Right EO }\end{array}$ & $\begin{array}{c}\text { Ch.4 } \\
\text { Left RA }\end{array}$ & $\begin{array}{c}\text { Ch.5 } \\
\text { Right LE }\end{array}$ & $\begin{array}{c}\text { Ch.6 } \\
\text { Left LE }\end{array}$ & $\begin{array}{c}\text { Ch.7 } \\
\text { Right TE }\end{array}$ & $\begin{array}{r}\text { Ch.8 } \\
\text { Left TE }\end{array}$ \\
\hline BHN & 200.0 & 90.2 & 91.5 & 136.5 & 91.3 & 127.5 & 102.5 & 129.4 \\
\hline $\mathbf{B N N}$ & 612.8 & 63.1 & 460.1 & 103.7 & 139.2 & 67.9 & 58.0 & 64.0 \\
\hline FHN & - & - & - & - & - & - & - & - \\
\hline FNN & - & - & - & - & - & - & - & - \\
\hline
\end{tabular}

Table 2: iEMG with No Visuals, Subject 6 
Visuals

\begin{tabular}{|c|c|c|c|c|c|c|c|c|}
\hline & $\begin{array}{c}\text { Ch.1 } \\
\text { Right RA }\end{array}$ & $\begin{array}{c}\text { Ch.2 } \\
\text { Left RA }\end{array}$ & $\begin{array}{c}\text { Ch.3 } \\
\text { Right EO }\end{array}$ & $\begin{array}{c}\text { Ch.4 } \\
\text { Left RA }\end{array}$ & $\begin{array}{c}\text { Ch.5 } \\
\text { Right LE }\end{array}$ & $\begin{array}{c}\text { Ch.6 } \\
\text { Left LE }\end{array}$ & $\begin{array}{c}\text { Ch.7 } \\
\text { Right TE }\end{array}$ & $\begin{array}{c}\text { Ch.8 } \\
\text { Left TE }\end{array}$ \\
\hline BHV & 0.1104 & 0.0323 & 0.0429 & 0.0424 & 0.0342 & 0.0392 & 0.0368 & 0.0418 \\
\hline BNV & 0.0120 & 0.0247 & 0.0466 & 0.0605 & 0.0121 & 0.0270 & 0.0063 & 0.1239 \\
\hline & & & & & & & & \\
\hline FHV & 0.4825 & 0.2514 & 0.0611 & 0.1786 & 0.0505 & 0.0282 & 0.0358 & 0.0563 \\
\hline FNV & 0.6551 & 0.1650 & 0.2062 & 0.7335 & 0.1718 & 0.1371 & 0.3437 & 0.2335 \\
\hline
\end{tabular}

Table 3: RMS with Visuals, Subject 6

\begin{tabular}{|c|c|c|c|c|c|c|c|c|}
\hline & $\begin{array}{c}\text { Ch.1 } \\
\text { Right RA }\end{array}$ & $\begin{array}{c}\text { Ch.2 } \\
\text { Left RA }\end{array}$ & $\begin{array}{c}\text { Ch.3 } \\
\text { Right EO }\end{array}$ & $\begin{array}{c}\text { Ch.4 } \\
\text { Left RA }\end{array}$ & $\begin{array}{c}\text { Ch.5 } \\
\text { Right LE }\end{array}$ & $\begin{array}{c}\text { Ch.6 } \\
\text { Left LE }\end{array}$ & $\begin{array}{c}\text { Ch.7 } \\
\text { Right TE }\end{array}$ & $\begin{array}{c}\text { Ch.8 } \\
\text { Left TE }\end{array}$ \\
\hline BHV & 172.8 & 73.4 & 83.2 & 97.4 & 73.5 & 85.0 & 72.0 & 88.1 \\
\hline BNV & 0.0 & 3.2 & 6.0 & 7.8 & 1.6 & 3.5 & 0.8 & 16.0 \\
\hline & & & & & & & & \\
\hline FHV & 983.2 & 344.2 & 116.3 & 346.5 & 108.7 & 61.3 & 74.7 & 106.5 \\
\hline FNV & 897.7 & 278.2 & 276.3 & 978.2 & 191.9 & 208.3 & 380.1 & 301.5 \\
\hline
\end{tabular}

Table 4: iEMG with Visuals, Subject 6 


\section{Subject 7}

No Visuals

\begin{tabular}{|c|c|c|c|c|c|c|c|c|}
\hline & $\begin{array}{c}\text { Ch.1 } \\
\text { Right RA }\end{array}$ & $\begin{array}{c}\text { Ch.2 } \\
\text { Left RA }\end{array}$ & $\begin{array}{c}\text { Ch.3 } \\
\text { Right EO }\end{array}$ & $\begin{array}{c}\text { Ch.4 } \\
\text { Left RA }\end{array}$ & $\begin{array}{c}\text { Ch.5 } \\
\text { Right LE }\end{array}$ & $\begin{array}{c}\text { Ch.6 } \\
\text { Left LE }\end{array}$ & $\begin{array}{c}\text { Ch.7 } \\
\text { Right TE }\end{array}$ & $\begin{array}{c}\text { Ch.8 } \\
\text { Left TE }\end{array}$ \\
\hline BHN & 0.3460 & 0.0639 & 0.0526 & 0.0616 & 0.0466 & 0.0395 & 0.0414 & 0.0428 \\
\hline BNN & 0.1828 & 0.0621 & 0.0591 & 0.0541 & 0.0770 & 0.0566 & 0.0569 & 0.1446 \\
\hline & & & & & & & & \\
\hline FHN & - & - & - & - & - & - & - & - \\
\hline FNN & 0.0307 & 0.1012 & 0.0290 & 0.0385 & 0.0346 & 0.0277 & 0.0403 & 0.0491 \\
\hline
\end{tabular}

Table 1: RMS with No Visuals, Subject 7

\begin{tabular}{|c|c|c|c|c|c|c|c|c|}
\hline & Ch.1 & Ch.2 & Ch.3 & Ch.4 & Ch.5 & Ch.6 & Ch.7 & Ch.8 \\
& Right RA & Left RA & Right EO & Left RA & Right LE & Left LE & Right TE & Left TE \\
\hline BHN & 692.4 & 133.2 & 109.2 & 113.8 & 101.5 & 93.7 & 98.9 & 103.1 \\
\hline BNN & 331.1 & 128.0 & 130.6 & 113.1 & 146.6 & 121.2 & 134.1 & 317.9 \\
\hline & & & & & & & & \\
\hline FHN & - & - & - & - & - & - & - & - \\
\hline FNN & 32.3 & 83.3 & 31.2 & 40.2 & 36.8 & 29.7 & 42.5 & 52.4 \\
\hline
\end{tabular}

Table 2: iEMG with No Visuals, Subject 7 
Visuals

\begin{tabular}{|c|c|c|c|c|c|c|c|c|}
\hline & $\begin{array}{c}\text { Ch.1 } \\
\text { Right RA }\end{array}$ & $\begin{array}{c}\text { Ch.2 } \\
\text { Left RA }\end{array}$ & $\begin{array}{c}\text { Ch.3 } \\
\text { Right EO }\end{array}$ & $\begin{array}{c}\text { Ch.4 } \\
\text { Left RA }\end{array}$ & $\begin{array}{c}\text { Ch.5 } \\
\text { Right LE }\end{array}$ & $\begin{array}{c}\text { Ch.6 } \\
\text { Left LE }\end{array}$ & $\begin{array}{c}\text { Ch.7 } \\
\text { Right TE }\end{array}$ & $\begin{array}{c}\text { Ch.8 } \\
\text { Left TE }\end{array}$ \\
\hline BHV & - & - & - & - & - & - & - & - \\
\hline BNV & - & - & - & - & - & - & - & - \\
\hline & & & & & & & & \\
\hline FHV & 0.0310 & 0.0325 & 0.0321 & 0.0283 & 0.0296 & 0.0276 & 0.0389 & 0.0420 \\
\hline FNV & - & - & - & - & - & - & - & - \\
\hline
\end{tabular}

Table 3: RMS with Visuals, Subject 7

\begin{tabular}{|c|c|c|c|c|c|c|c|c|}
\hline & $\begin{array}{c}\text { Ch.1 } \\
\text { Right RA }\end{array}$ & $\begin{array}{c}\text { Ch.2 } \\
\text { Left RA }\end{array}$ & $\begin{array}{c}\text { Ch.3 } \\
\text { Right EO }\end{array}$ & $\begin{array}{c}\text { Ch.4 } \\
\text { Left RA }\end{array}$ & $\begin{array}{c}\text { Ch.5 } \\
\text { Right LE }\end{array}$ & $\begin{array}{c}\text { Ch.6 } \\
\text { Left LE }\end{array}$ & $\begin{array}{c}\text { Ch.7 } \\
\text { Right TE }\end{array}$ & $\begin{array}{c}\text { Ch.8 } \\
\text { Left TE }\end{array}$ \\
\hline BHV & - & - & - & - & - & - & - & - \\
\hline BNV & - & - & - & - & - & - & - & - \\
\hline & & & & & & & & \\
\hline FHV & 31.9 & 33.9 & 33.6 & 29.2 & 30.8 & 29.0 & 39.8 & 42.7 \\
\hline FNV & - & - & - & - & - & - & - & - \\
\hline
\end{tabular}

Table 4: iEMG with Visuals, Subject 7 


\section{$\underline{\text { Subject } 8}$}

No Visuals

\begin{tabular}{|c|c|c|c|c|c|c|c|c|}
\hline & Ch.1 & Ch.2 & Ch.3 & Ch.4 & Ch.5 & Ch.6 & Ch.7 & Ch.8 \\
& Right RA & Left RA & Right EO & Left RA & Right LE & Left LE & Right TE & Left TE \\
\hline BHN & 0.0889 & 0.1152 & 0.0755 & 0.0899 & 0.0724 & 0.2689 & 0.1020 & 0.0836 \\
\hline BNN & - & - & - & - & - & - & - & - \\
\hline & & & & & & & & \\
\hline FHN & 0.0545 & 0.0440 & 0.0318 & 0.0350 & 0.0289 & 0.1144 & 0.0877 & 0.0626 \\
\hline FNN & - & - & - & - & - & - & - & - \\
\hline
\end{tabular}

Table 1: RMS with No Visuals, Subject 8

\begin{tabular}{|c|c|c|c|c|c|c|c|c|}
\hline & Ch.1 & Ch.2 & Ch.3 & Ch.4 & Ch.5 & Ch.6 & Ch.7 & Ch.8 \\
\hline Right RA & Left RA & Right EO & Left RA & Right LE & Left LE & Right TE & Left TE \\
\hline BNN & 217.7 & 260.4 & 214.6 & 253.9 & 260.1 & 804.6 & 271.0 & 332.1 \\
\hline & - & - & - & - & - & - & - & - \\
\hline FHN & 186.2 & 153.1 & 118.2 & 124.5 & 107.7 & 259.6 & 285.5 & 226.9 \\
\hline FNN & - & - & - & - & - & - & - & - \\
\hline
\end{tabular}

Table 2: iEMG with No Visuals, Subject 8 
Visuals

\begin{tabular}{|c|c|c|c|c|c|c|c|c|}
\hline & $\begin{array}{c}\text { Ch.1 } \\
\text { Right RA }\end{array}$ & $\begin{array}{c}\text { Ch.2 } \\
\text { Left RA }\end{array}$ & $\begin{array}{c}\text { Ch.3 } \\
\text { Right EO }\end{array}$ & $\begin{array}{c}\text { Ch.4 } \\
\text { Left RA }\end{array}$ & $\begin{array}{c}\text { Ch.5 } \\
\text { Right LE }\end{array}$ & $\begin{array}{c}\text { Ch.6 } \\
\text { Left LE }\end{array}$ & $\begin{array}{c}\text { Ch.7 } \\
\text { Right TE }\end{array}$ & $\begin{array}{c}\text { Ch.8 } \\
\text { Left TE }\end{array}$ \\
\hline BHV & 0.0476 & 0.0387 & 0.0331 & 0.0306 & 0.0965 & 0.0562 & 0.0493 & 0.0566 \\
\hline BNV & 0.0527 & 0.0361 & 0.0324 & 0.0315 & 0.0660 & 0.0478 & 0.0375 & 0.0776 \\
\hline & & & & & & & & \\
\hline FHV & 0.1320 & 0.0392 & 0.0317 & 0.0296 & 0.1381 & 0.1421 & 0.0897 & 0.0625 \\
\hline FNV & 0.1582 & 0.0405 & 0.0319 & 0.0358 & 0.0817 & 0.1859 & 0.0517 & 0.0601 \\
\hline
\end{tabular}

Table 3: RMS with Visuals, Subject 8

\begin{tabular}{|c|c|c|c|c|c|c|c|c|}
\hline & $\begin{array}{c}\text { Ch.1 } \\
\text { Right RA }\end{array}$ & $\begin{array}{c}\text { Ch.2 } \\
\text { Left RA }\end{array}$ & $\begin{array}{c}\text { Ch.3 } \\
\text { Right EO }\end{array}$ & $\begin{array}{c}\text { Ch.4 } \\
\text { Left RA }\end{array}$ & $\begin{array}{c}\text { Ch.5 } \\
\text { Right LE }\end{array}$ & $\begin{array}{c}\text { Ch.6 } \\
\text { Left LE }\end{array}$ & $\begin{array}{c}\text { Ch.7 } \\
\text { Right TE }\end{array}$ & $\begin{array}{c}\text { Ch.8 } \\
\text { Left TE }\end{array}$ \\
\hline BHV & 243.2 & 221.4 & 198.6 & 183.2 & 443.3 & 300.4 & 272.2 & 323.3 \\
\hline BNV & 246.0 & 218.6 & 202.7 & 196.3 & 305.3 & 254.1 & 229.5 & 410.6 \\
\hline & & & & & & & & \\
\hline FHV & 360.4 & 123.4 & 103.2 & 95.7 & 304.3 & 343.0 & 248.5 & 191.9 \\
\hline FNV & 506.5 & 206.0 & 173.0 & 192.0 & 265.3 & 673.7 & 261.7 & 305.9 \\
\hline
\end{tabular}

Table 4: iEMG with Visuals, Subject 8 


\section{$\underline{\text { Subject } 9}$}

No Visuals

\begin{tabular}{|c|c|c|c|c|c|c|c|c|}
\hline & $\begin{array}{c}\text { Ch.1 } \\
\text { Right RA }\end{array}$ & $\begin{array}{c}\text { Ch.2 } \\
\text { Left RA }\end{array}$ & $\begin{array}{c}\text { Ch.3 } \\
\text { Right EO }\end{array}$ & $\begin{array}{c}\text { Ch.4 } \\
\text { Left RA }\end{array}$ & $\begin{array}{c}\text { Ch.5 } \\
\text { Right LE }\end{array}$ & $\begin{array}{c}\text { Ch.6 } \\
\text { Left LE }\end{array}$ & $\begin{array}{c}\text { Ch.7 } \\
\text { Right TE }\end{array}$ & $\begin{array}{c}\text { Ch.8 } \\
\text { Left TE }\end{array}$ \\
\hline BHN & 0.0510 & 0.0636 & 0.0284 & 0.0301 & 0.0707 & 0.0375 & 0.0317 & 0.0307 \\
\hline BNN & - & - & - & - & - & - & - & - \\
\hline & & & & & & & & \\
\hline FHN & 0.0375 & 0.3862 & 0.0326 & 0.0320 & 0.0436 & 0.0324 & 0.0468 & 0.2738 \\
\hline FNN & 0.0215 & 0.0463 & 0.0279 & 0.0256 & 0.0298 & 0.0126 & 0.0093 & 0.0111 \\
\hline
\end{tabular}

Table 1: RMS with No Visuals, Subject 9

\begin{tabular}{|c|c|c|c|c|c|c|c|c|}
\hline & Ch.1 & Ch.2 & Ch.3 & Ch.4 & Ch.5 & Ch.6 & Ch.7 & Ch.8 \\
& Right RA & Left RA & Right EO & Left RA & Right LE & Left LE & Right TE & Left TE \\
\hline BHN & 208.4 & 240.4 & 138.4 & 142.5 & 259.6 & 173.5 & 153.1 & 148.0 \\
\hline BNN & - & - & - & - & - & - & - & - \\
\hline & & & & & & & & \\
\hline FHN & 78.8 & 578.0 & 70.8 & 69.2 & 87.1 & 70.4 & 92.2 & 366.8 \\
\hline FNN & 3.2 & 6.9 & 4.1 & 3.8 & 4.4 & 1.8 & 1.3 & 1.6 \\
\hline
\end{tabular}

Table 2: iEMG with No Visuals, Subject 9 
Visuals

\begin{tabular}{|c|c|c|c|c|c|c|c|c|}
\hline & $\begin{array}{c}\text { Ch.1 } \\
\text { Right RA }\end{array}$ & $\begin{array}{c}\text { Ch.2 } \\
\text { Left RA }\end{array}$ & $\begin{array}{c}\text { Ch.3 } \\
\text { Right EO }\end{array}$ & $\begin{array}{c}\text { Ch.4 } \\
\text { Left RA }\end{array}$ & $\begin{array}{c}\text { Ch.5 } \\
\text { Right LE }\end{array}$ & $\begin{array}{c}\text { Ch.6 } \\
\text { Left LE }\end{array}$ & $\begin{array}{c}\text { Ch.7 } \\
\text { Right TE }\end{array}$ & $\begin{array}{c}\text { Ch.8 } \\
\text { Left TE }\end{array}$ \\
\hline BHV & 0.0252 & 0.0305 & 0.0294 & 0.0280 & 0.0305 & 0.0257 & 0.0326 & 0.0260 \\
\hline BNV & 0.0000 & 0.0369 & 0.0121 & 0.0007 & 0.0727 & 0.0004 & 0.0245 & 0.0231 \\
\hline & & & & & & & & \\
\hline FHV & 0.0795 & 0.4560 & 0.0300 & 0.0447 & 0.0928 & 0.0401 & 0.1823 & 0.1381 \\
\hline FNV & 0.0319 & 0.0289 & 0.0329 & 0.0302 & 0.0651 & 0.0296 & 0.0411 & 0.0302 \\
\hline
\end{tabular}

Table 3: RMS with Visuals, Subject 9

\begin{tabular}{|c|c|c|c|c|c|c|c|c|}
\hline & $\begin{array}{c}\text { Ch.1 } \\
\text { Right RA }\end{array}$ & $\begin{array}{c}\text { Ch.2 } \\
\text { Left RA }\end{array}$ & $\begin{array}{c}\text { Ch.3 } \\
\text { Right EO }\end{array}$ & $\begin{array}{c}\text { Ch.4 } \\
\text { Left RA }\end{array}$ & $\begin{array}{c}\text { Ch.5 } \\
\text { Right LE }\end{array}$ & $\begin{array}{c}\text { Ch.6 } \\
\text { Left LE }\end{array}$ & $\begin{array}{c}\text { Ch.7 } \\
\text { Right TE }\end{array}$ & $\begin{array}{c}\text { Ch.8 } \\
\text { Left TE }\end{array}$ \\
\hline BHV & 41.2 & 50.2 & 47.8 & 45.1 & 49.5 & 41.8 & 53.0 & 42.7 \\
\hline BNV & 0.0 & 1.4 & 0.5 & 0.0 & 2.8 & 0.0 & 1.0 & 0.0 \\
\hline & & & & & & & & \\
\hline FHV & 145.0 & 644.8 & 66.0 & 90.0 & 149.6 & 84.1 & 257.0 & 224.1 \\
\hline FNV & 9.5 & 8.6 & 9.5 & 8.7 & 15.7 & 8.8 & 11.5 & 8.1 \\
\hline
\end{tabular}

Table 4: iEMG with Visuals, Subject 9 


\section{Appendix F: Results: Averaged EMG Figures}

*Please note that all amplitude values are in $m V$

\section{BHN}

Subject 1
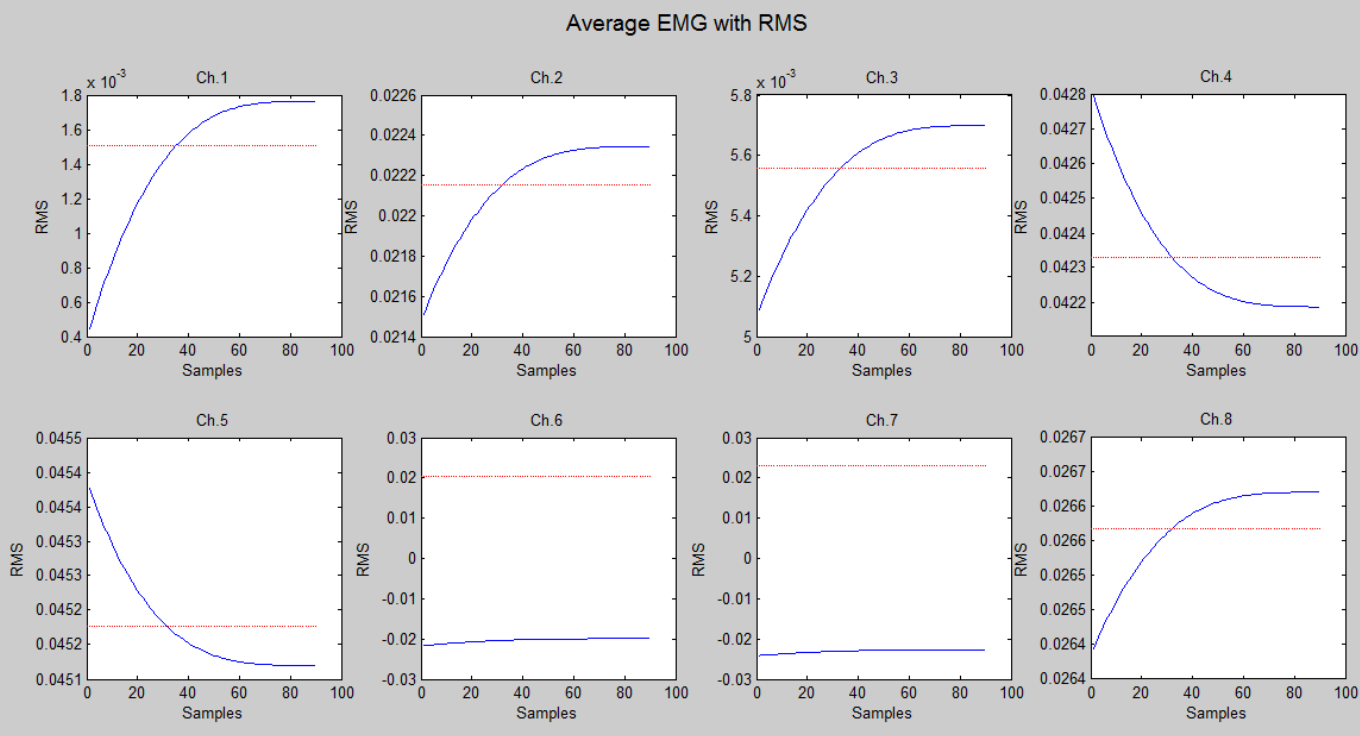

Subject 2
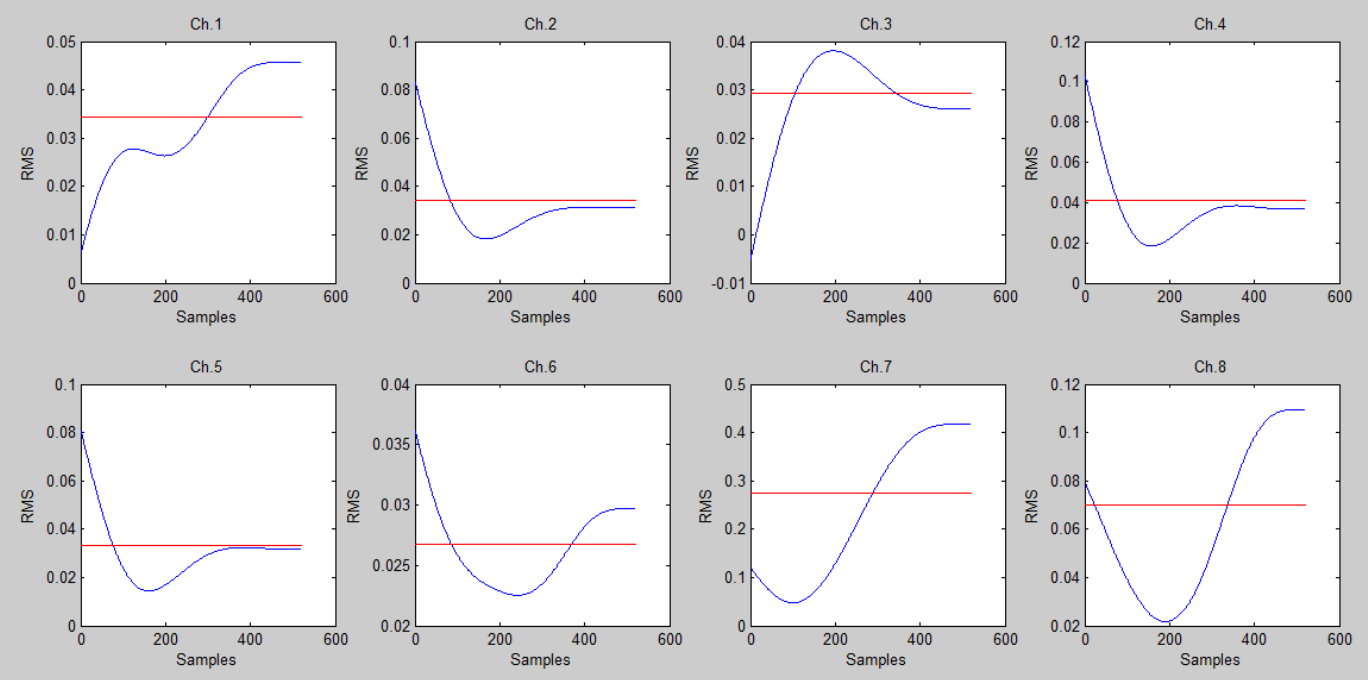


\section{Subject 3}
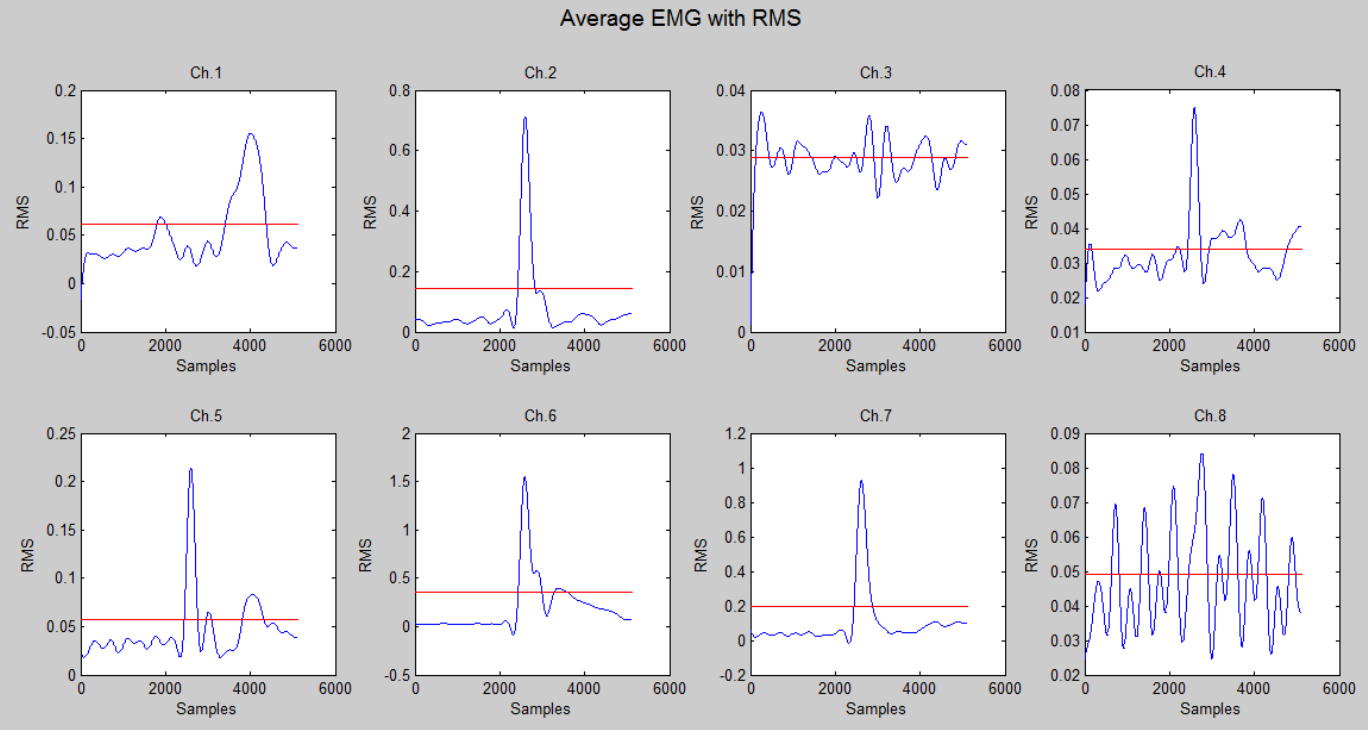

\section{Subject 4}
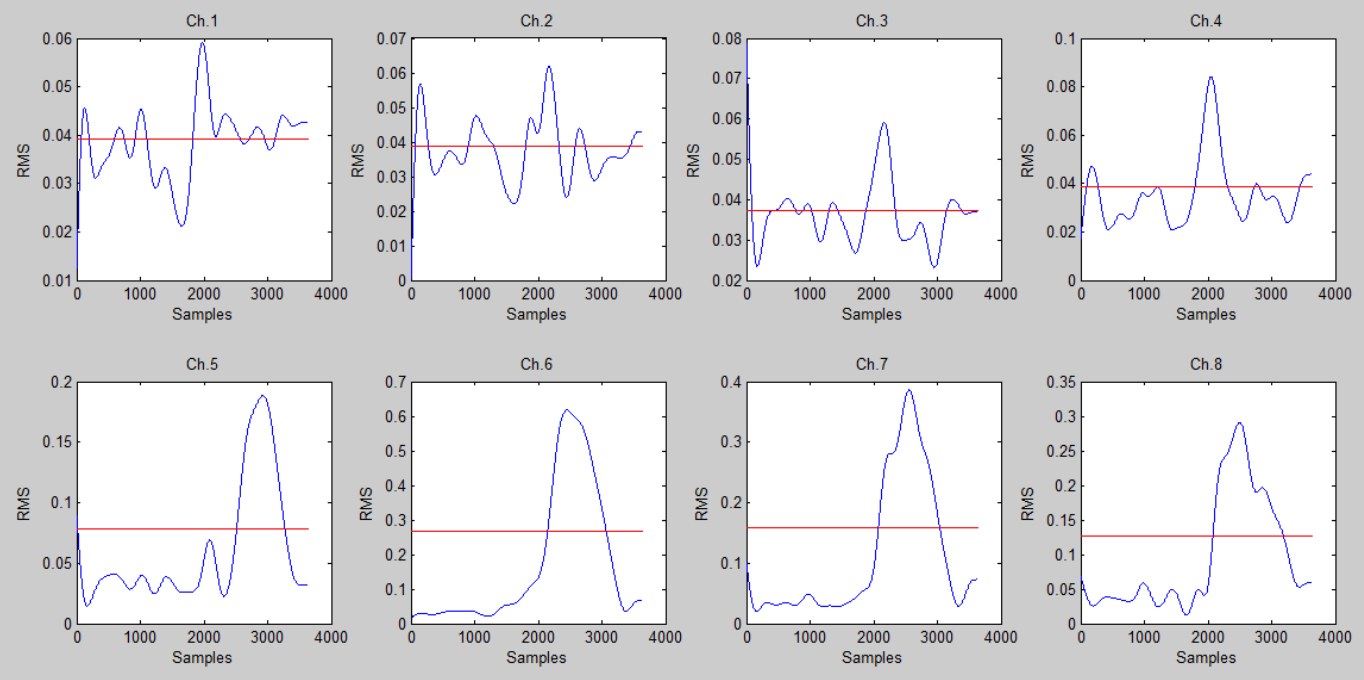


\section{Subject 5}
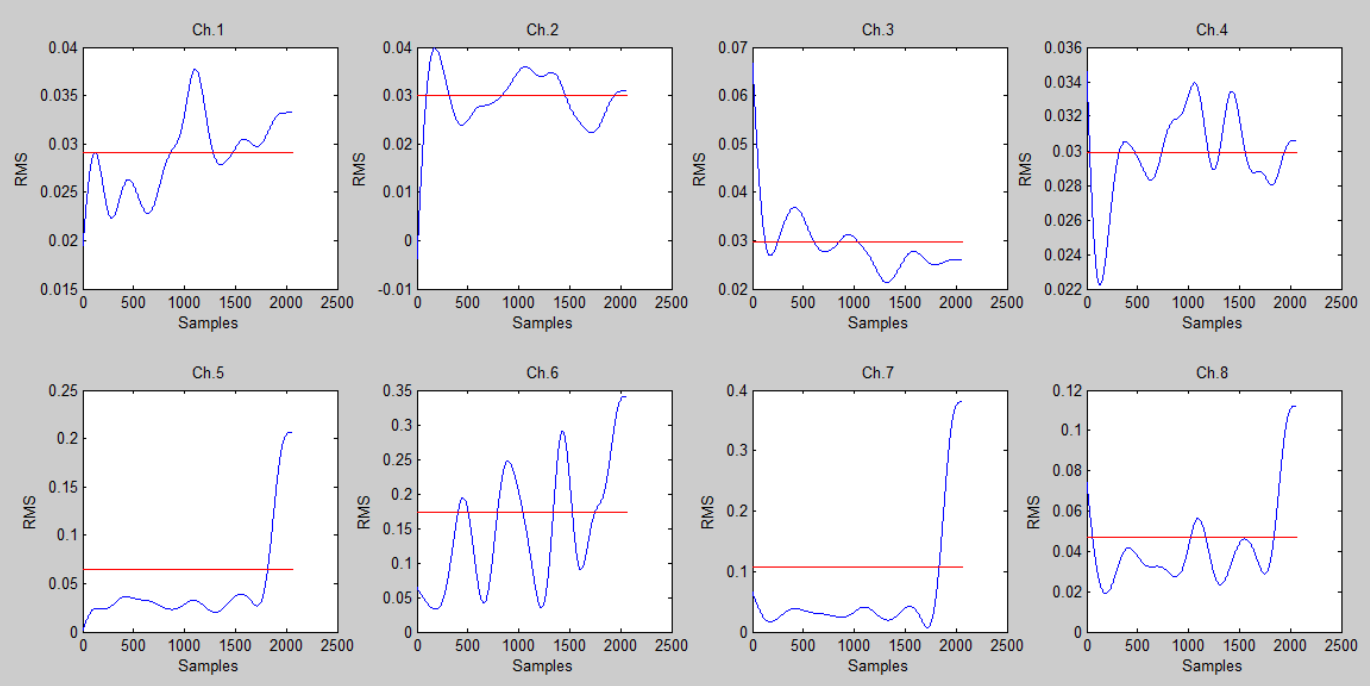

\section{Subject 6}
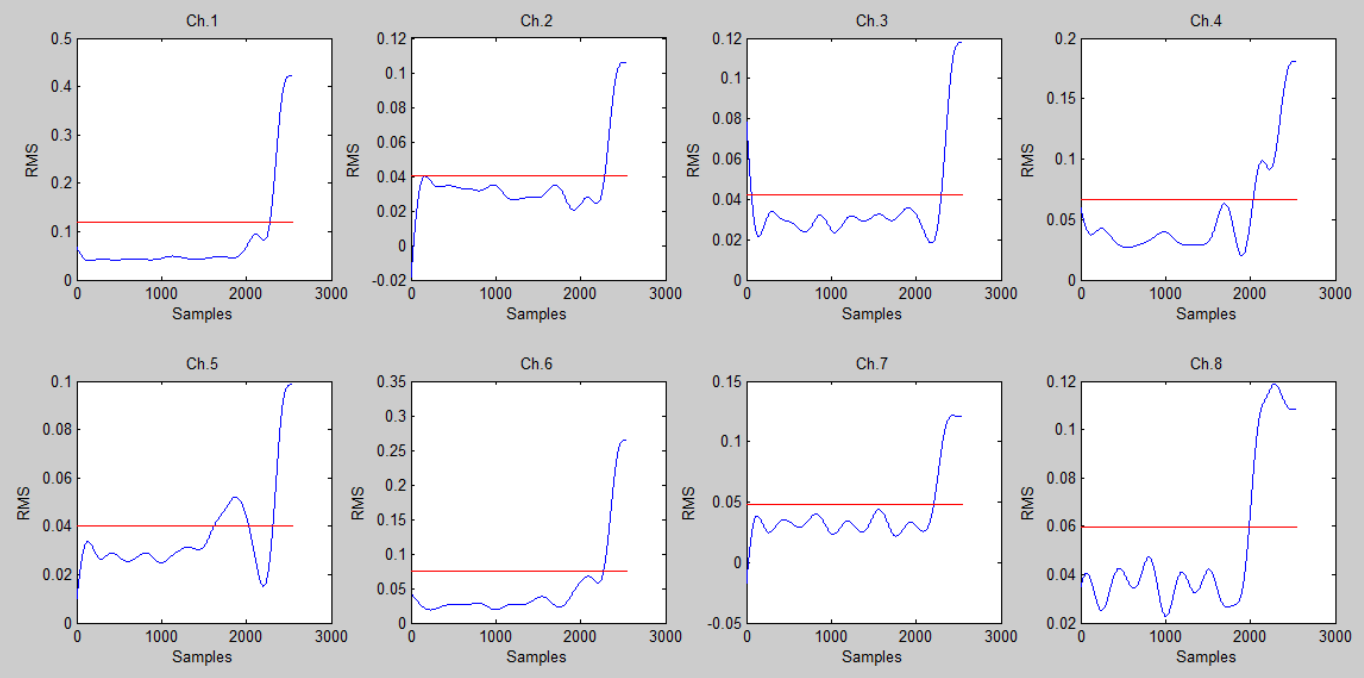


\section{Subject 7}

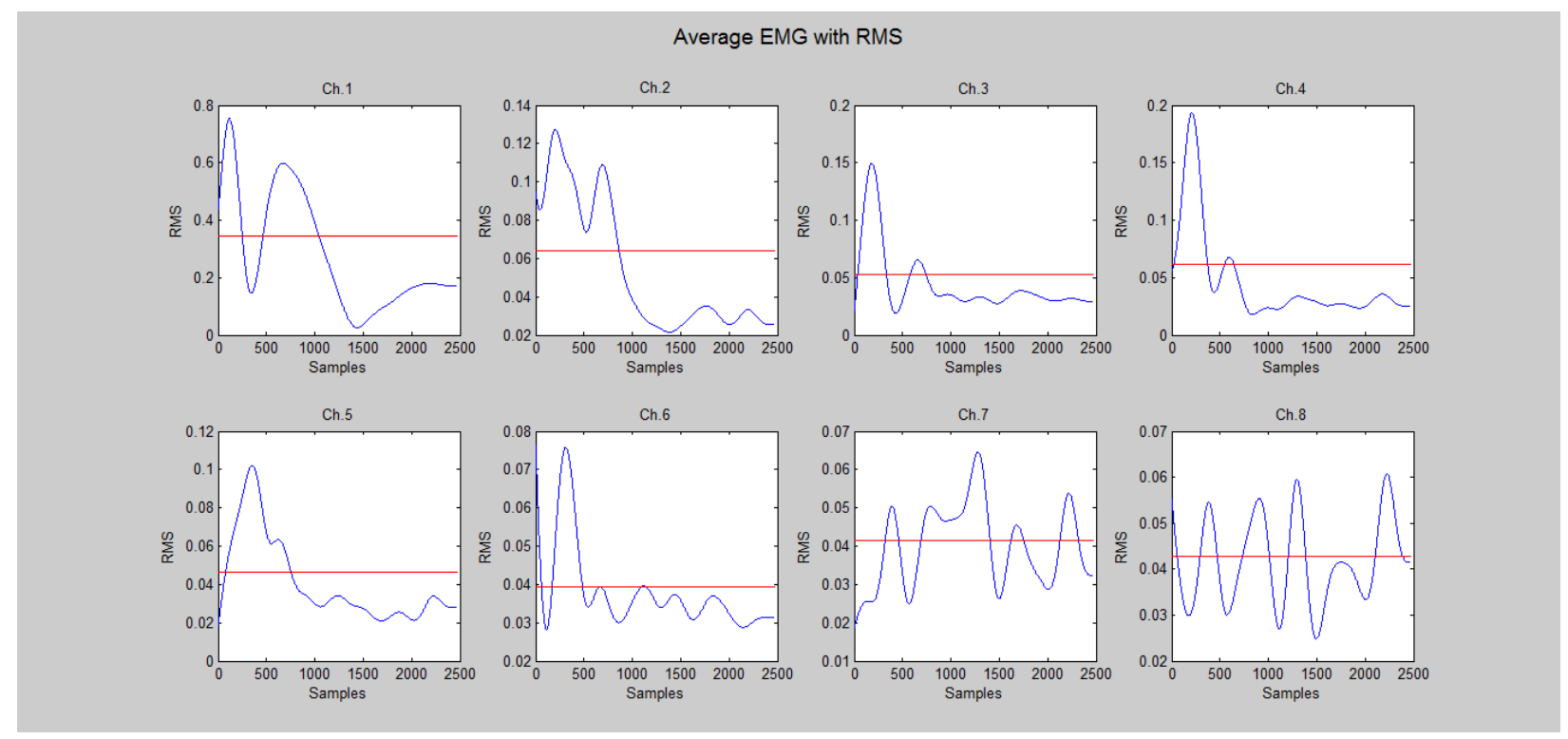

\section{Subject 8}

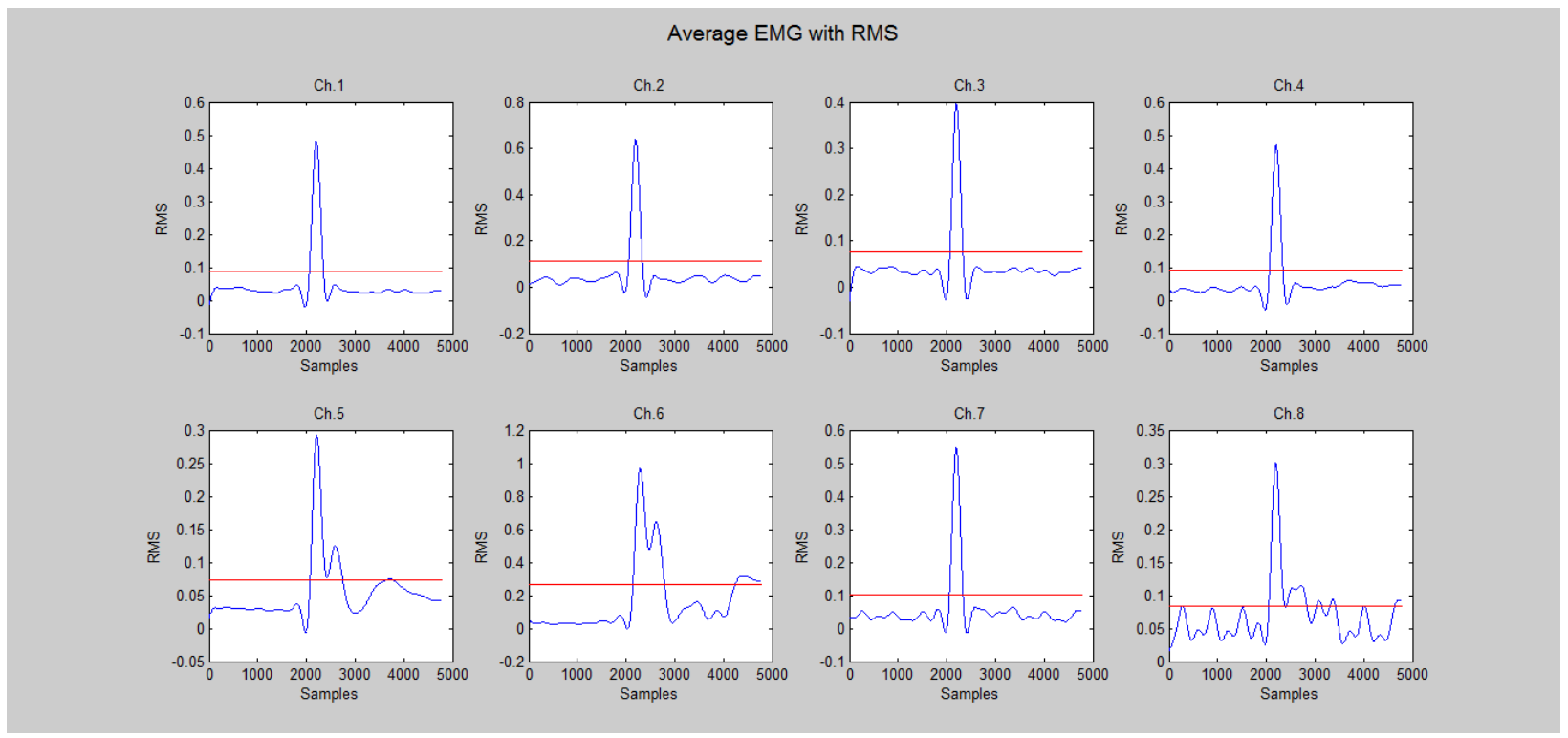




\section{Subject 9}

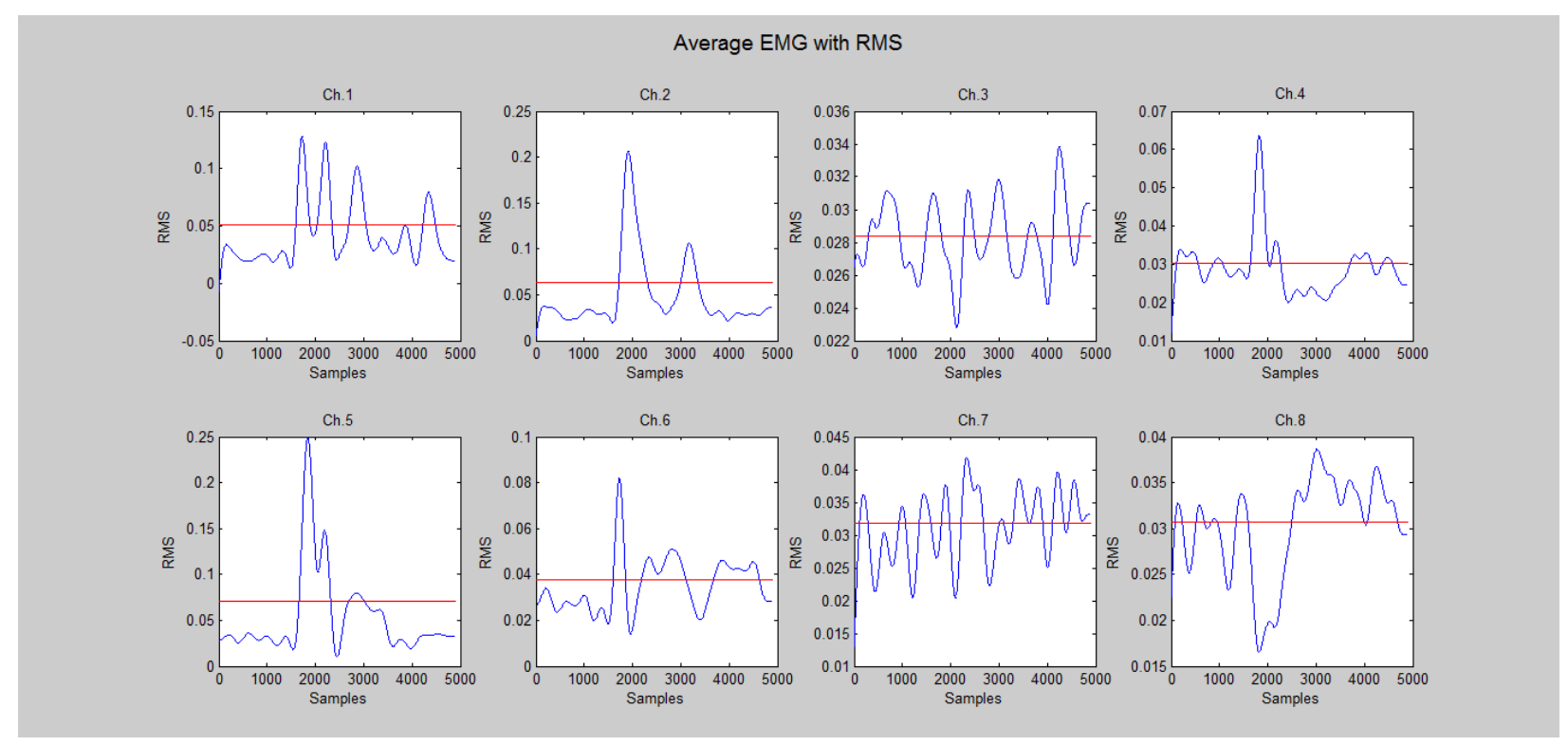

\section{Subject 1}

\section{BHV}
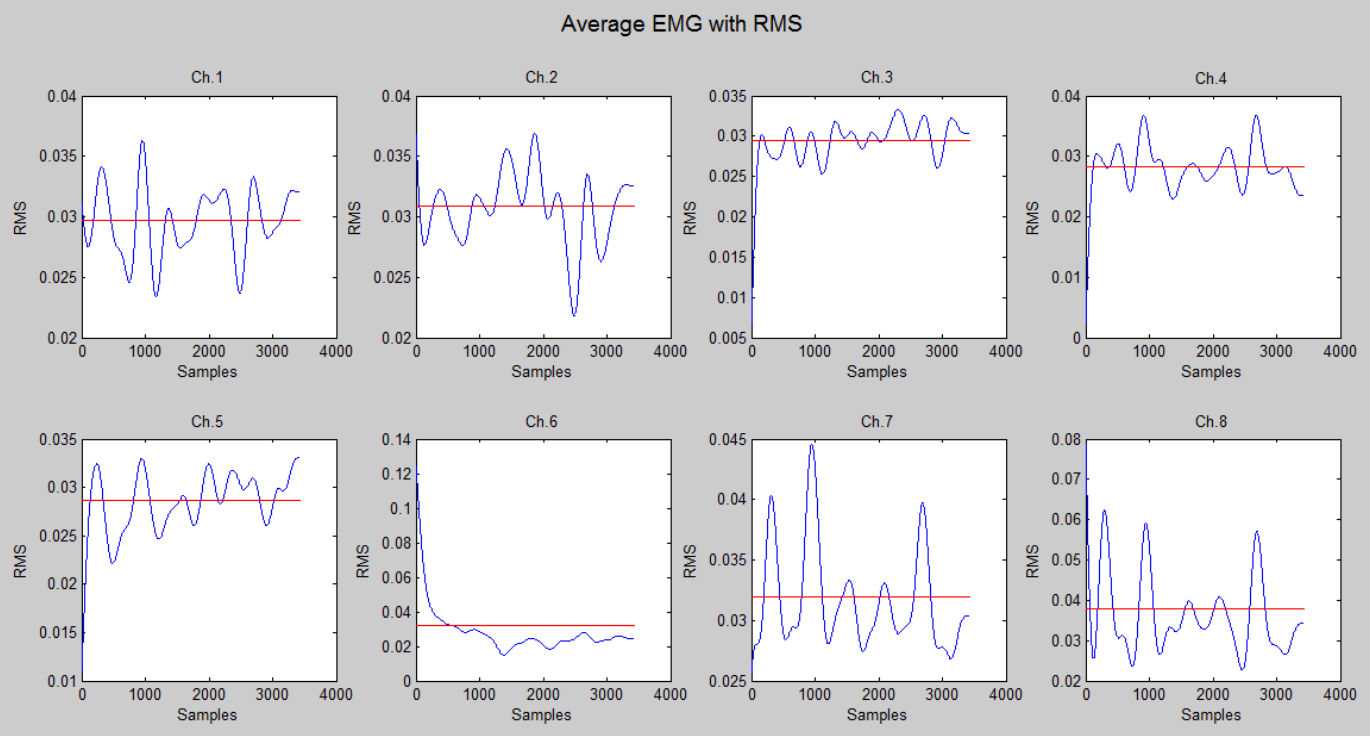


\section{Subject 2}

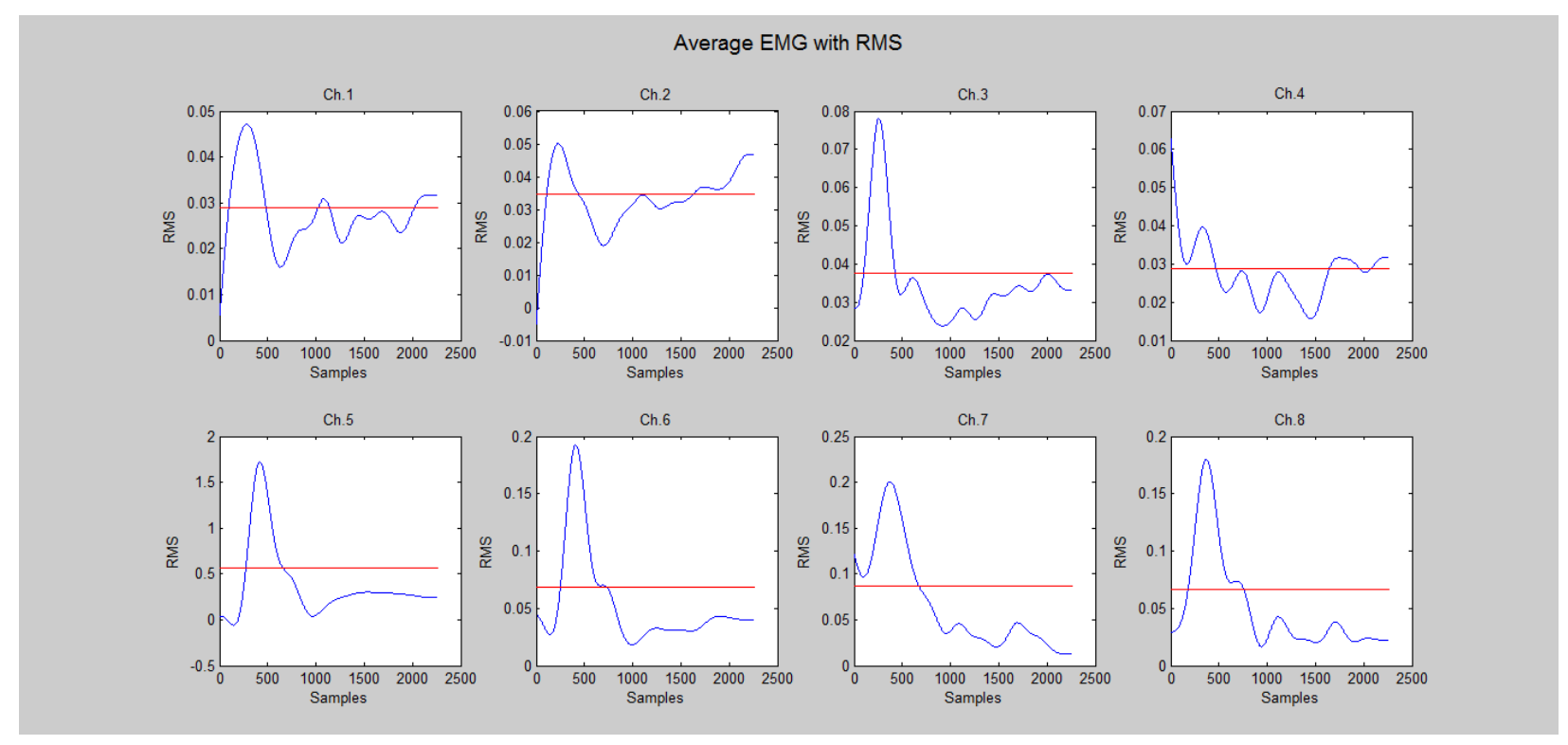

\section{Subject 3}

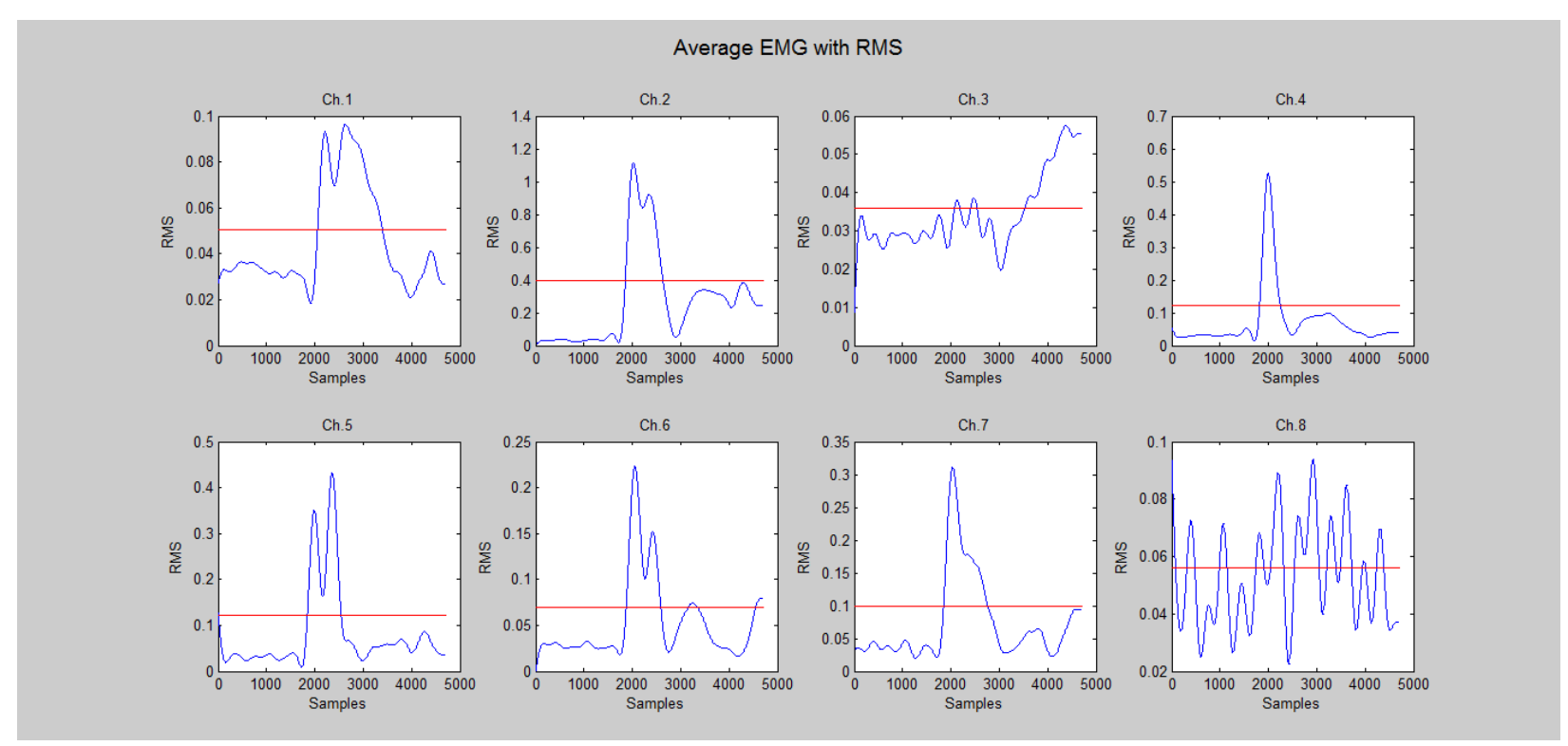




\section{Subject 4}

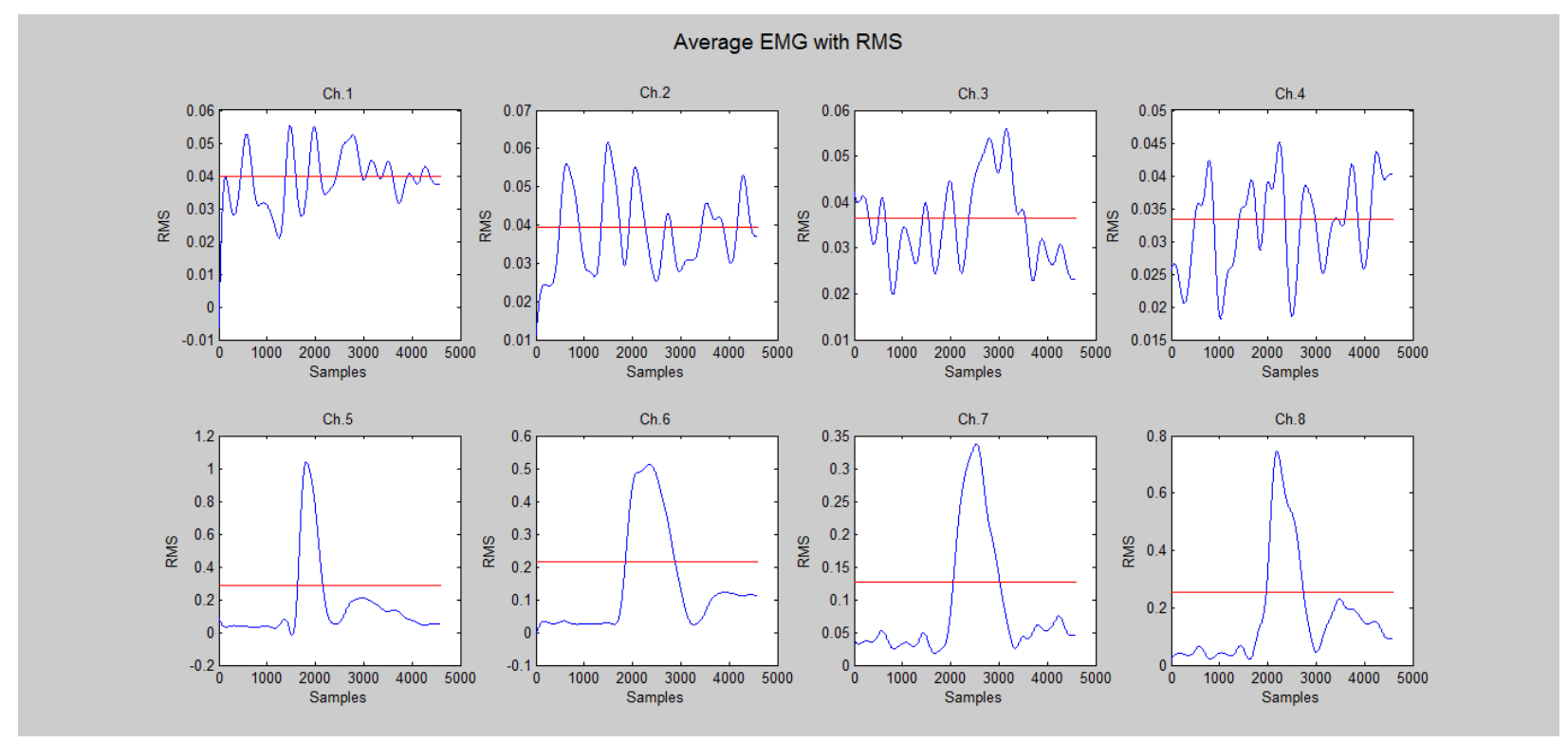

\section{Subject 5}
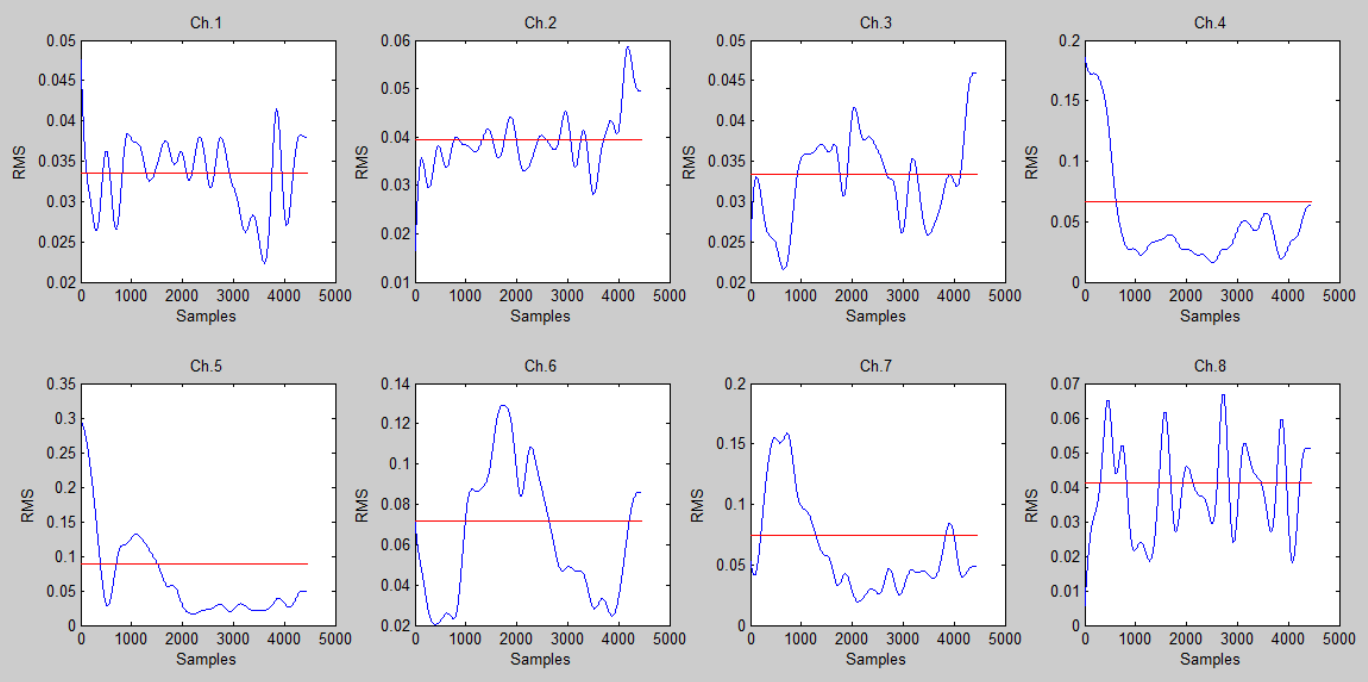


\section{Subject 6}

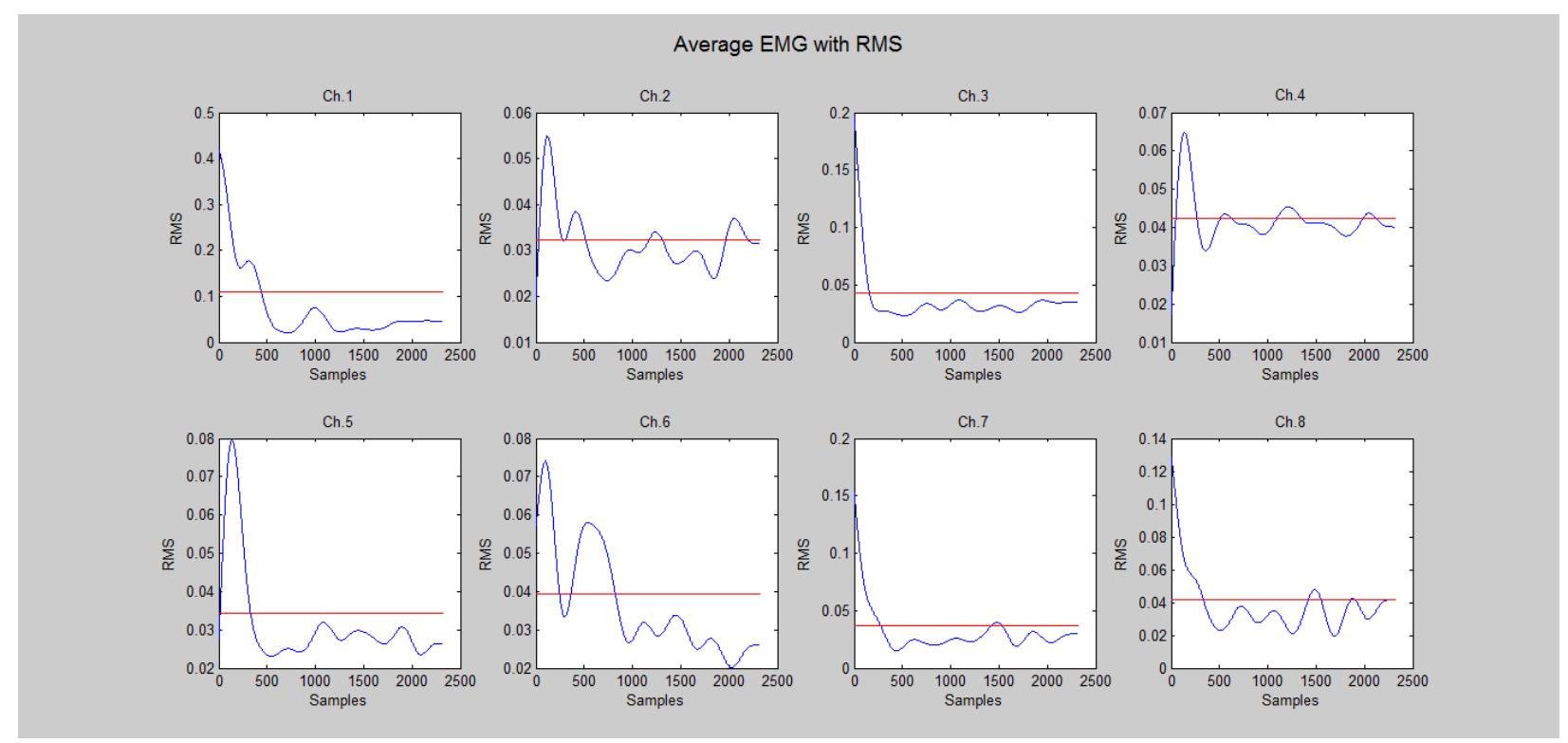

\section{Subject 8}
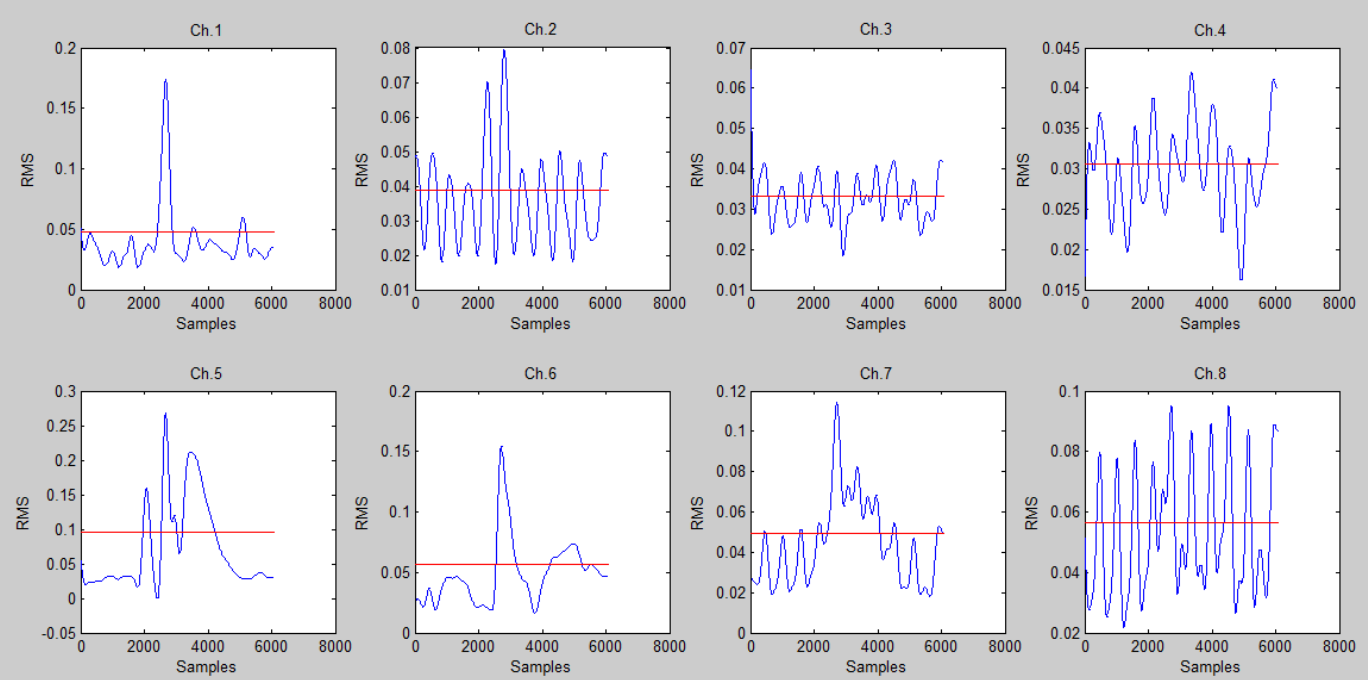


\section{Subject 9}
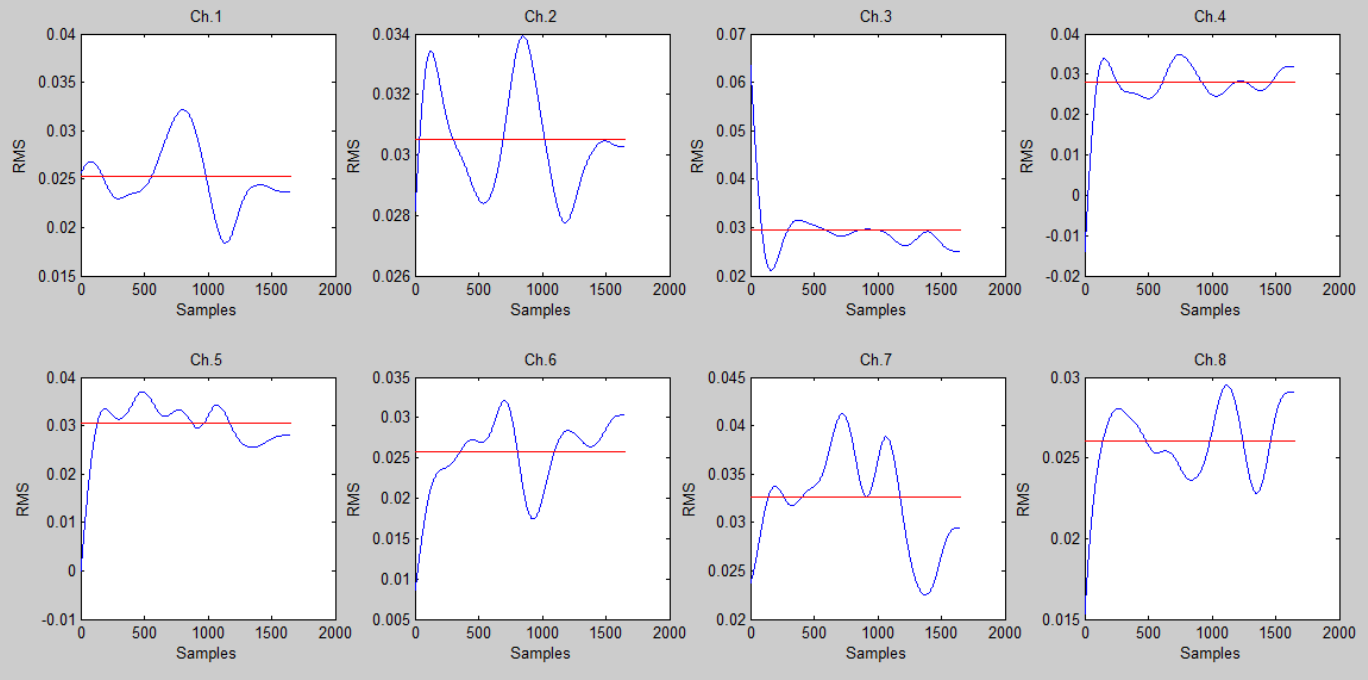

\section{BNN}

Subject 1
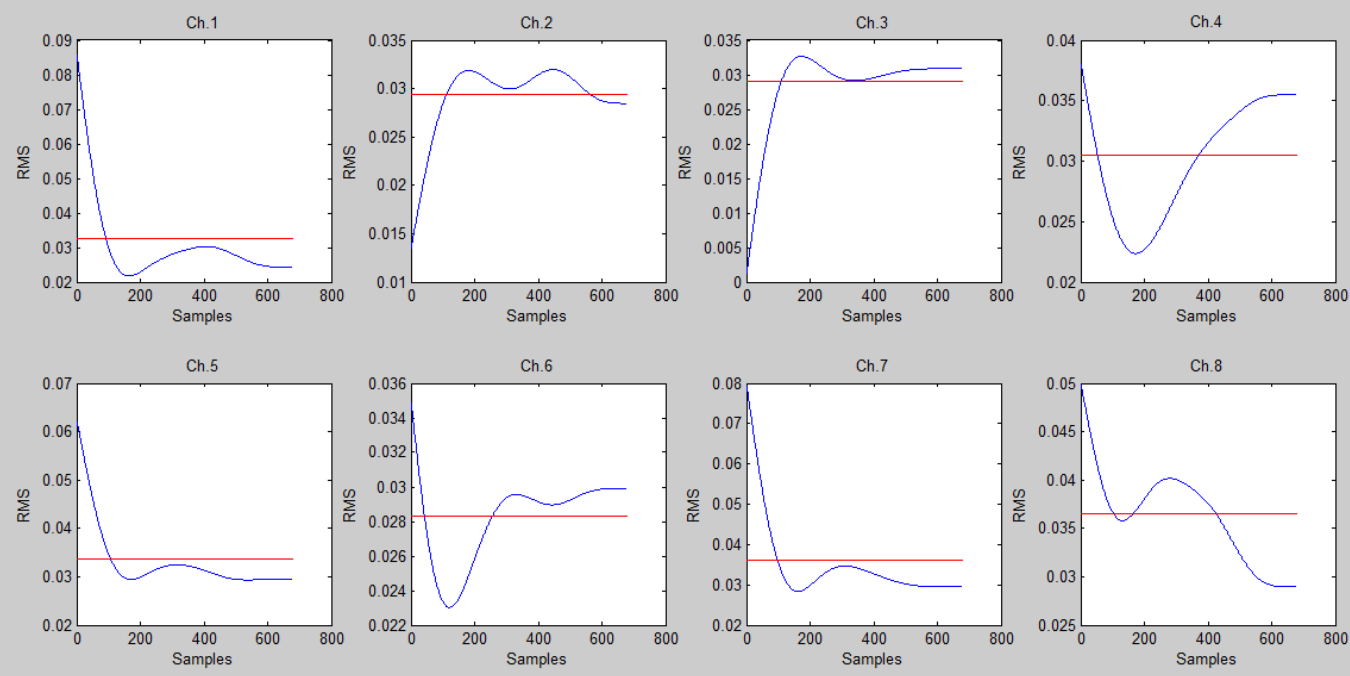


\section{Subject 2}

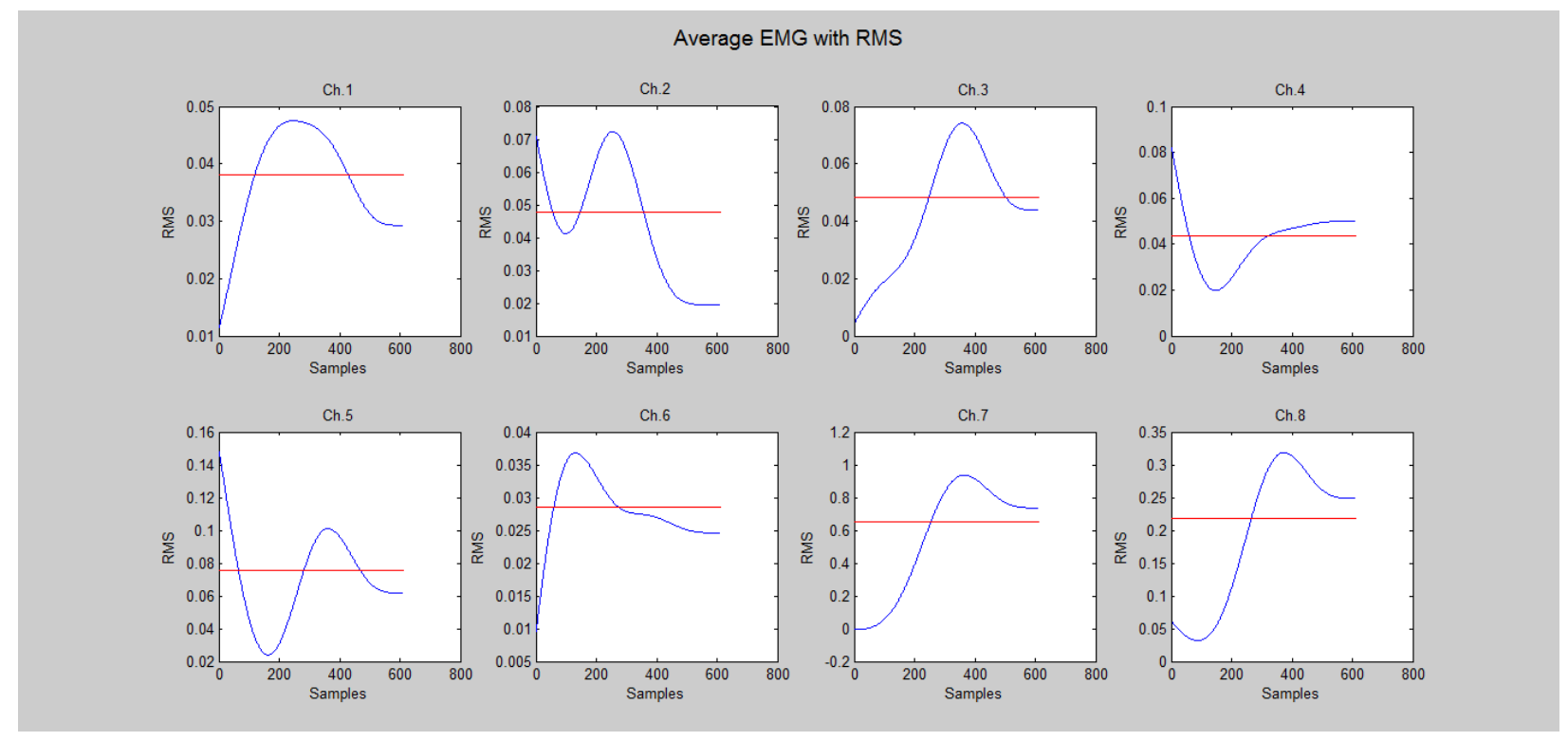

\section{Subject 3}
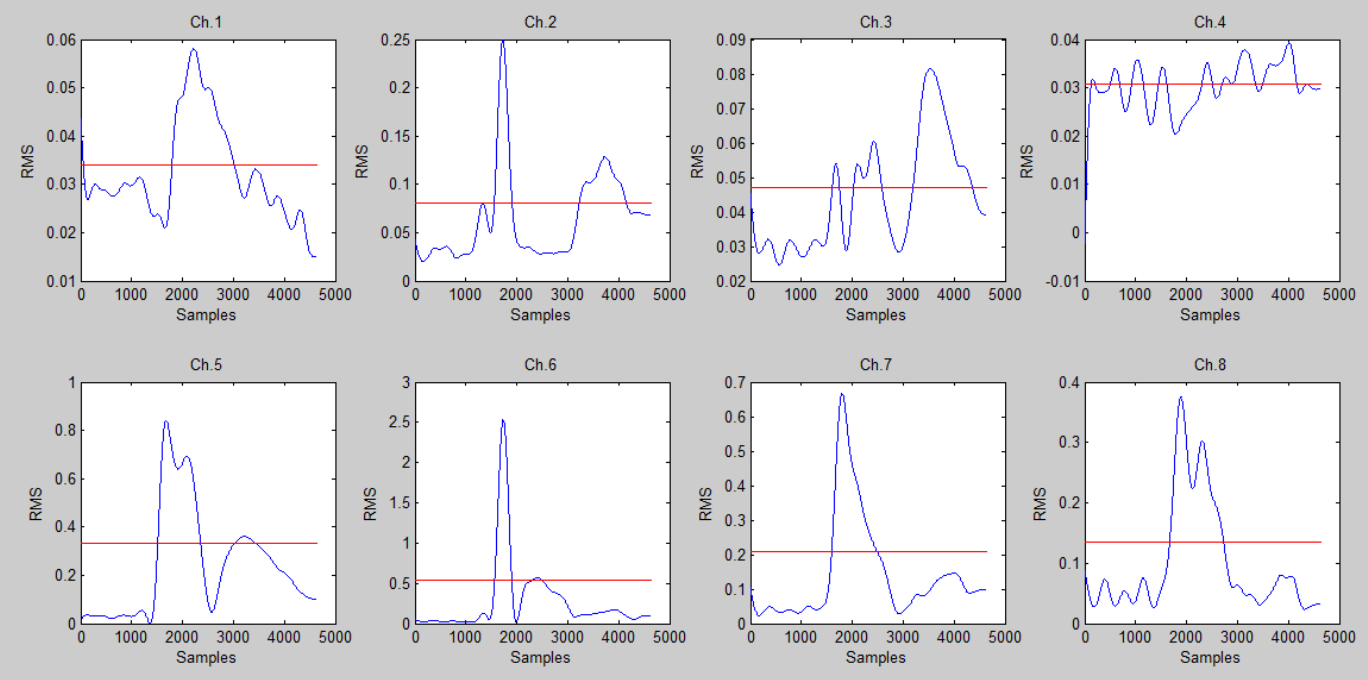
Subject 4

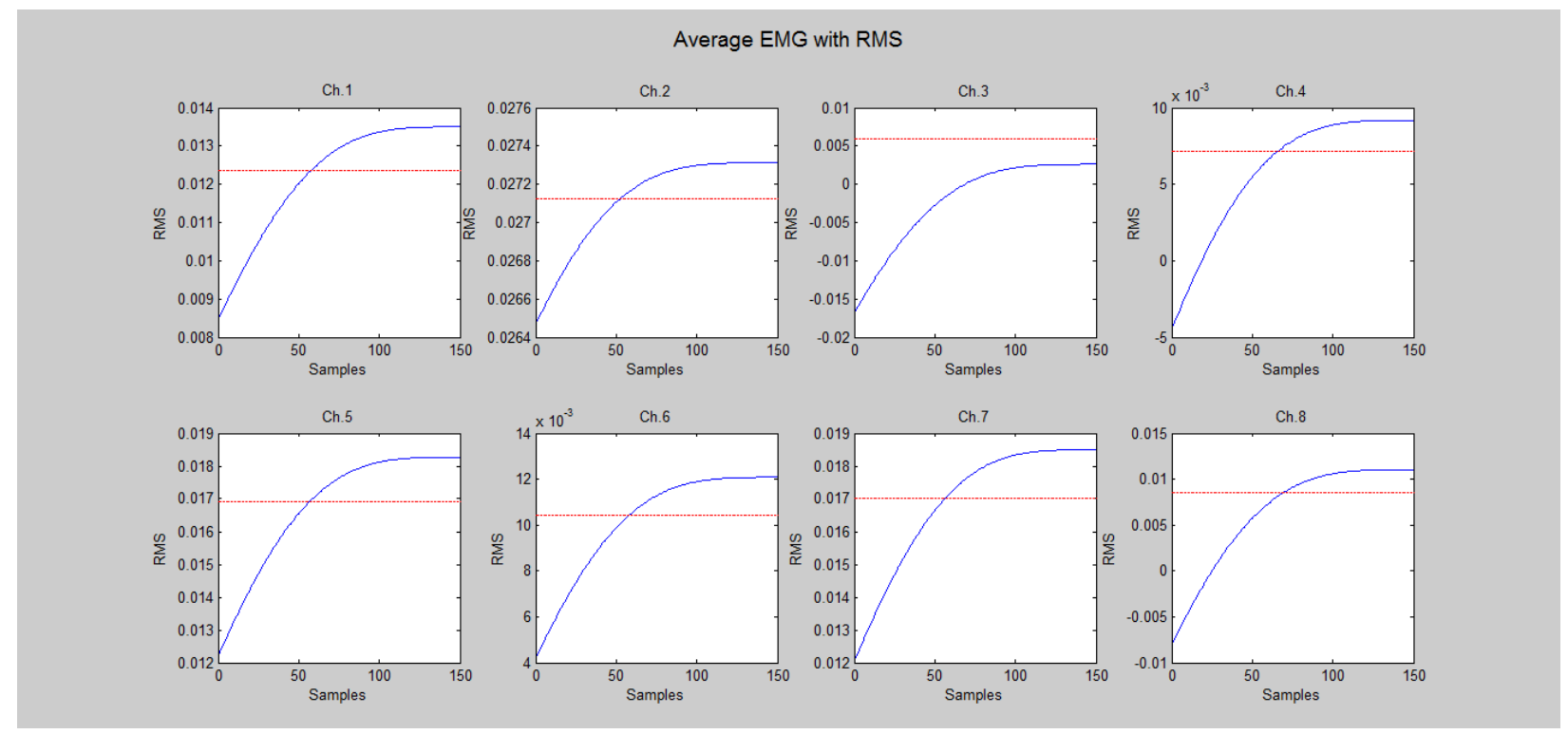

\section{Subject 5}
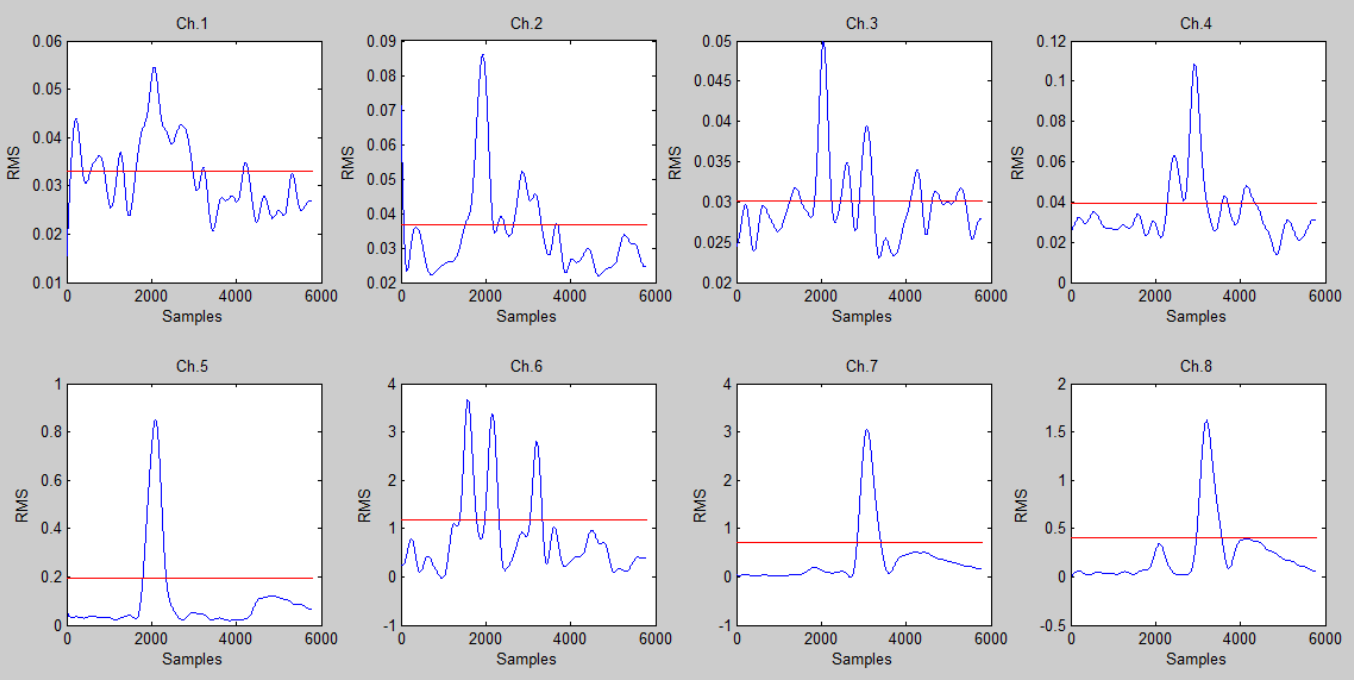


\section{Subject 6}

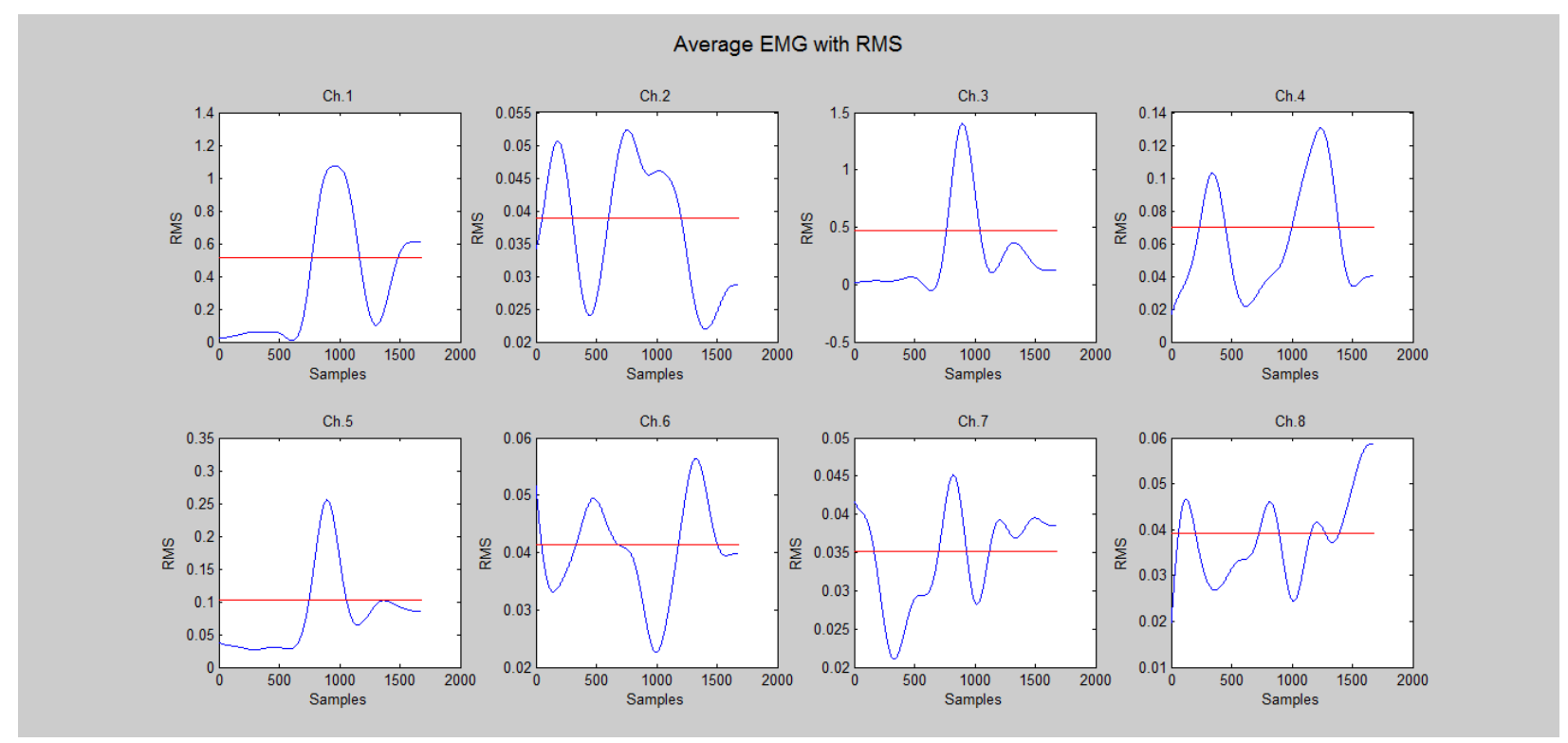

\section{Subject 7}
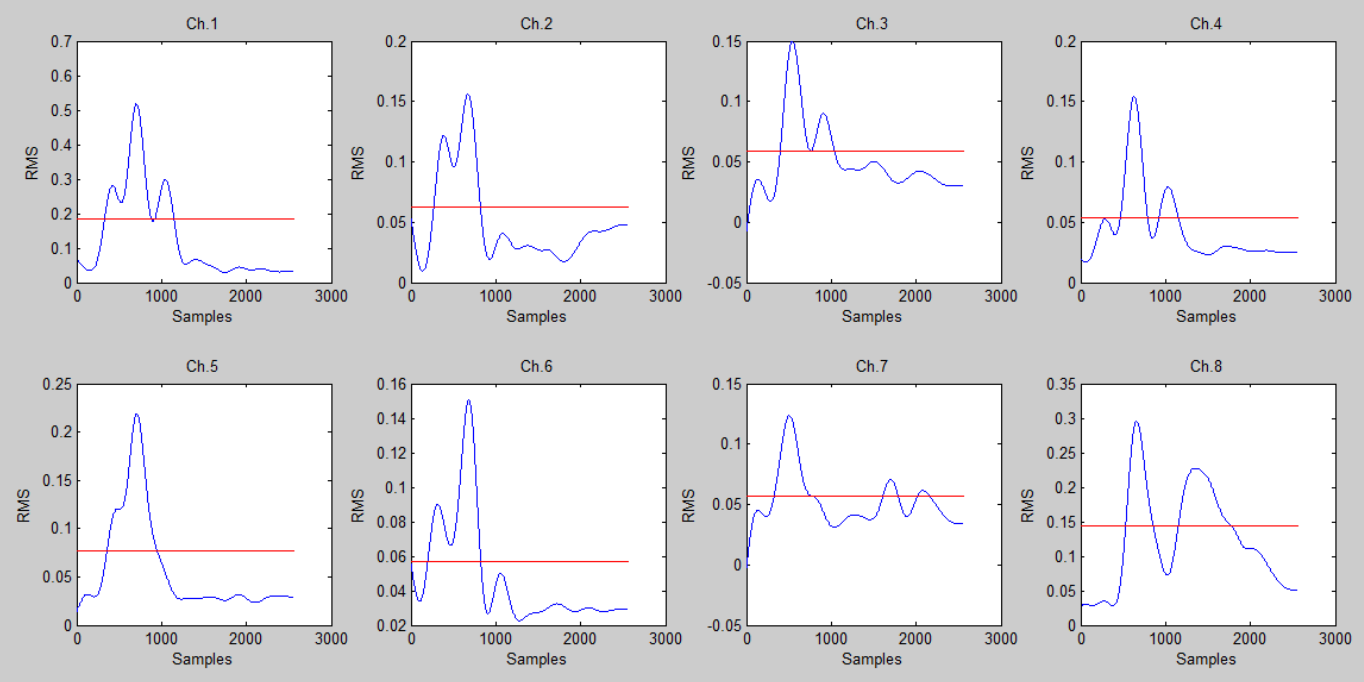


\section{BNV}

Subject 1
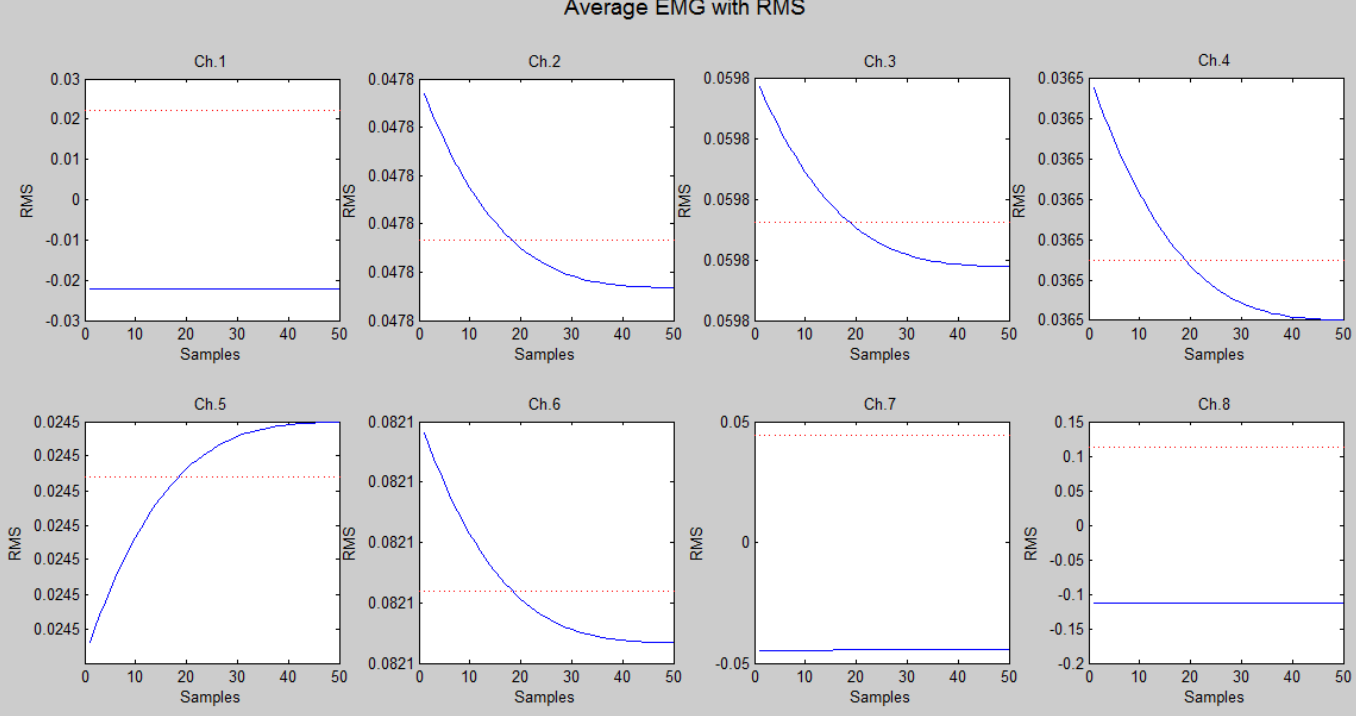

\section{Subject 2}
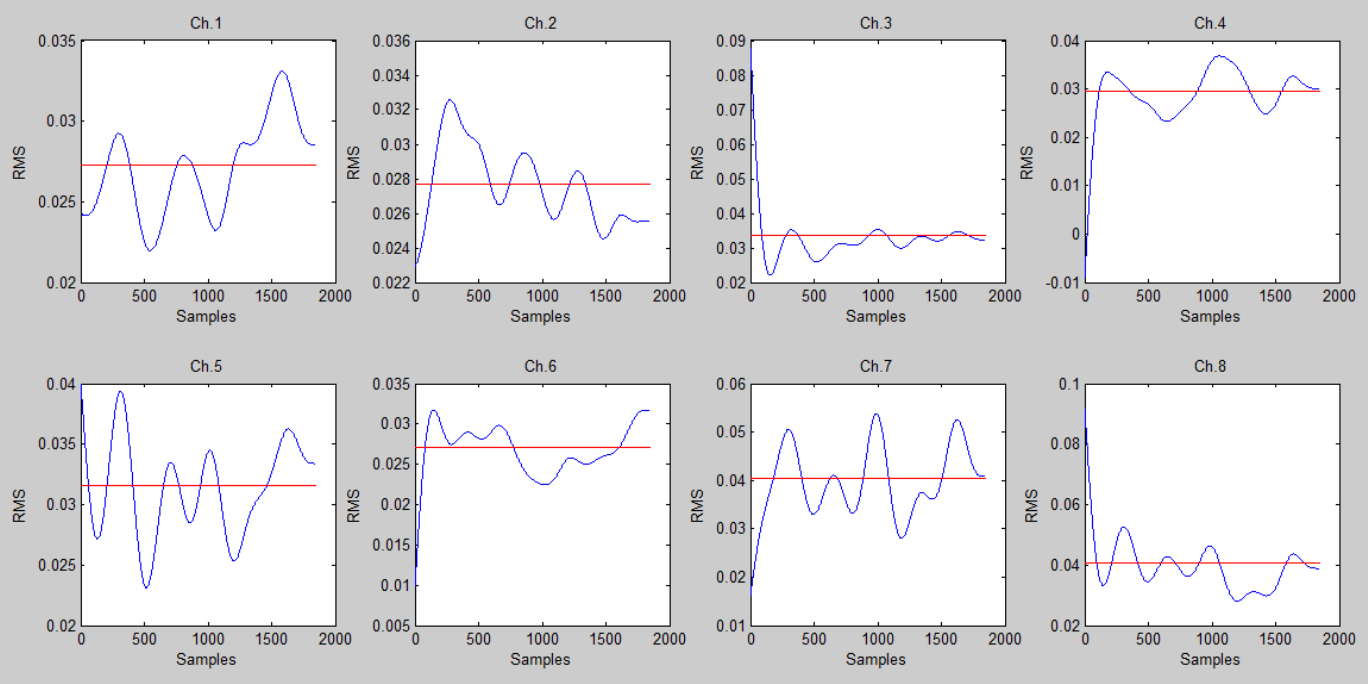


\section{Subject 3}

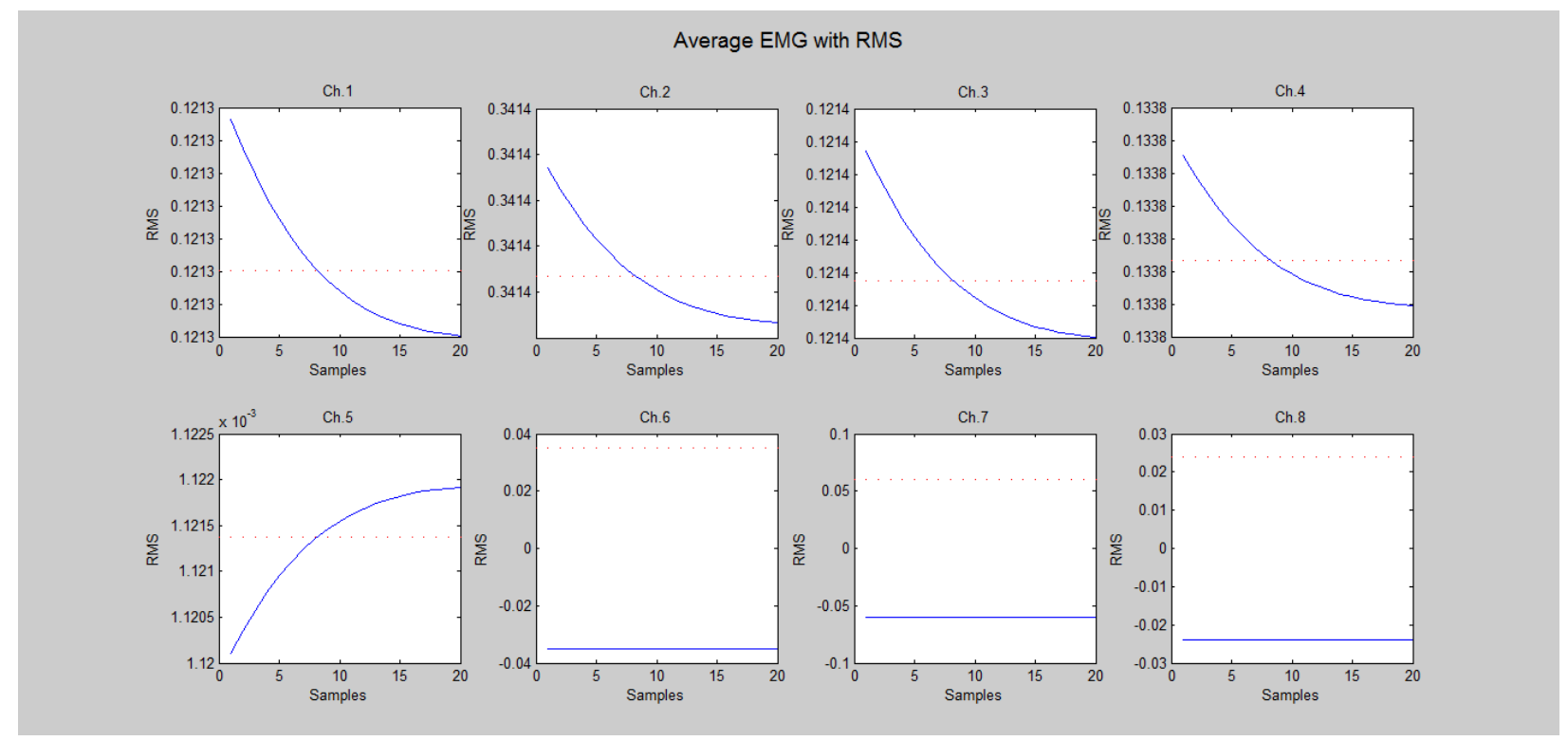

\section{Subject 4}
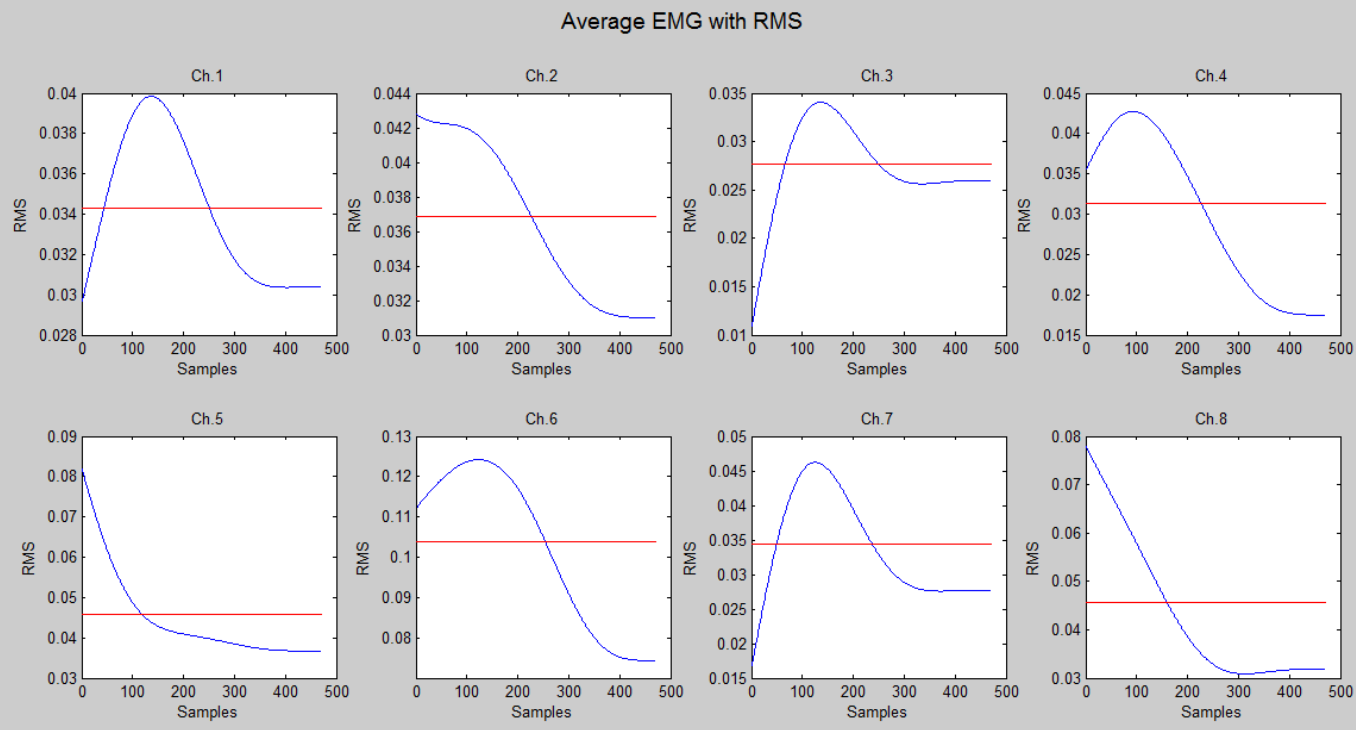


\section{Subject 5}
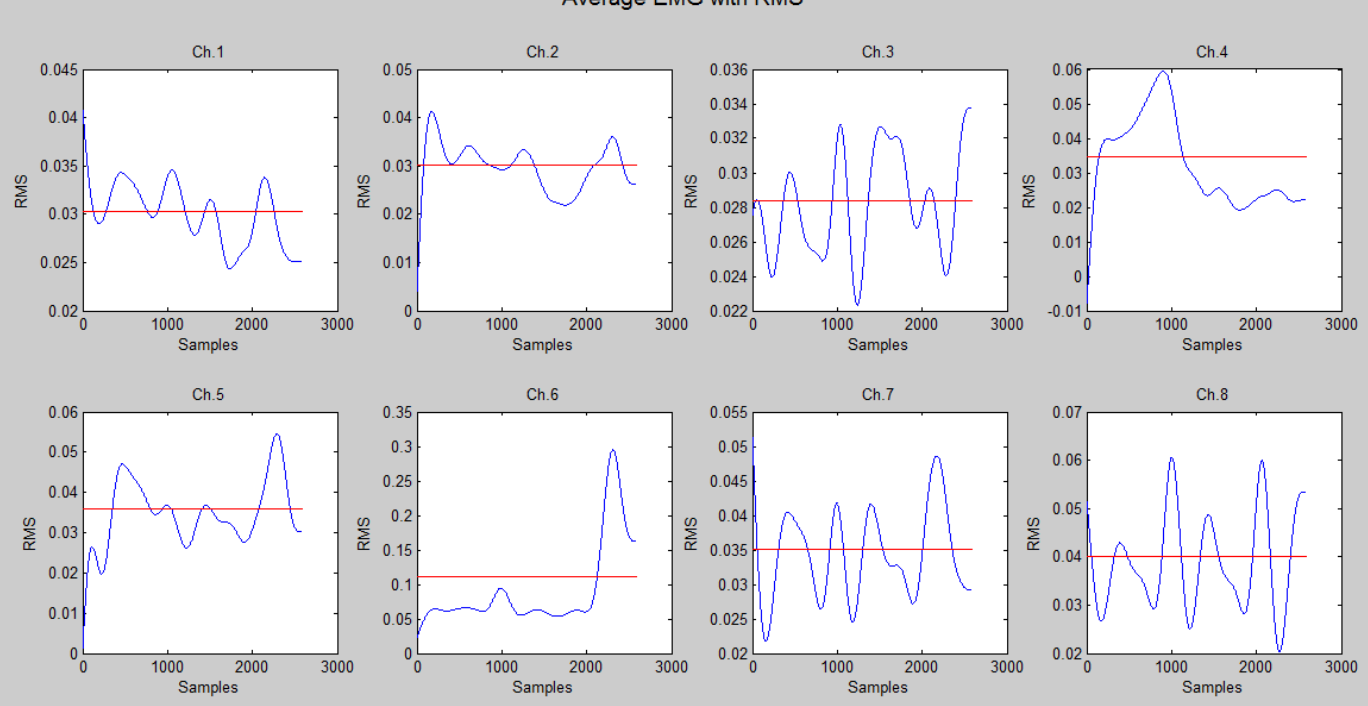

\section{Subject 6}
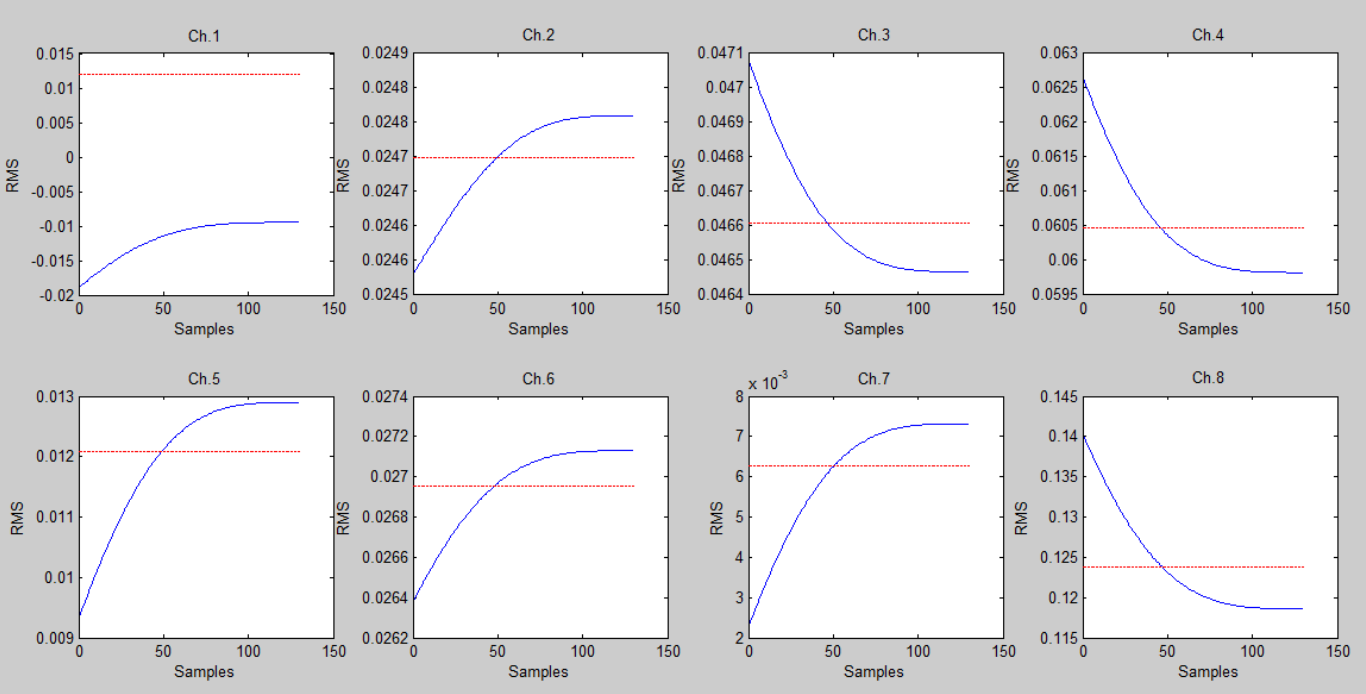


\section{Subject 8}

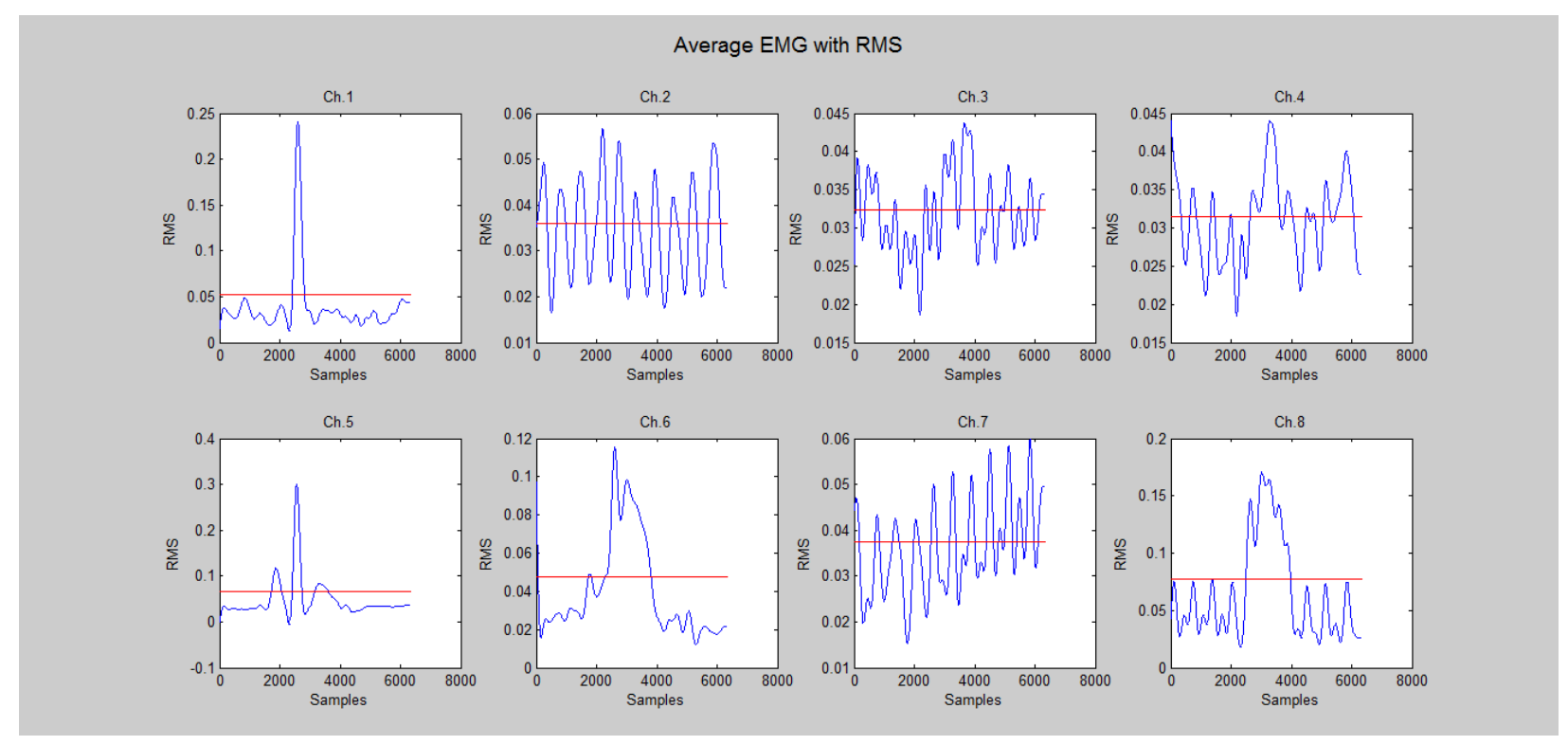

\section{Subject 9}
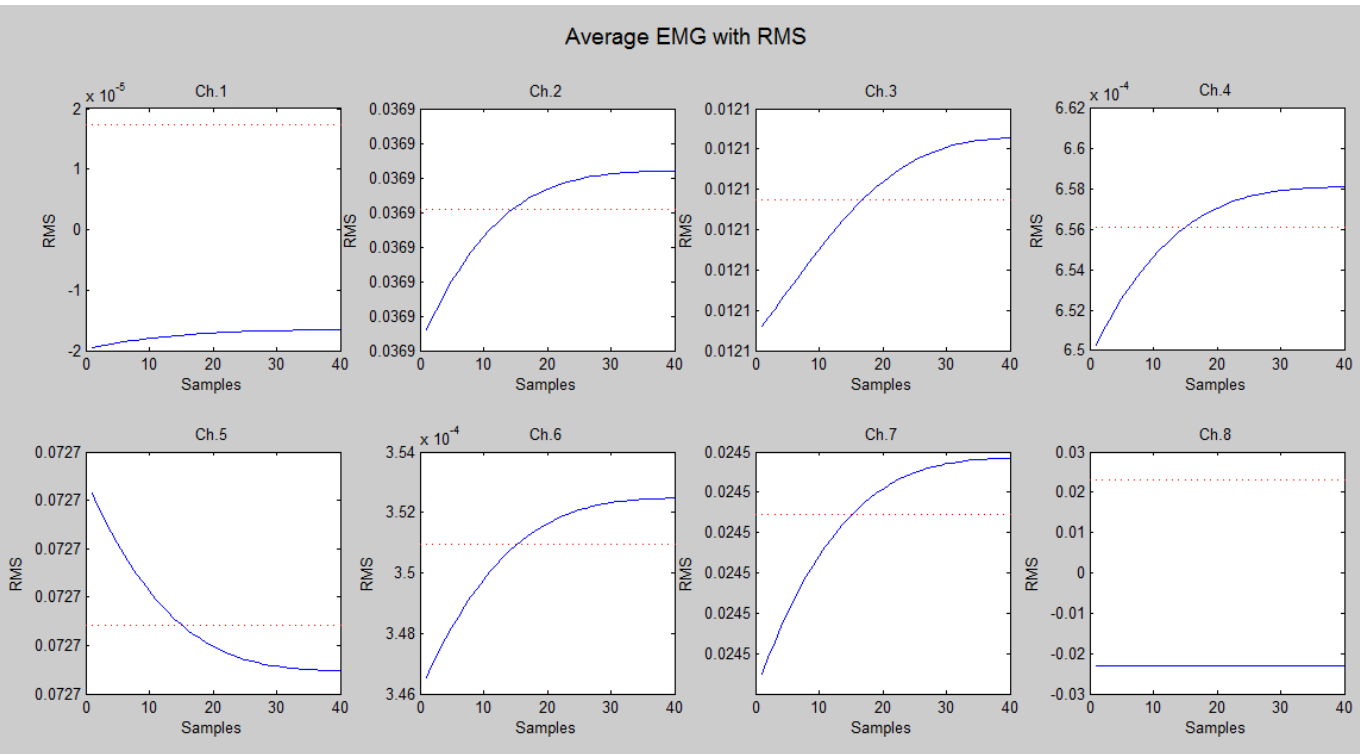


\section{FHN}

\section{Subject 2}
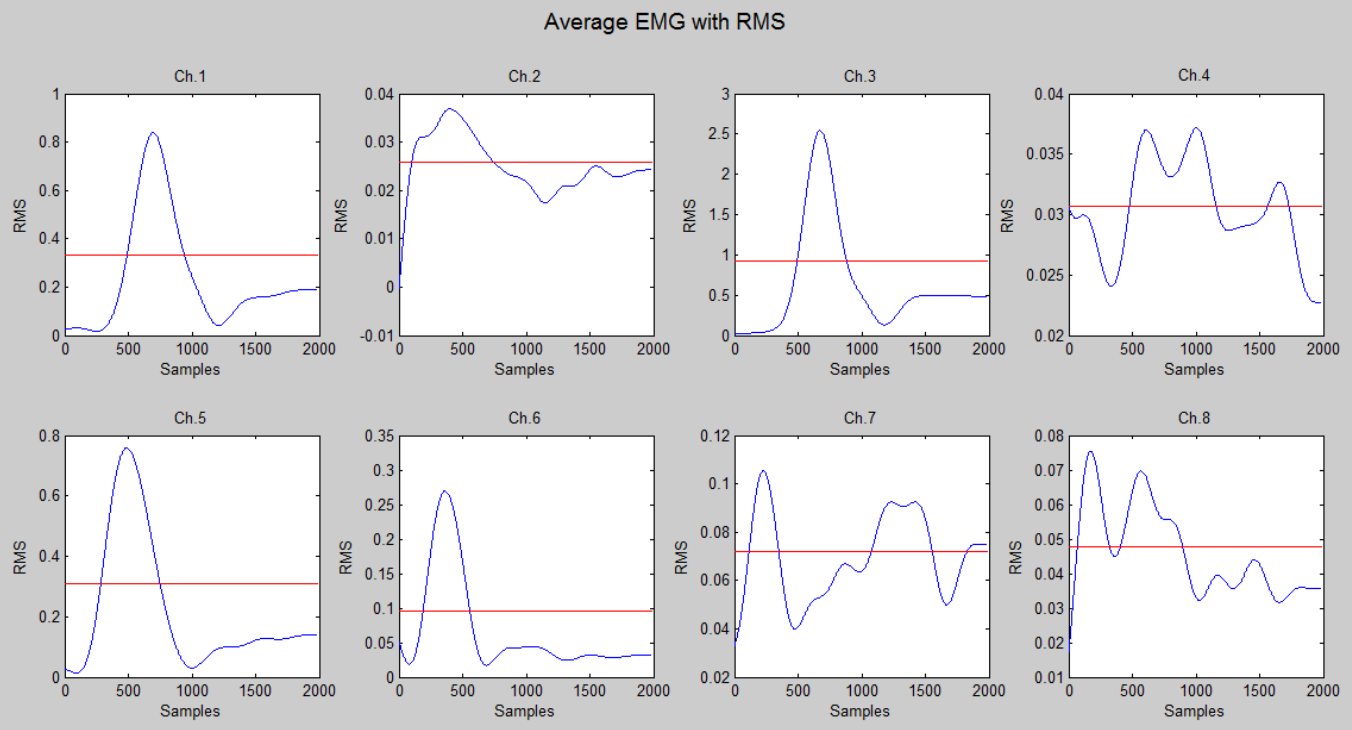

\section{Subject 3}
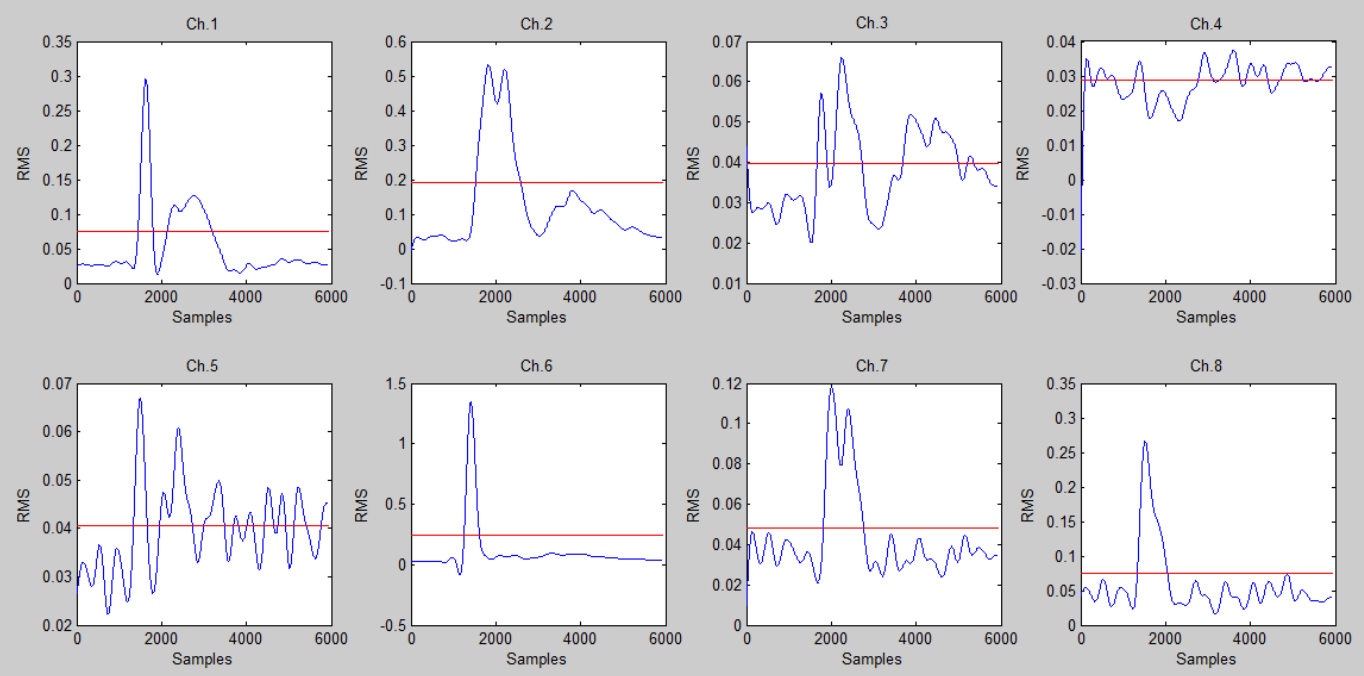


\section{Subject 4}

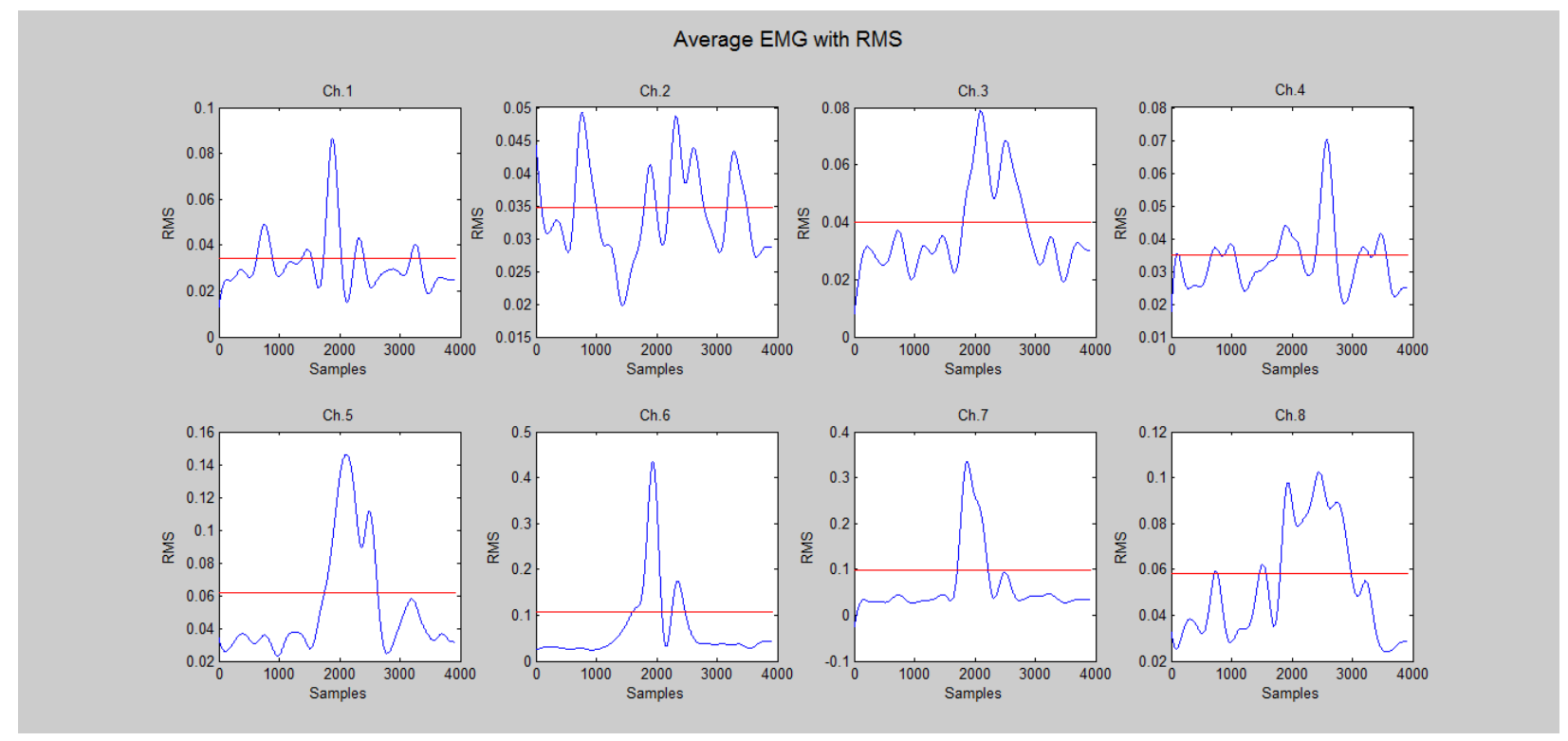

\section{Subject 5}
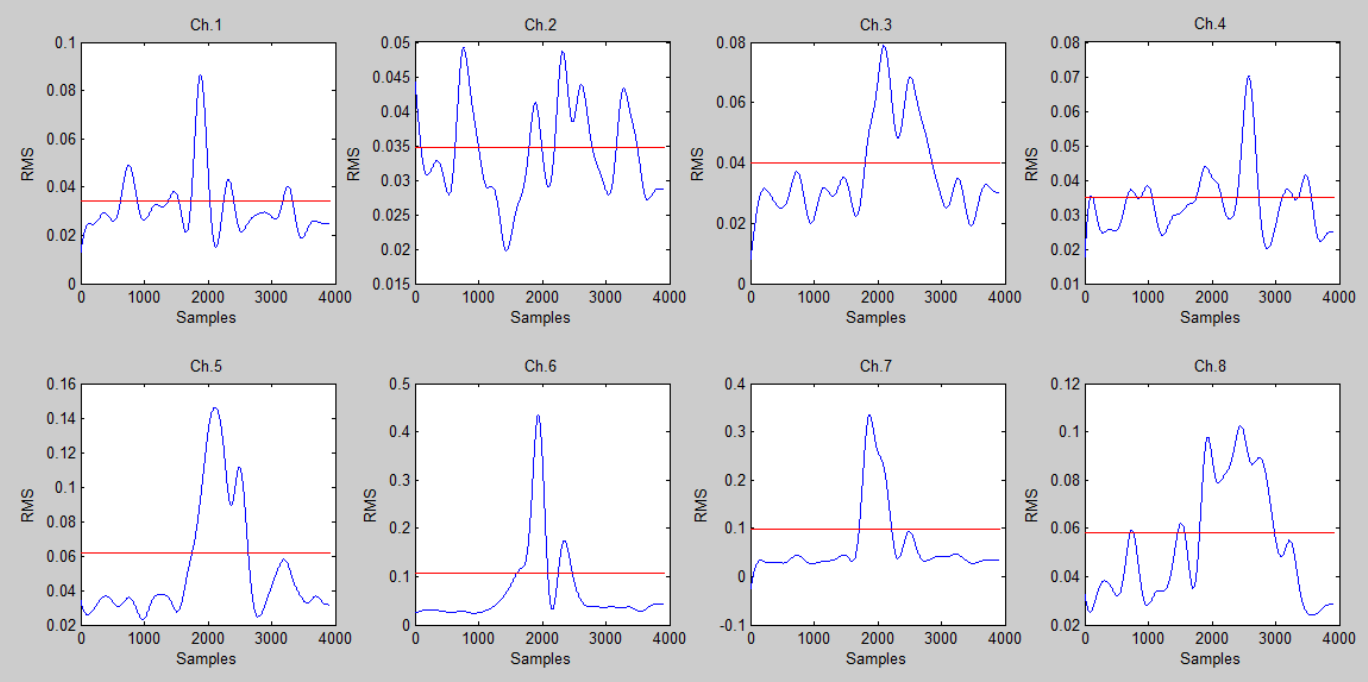


\section{Subject 8}

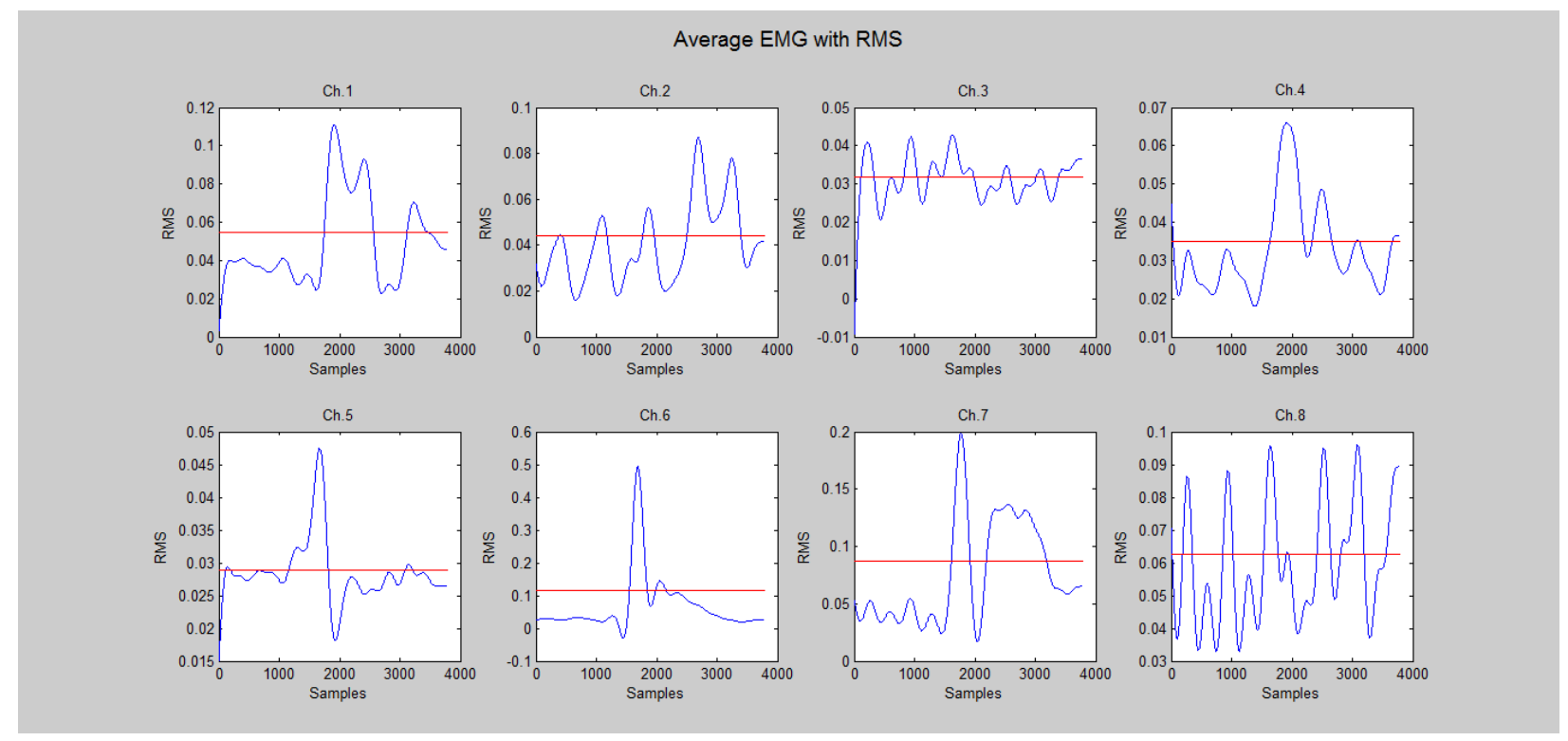

\section{Subject 9}
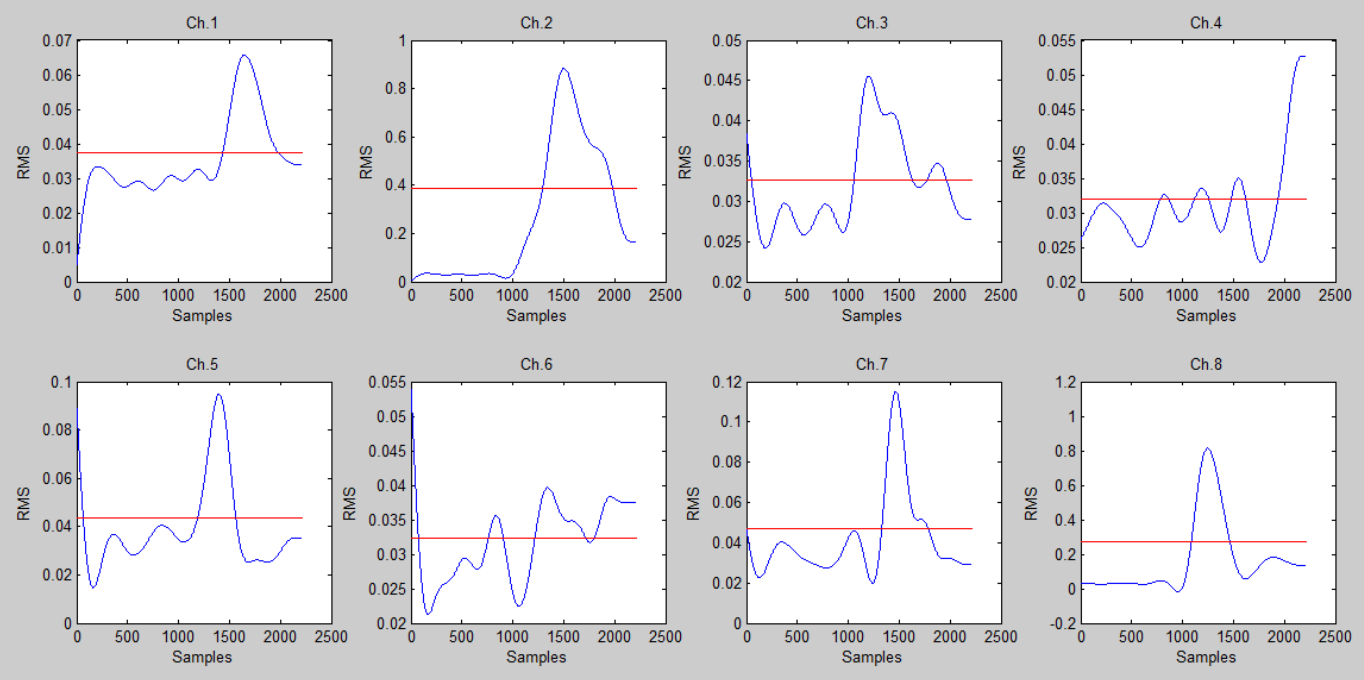


\section{FHV}

\section{Subject 2}
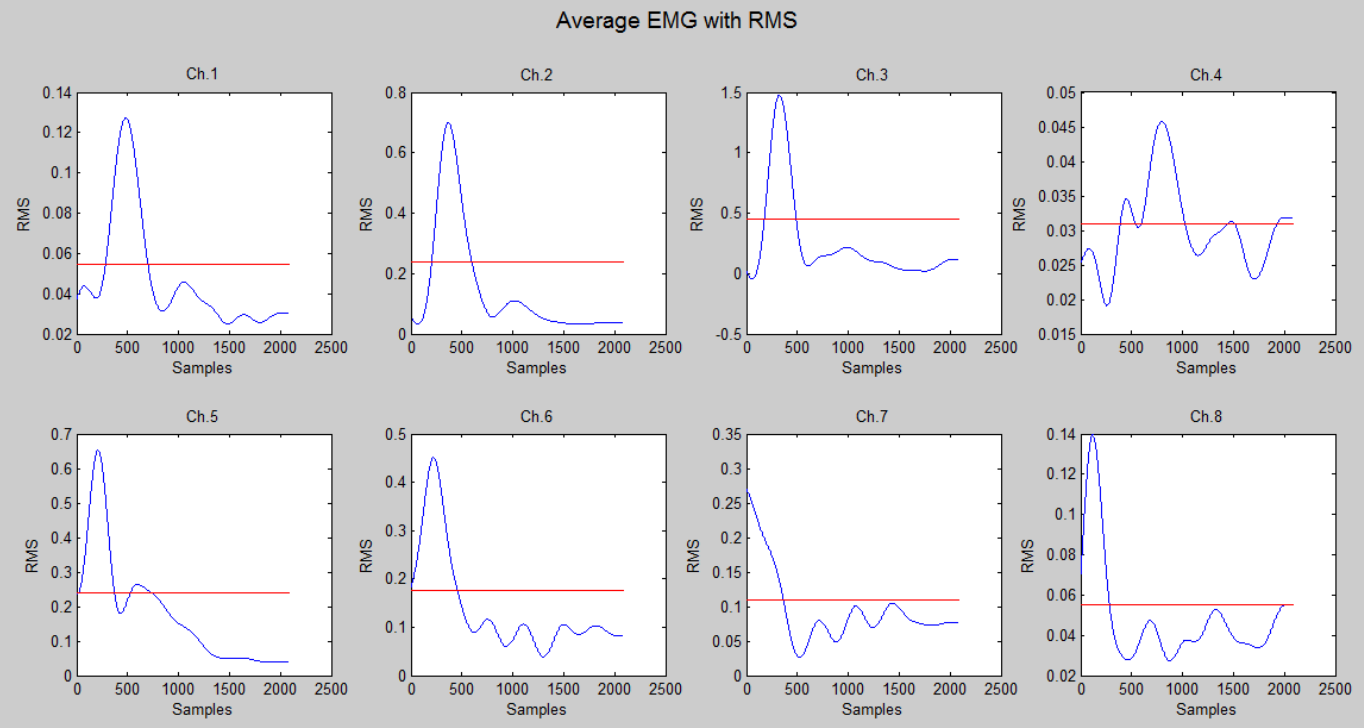

\section{Subject 3}
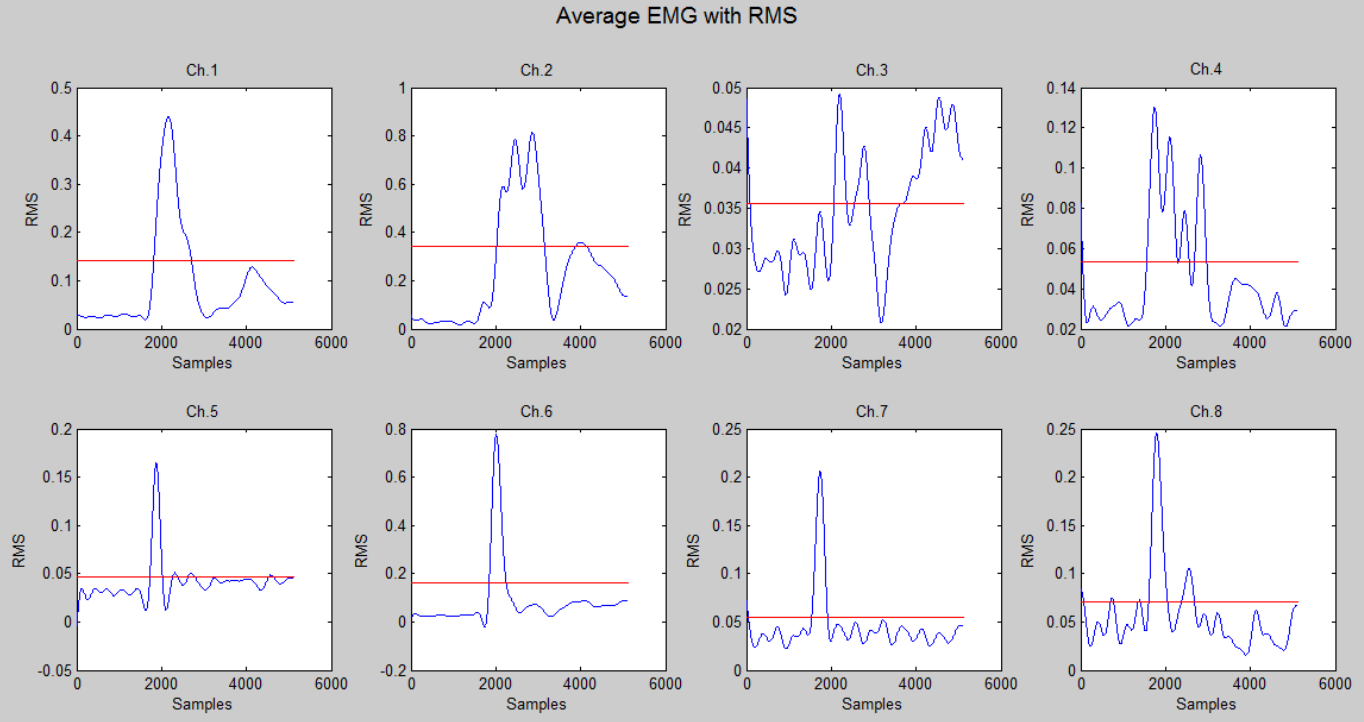


\section{Subject 4}

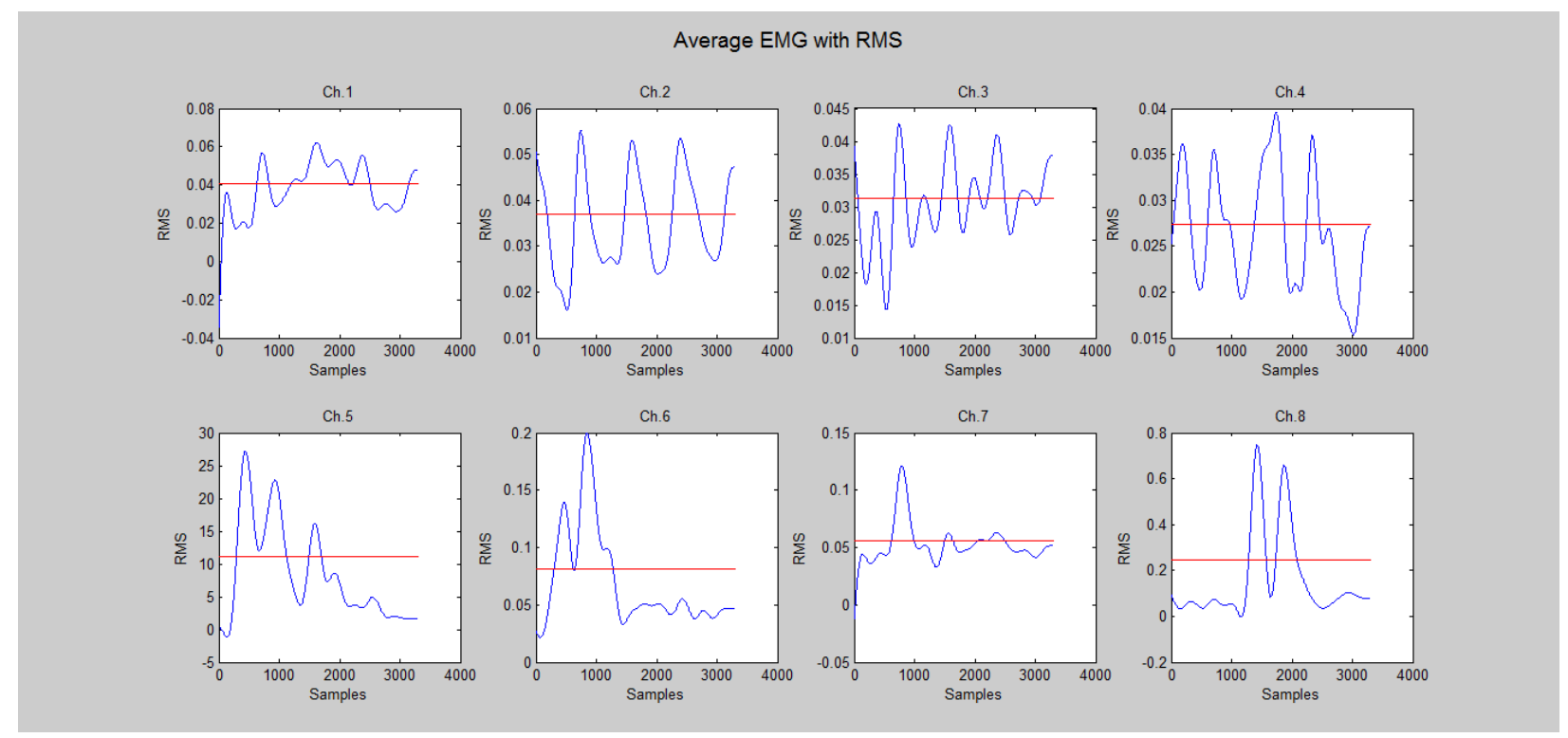

\section{Subject 5}
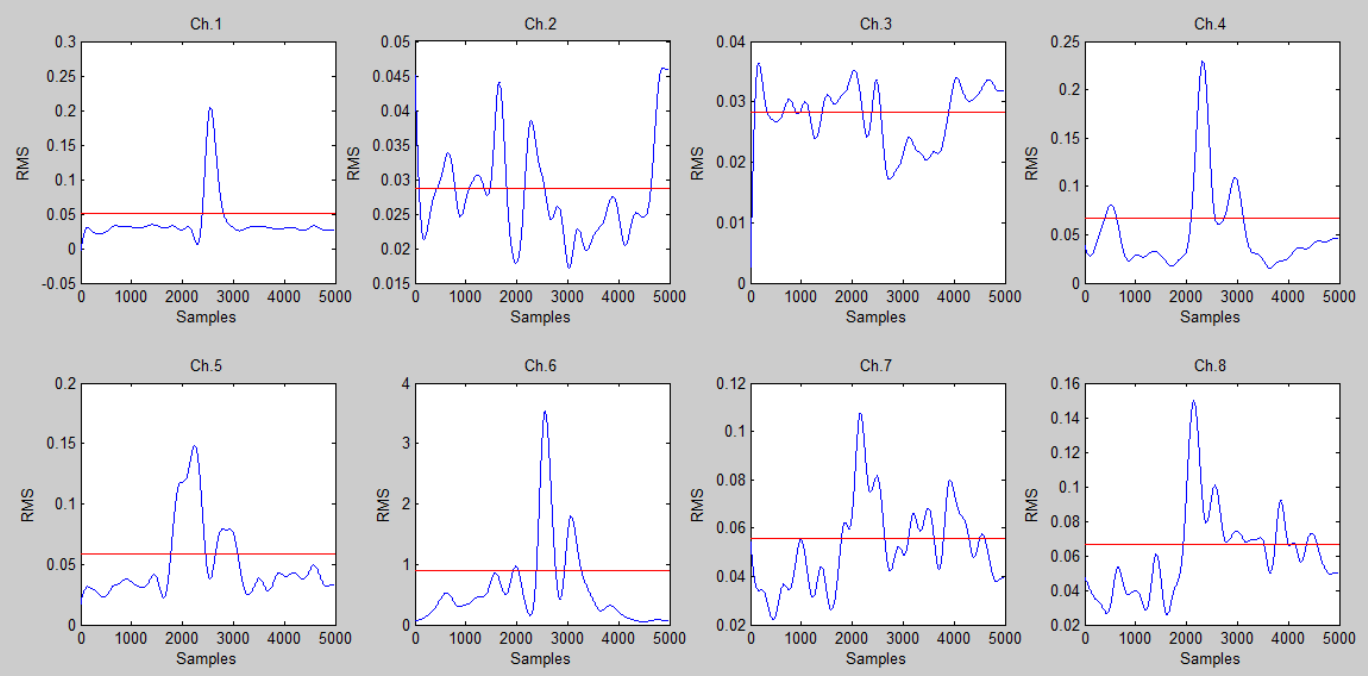


\section{Subject 6}

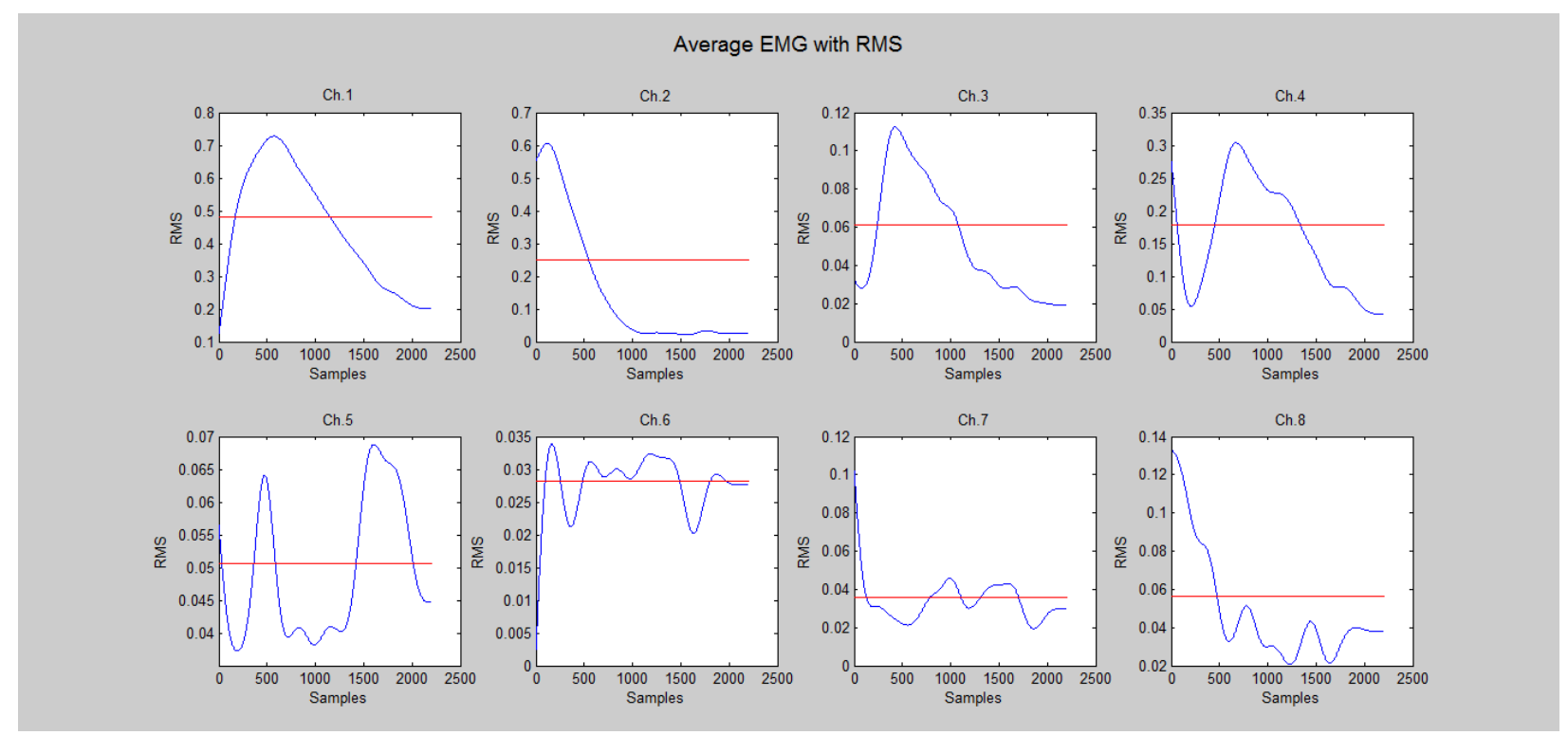

\section{Subject 7}

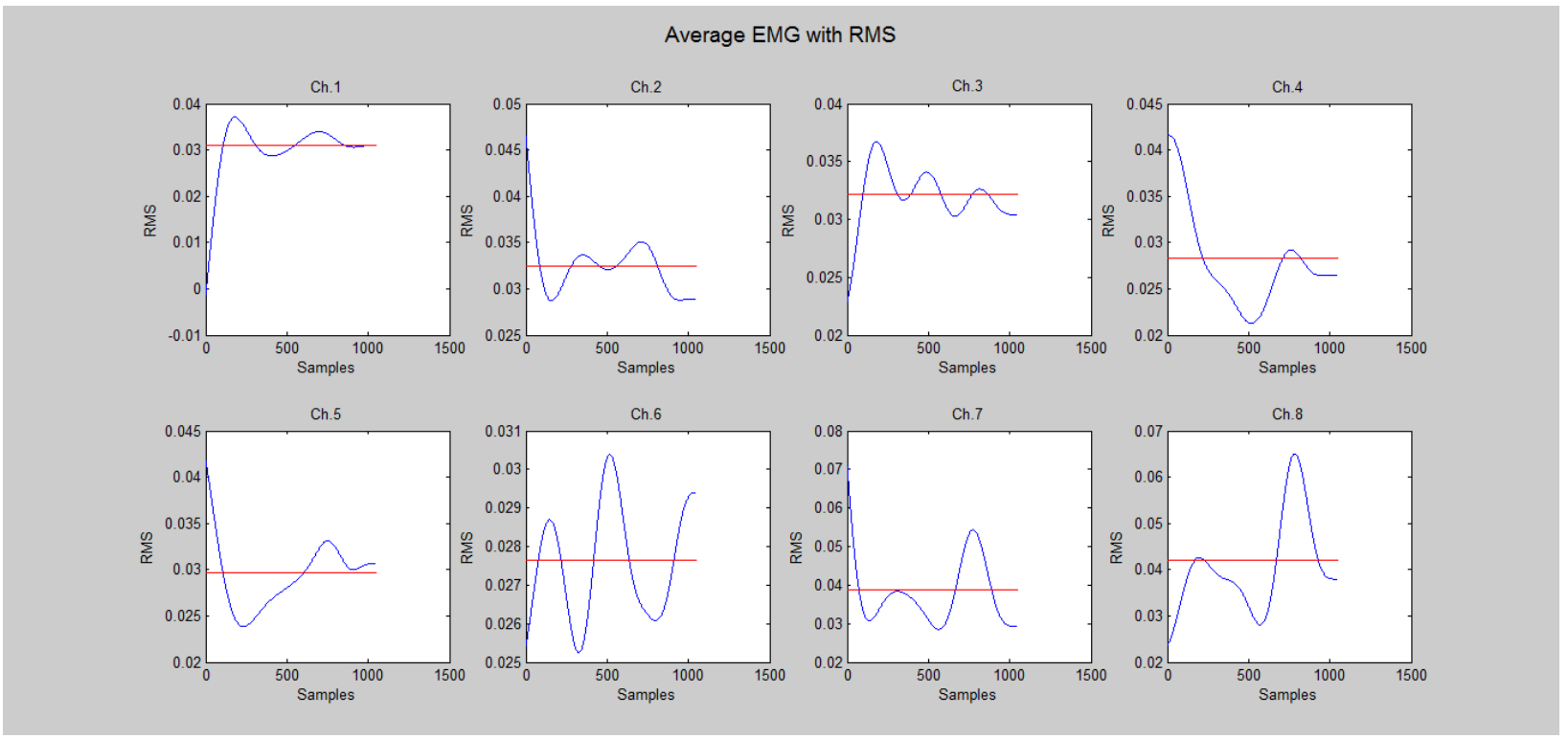




\section{Subject 8}
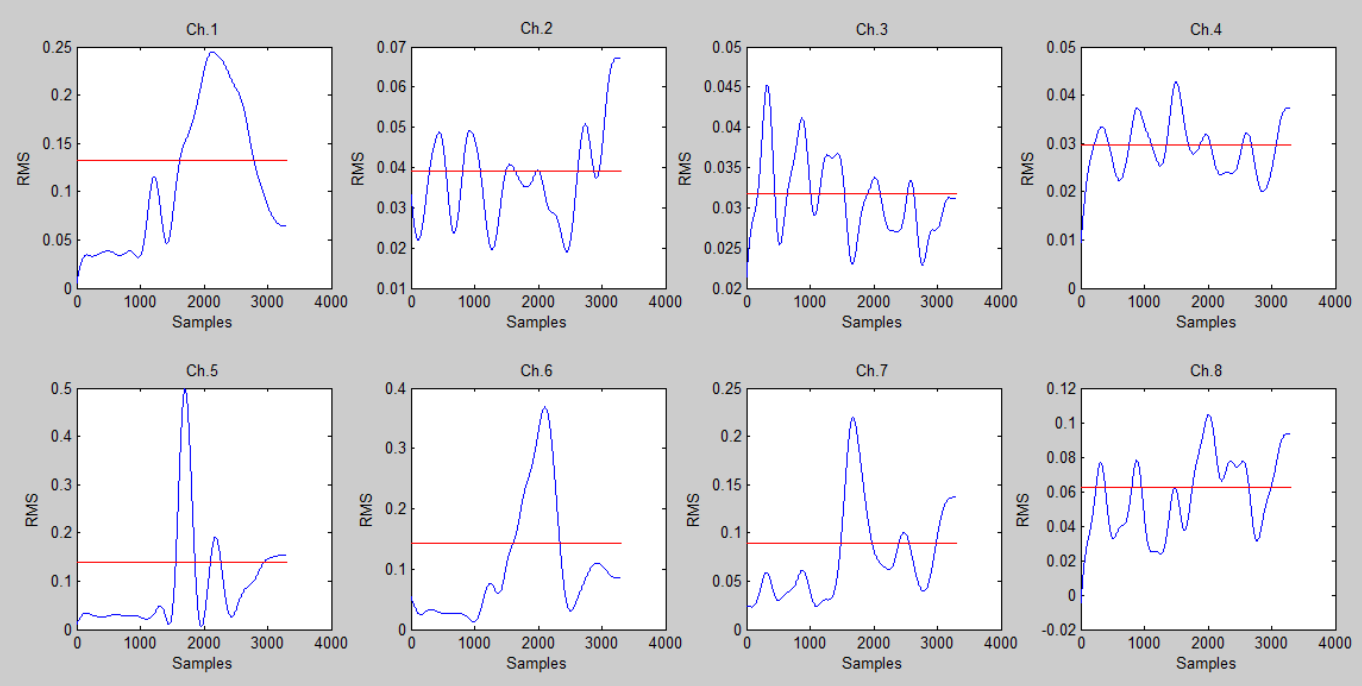

\section{Subject 9}
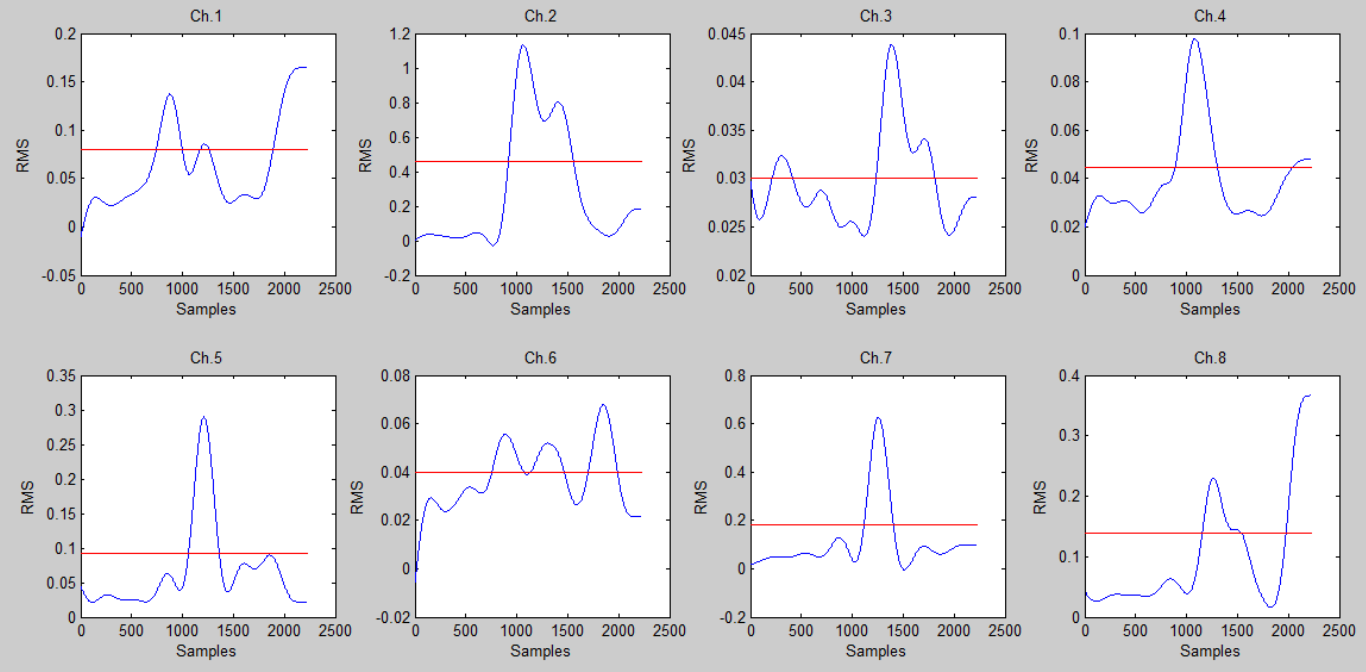


\section{Subject 2}

\section{FNN}

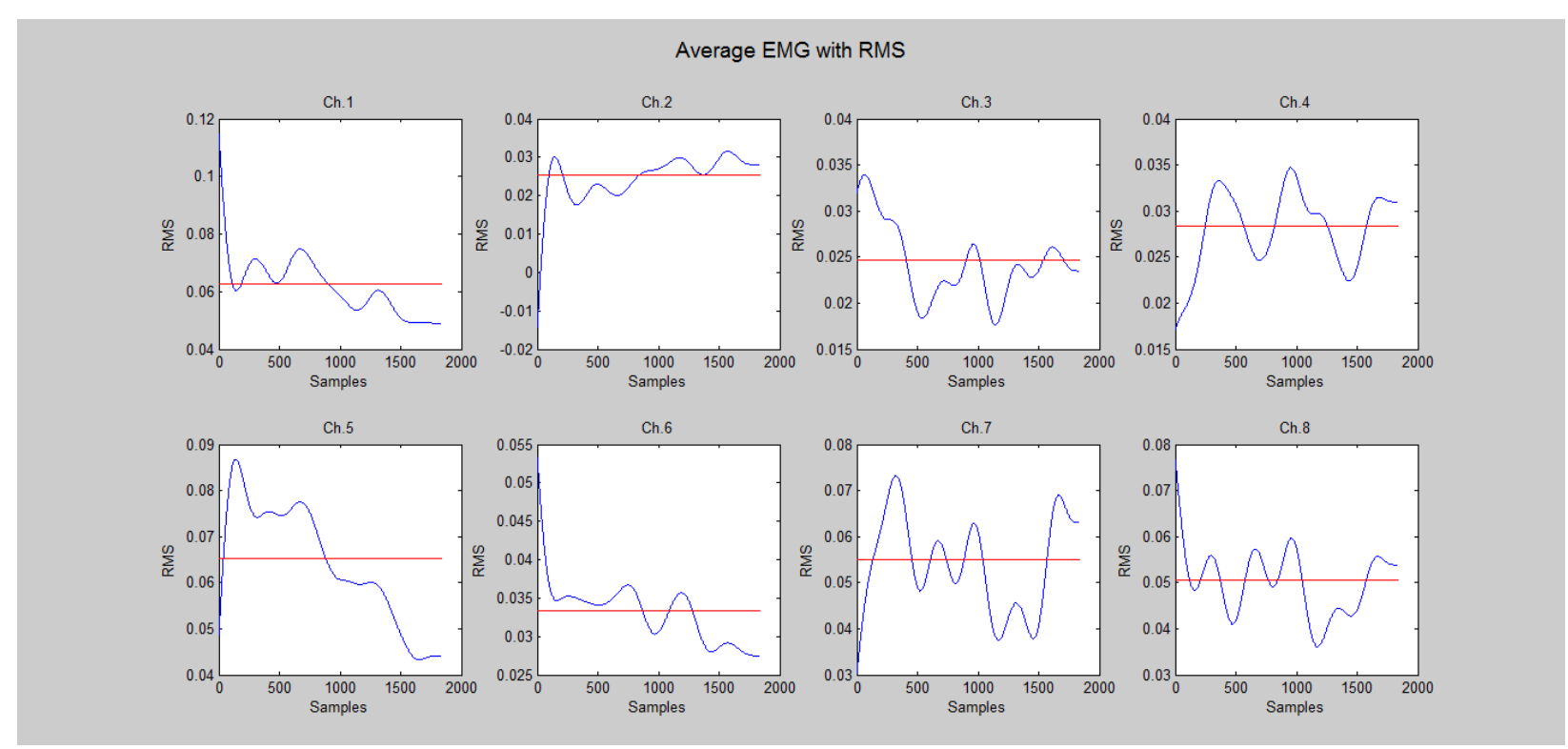

Subject 3
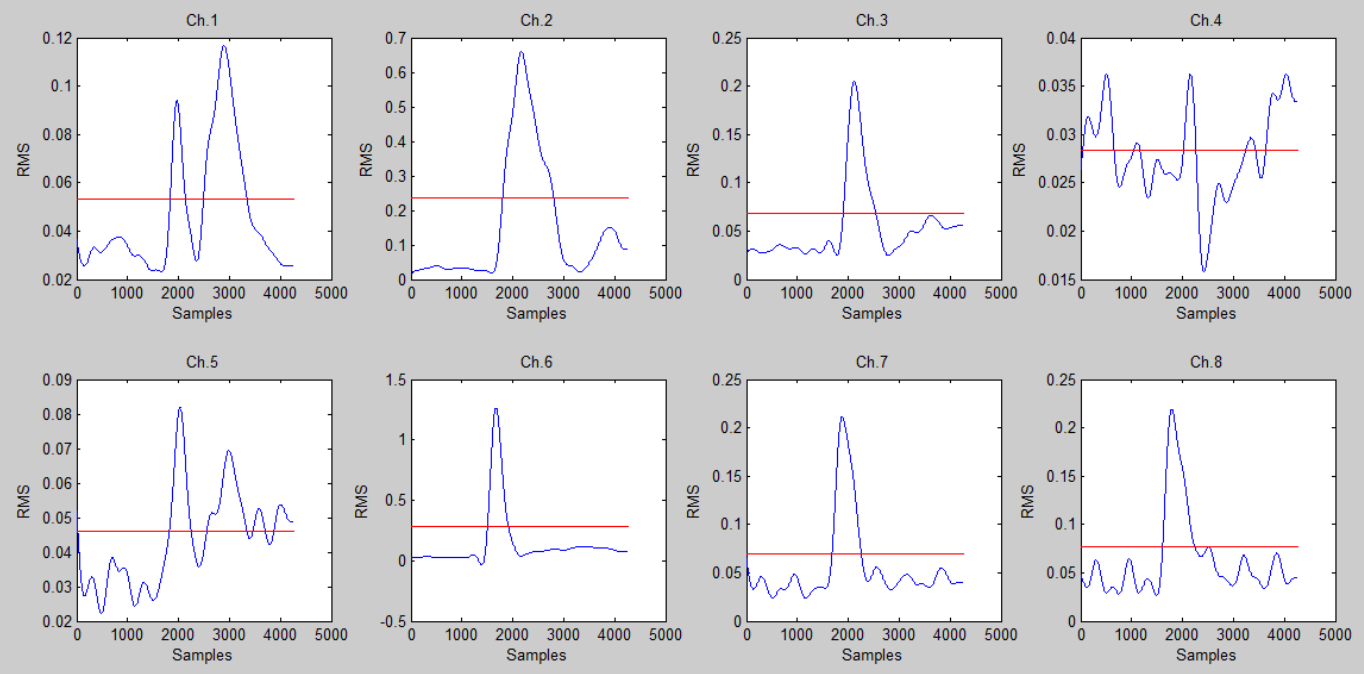


\section{Subject 4}

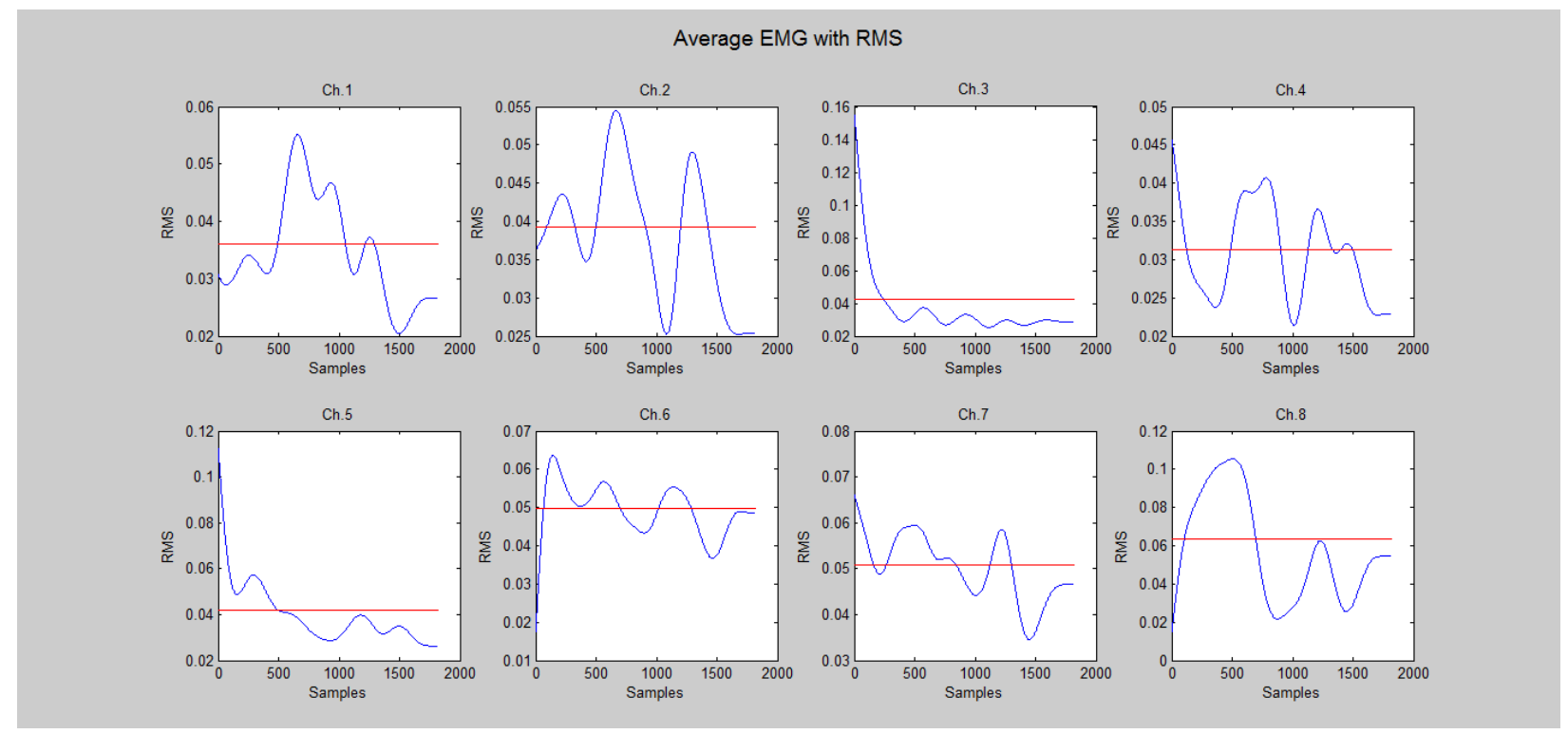

\section{Subject 5}
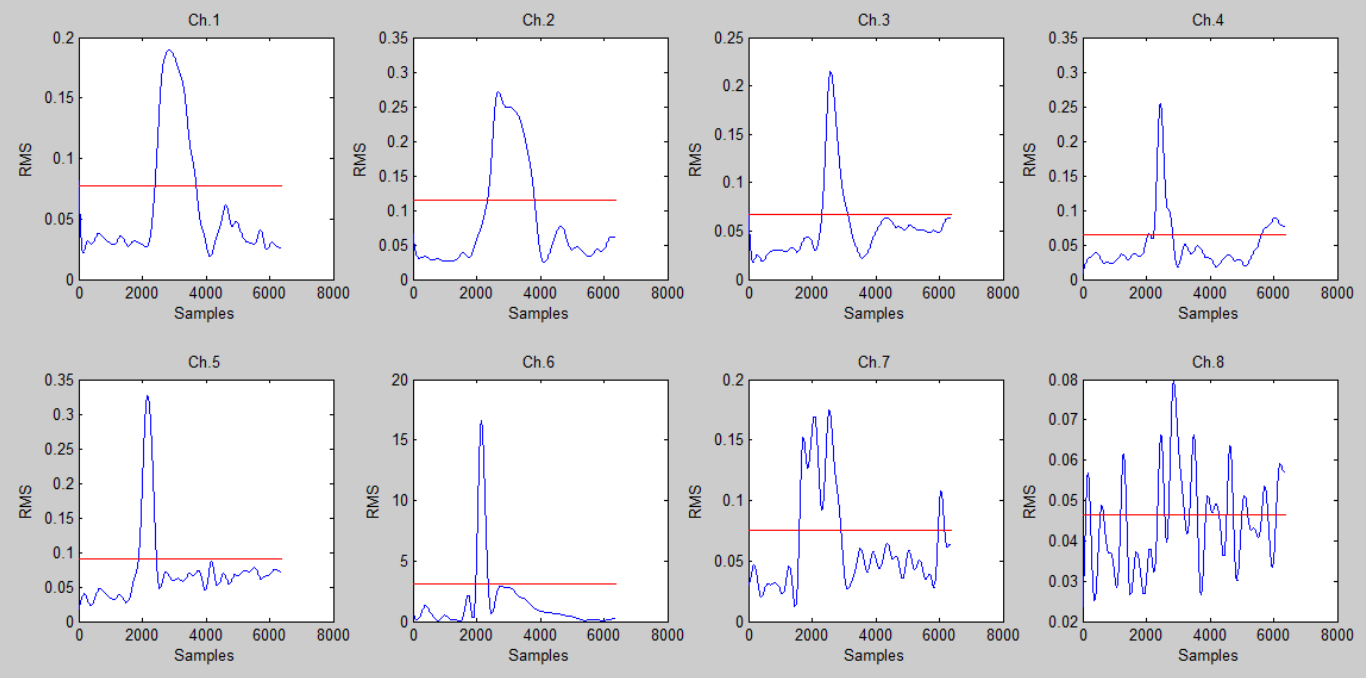
Subject 7

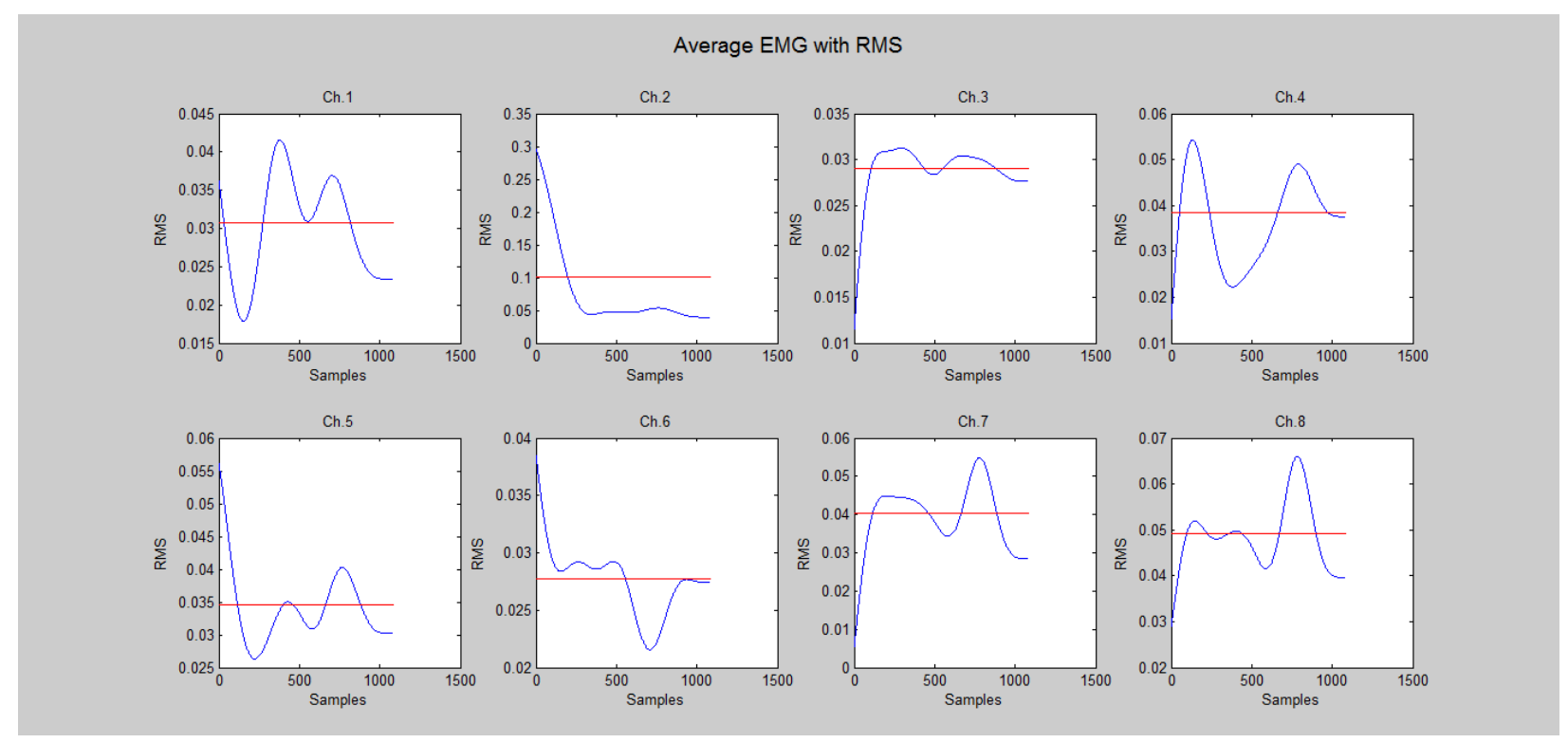

\section{Subject 9}
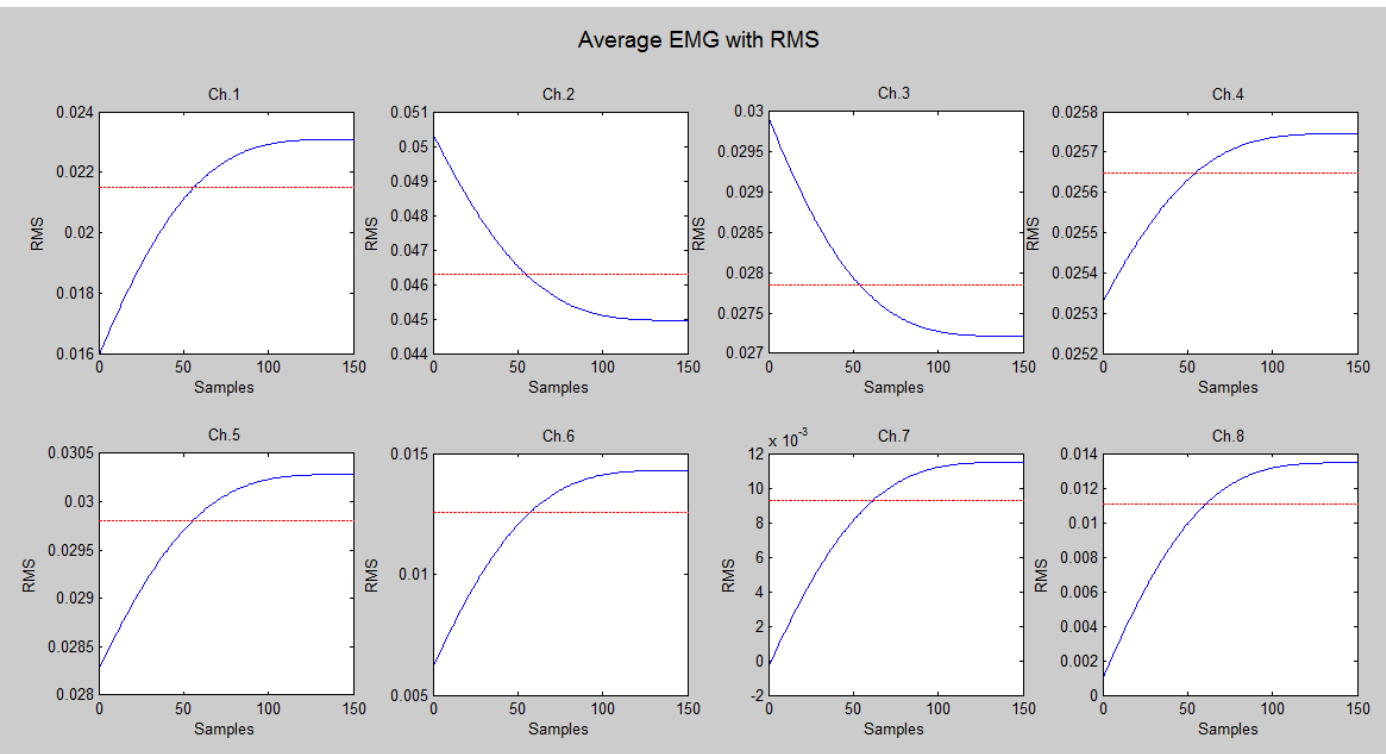


\section{FNV}

\section{Subject 1}
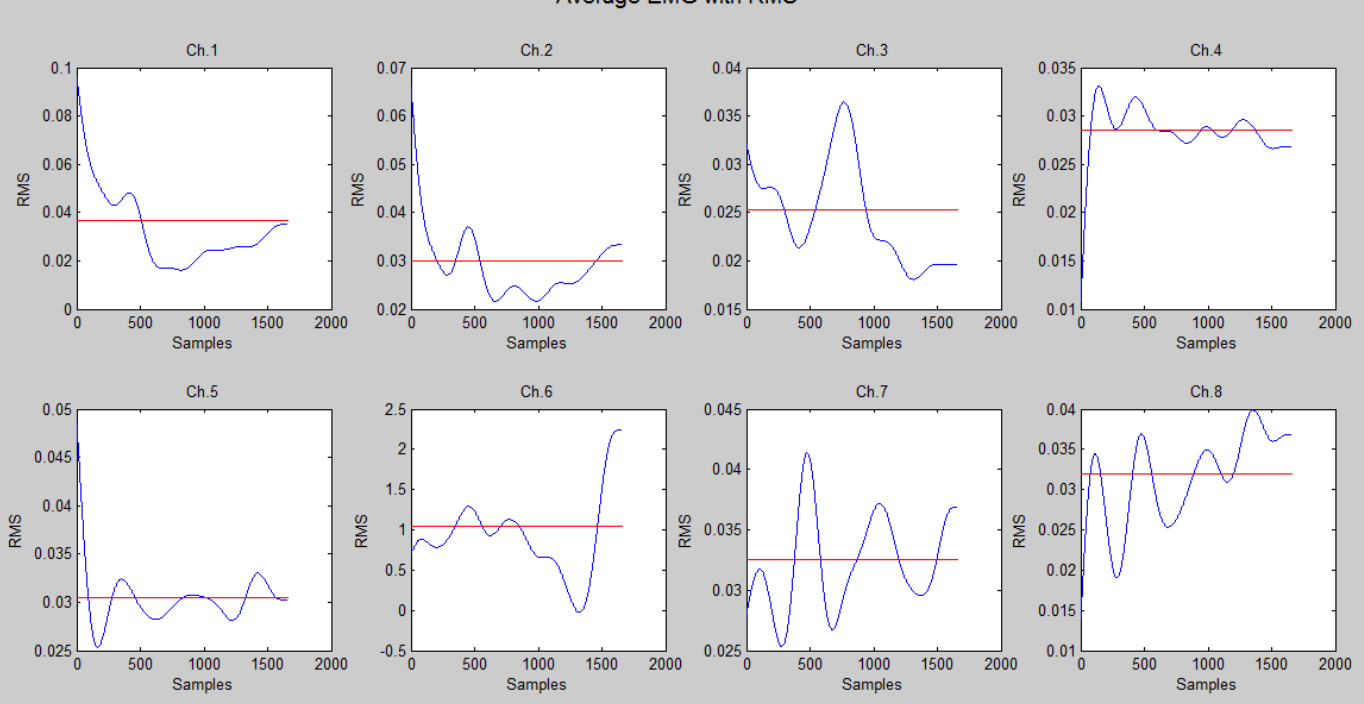

\section{Subject 2}
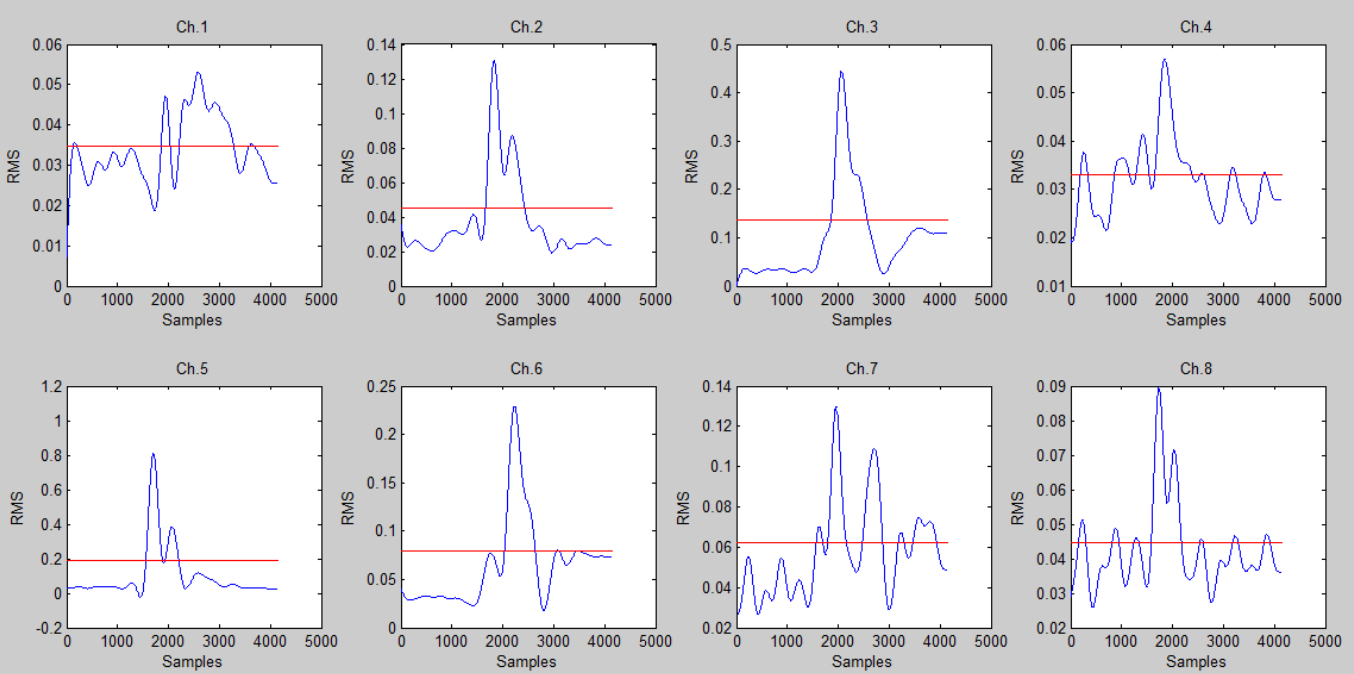


\section{Subject 3}

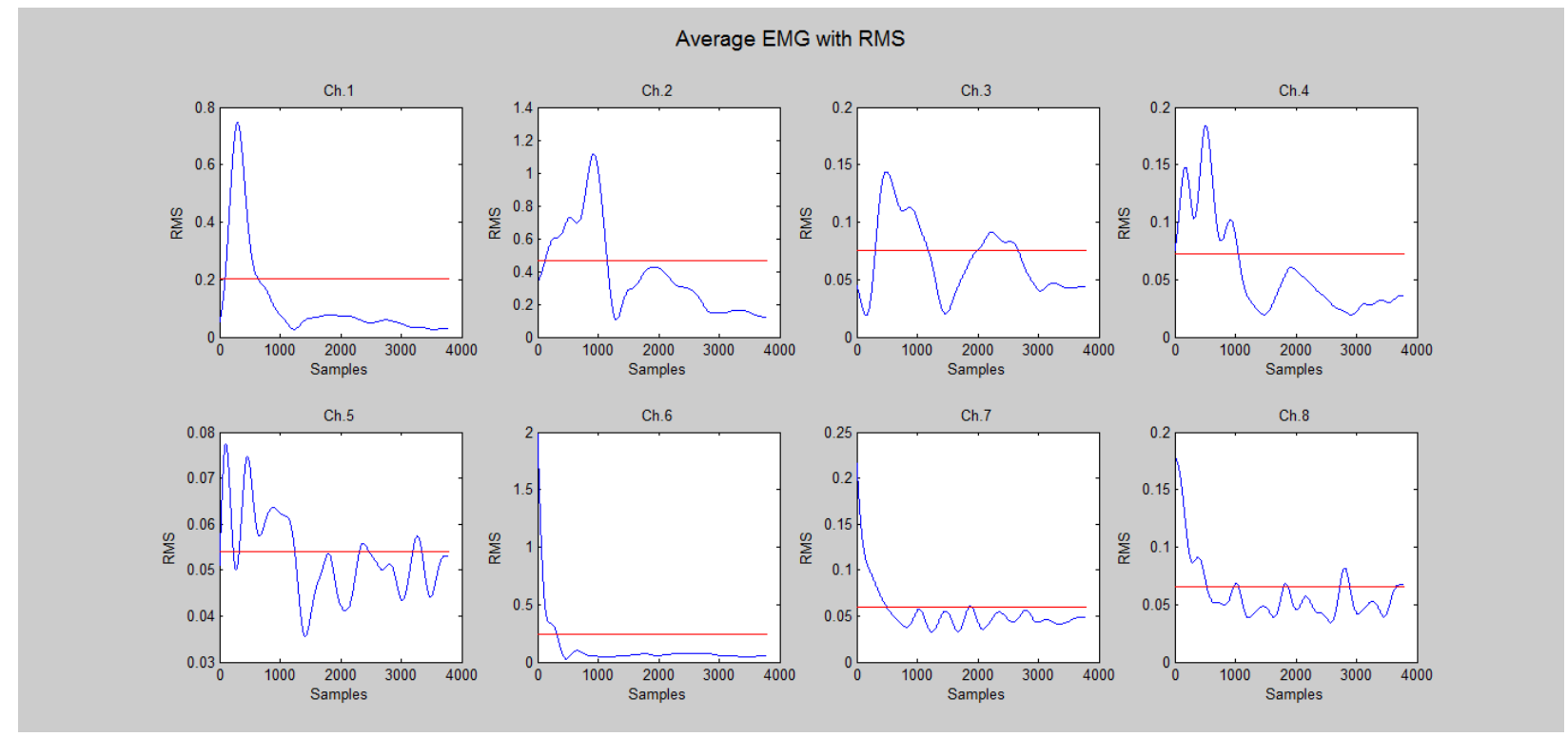

\section{Subject 4}
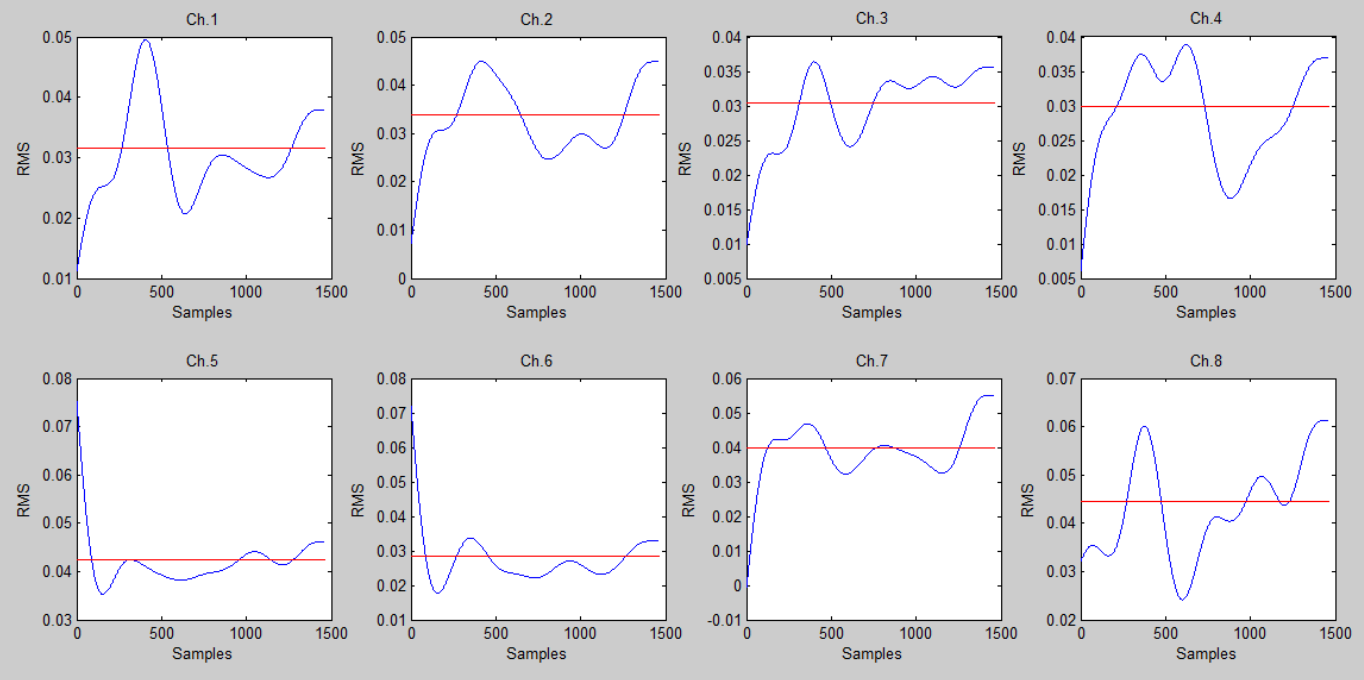


\section{Subject 5}
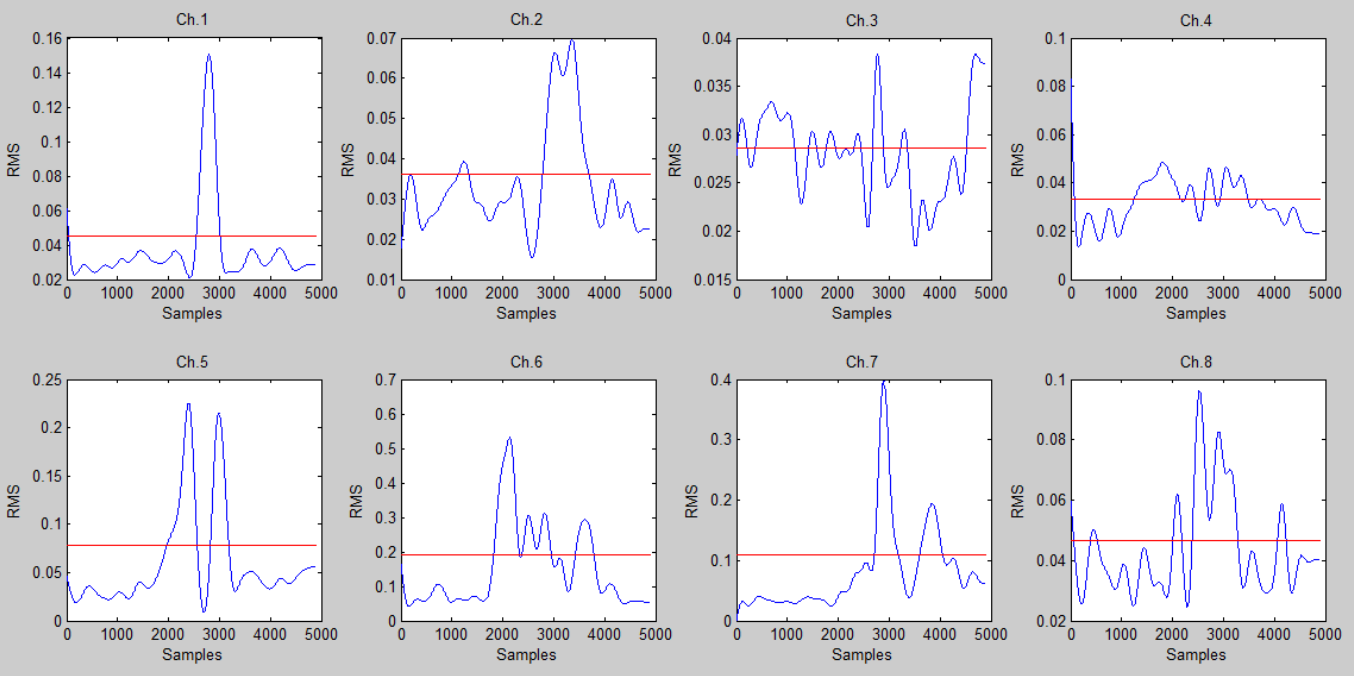

\section{Subject 6}
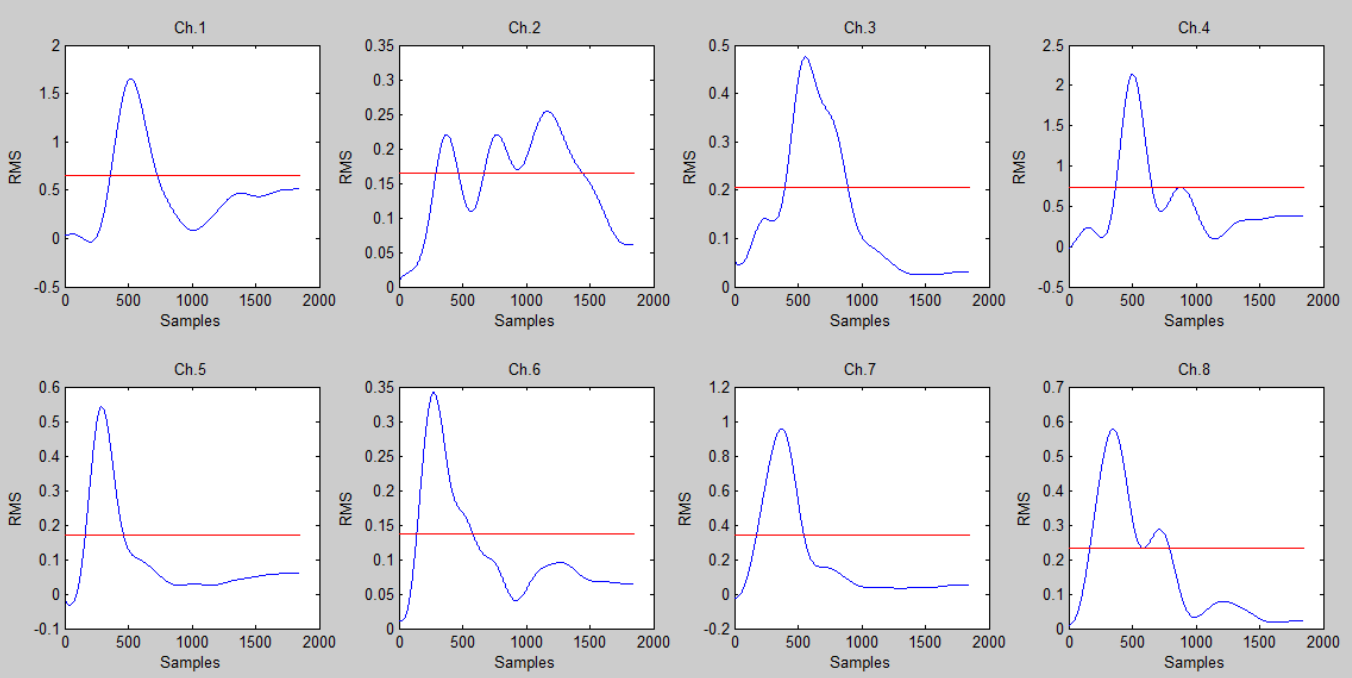


\section{Subject 8}

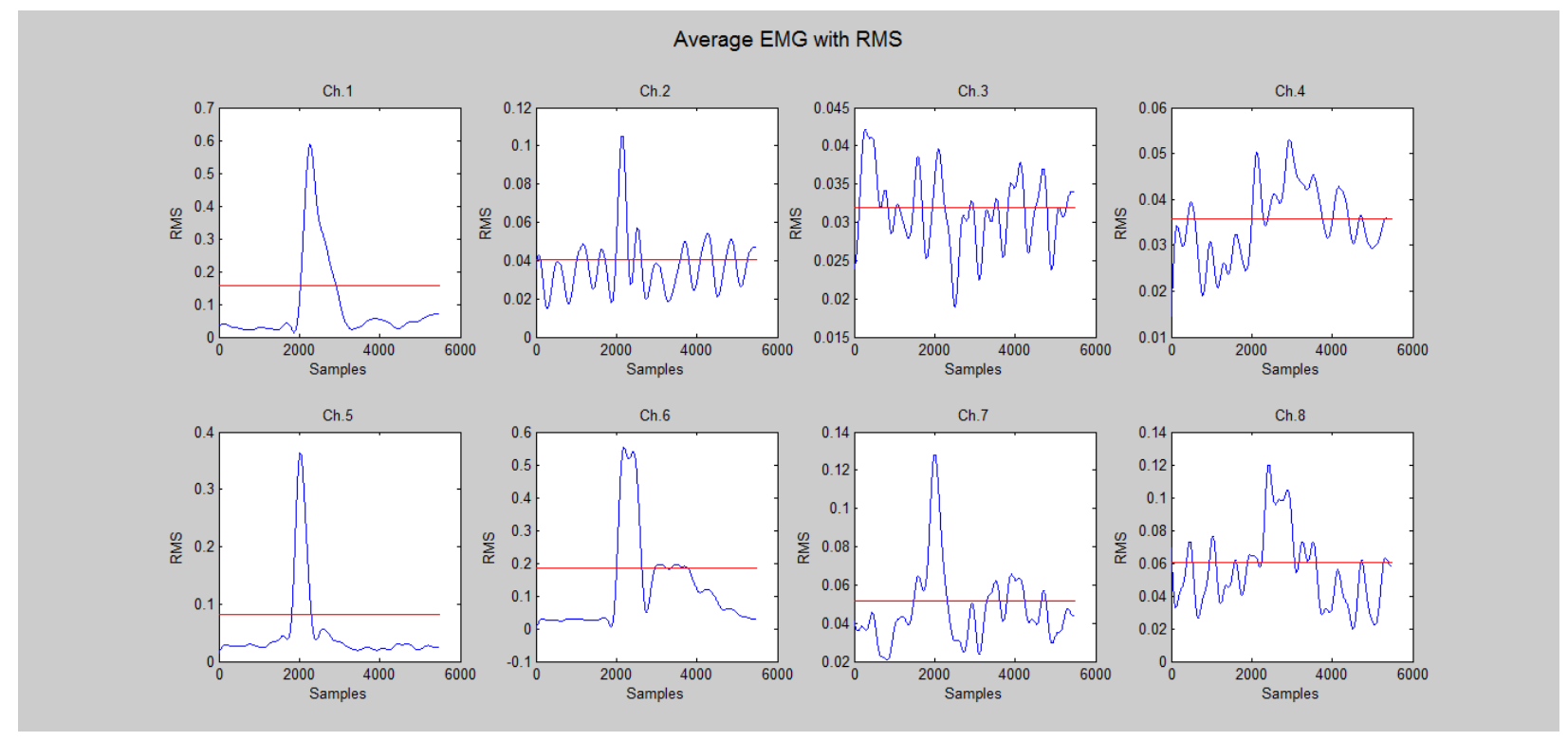

\section{Subject 9}

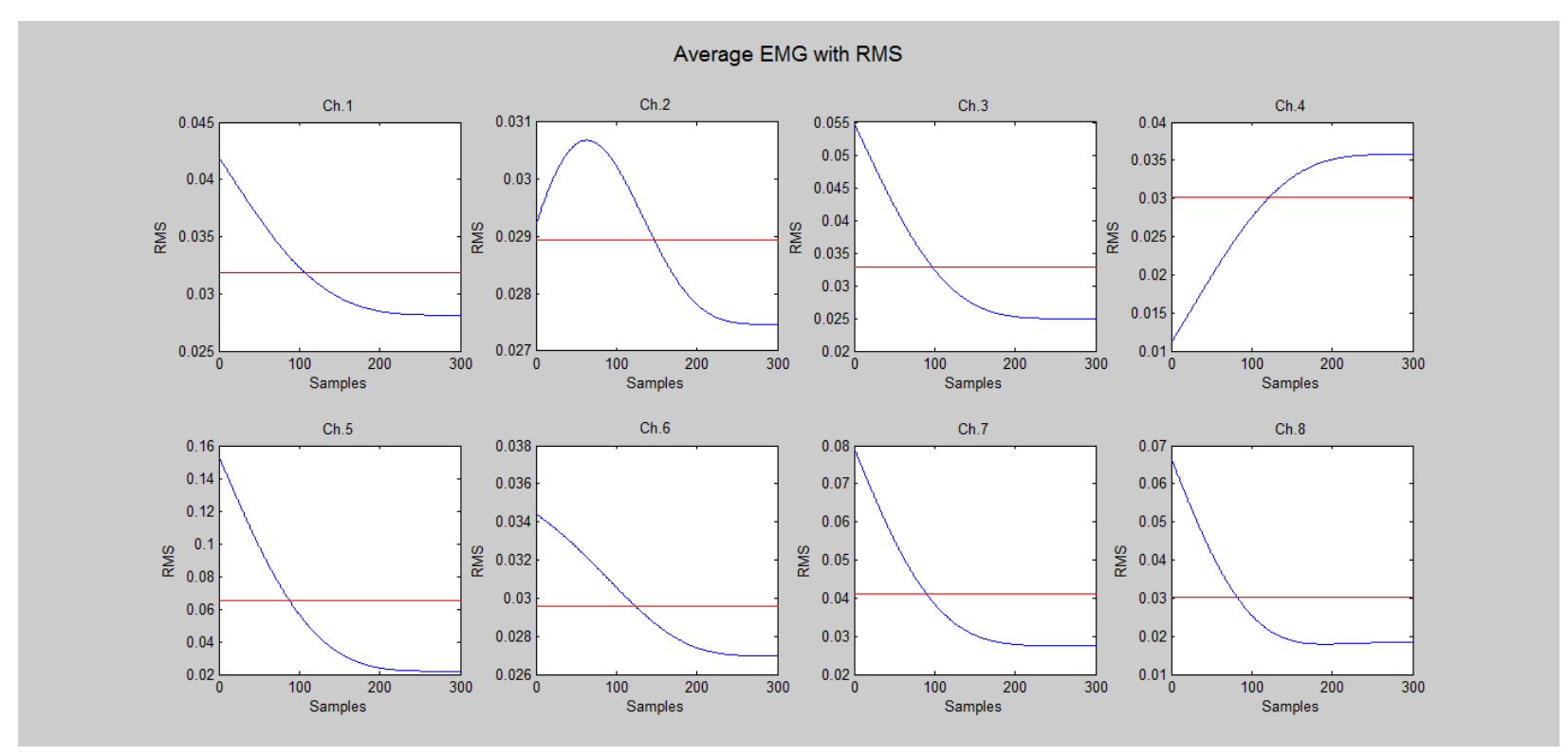




\section{References}

[1] Serra-Añó P, Pellicer-Chenoll M, Garcia-Massó X et al, "Sitting balance and limits of stability in persons with Paraplegia", Spinal Cord, vol. 51, pp. 267-272, 2013.

[2] Samuelsson K, Larsson H, Thyberg M, Gerdle B, "Wheelchair seating intervention," Disability and Rehabilitation, vol. 23, pp. 677-682, 2001.

[3] Sanderson DJ, Sommer HJ, "Kinematic features of wheelchair propulsion," Journal of Biomechanics, vol. 18, pp. 423-429, 1985.

[4] Curtis KA, Drysdale GA, Lanza RD et al, "Shoulder pain in wheelchair users with tetraplegia and paraplegia," Archives of Physical Medicine and Rehabilitation, vol. 80, pp. 453-457, 1999.

[5] Rintala DH, Loubser PG, Castro J et al, "Chronic pain in a community-based sample of men with spinal cord injury: prevalence, severity, and relationship with impairment, disability, handicap, and subjective well-being," Archives of Physical Medicine and Rehabilitation, vol. 79, pp. 604-614, 1996.

[6] Samuelsson KA, Tropp H, Nylander E et al, "The effect of rear-wheel position on seating ergonomics and mobility efficiency in wheelchair users with spinal cord injuries: a pilot study," Journal of Rehabilitation Research and Development, vol. 41, pp. 65-74, 2004.

[7] Sinnott KA, Milburn P, McNaughton H, "Factors associated with thoracic spinal cord injury, lesion level and rotator cuff disorders," Spinal Cord, vol. 38, pp. 748-753, 2000.

[8] Chow JW, Millikan TA, Carlton LG et al, "Kinematic and electromyographic analysis of wheelchair propulsion on ramps of different slopes for young men with paraplegia," Archives of Physical Medicine and Rehabilitation, vol. 90, pp. 271-278, 2009.

[9] Milosevic M, McConville KMV, Sejdic E et al, "Visualization of Trunk Muscle Synergies During Sitting Perturbations Using Self-Organizing Maps (SOM)", IEEE Transactions on Biomedical Engineering, vol. 59, pp. 2516-2523, 2012.

[10] Bjerkefors A, Carpenter MG, Cresswell AG et al, "Trunk muscle activation in a person with clinically complete thoracic spinal cord injury," Journal of Rehabilitation Medicine, vol. 41, pp. 390-392, 2009. 
[11] Mulroy SJ, Gronley JK, Newsam CJ et al, "Electromyographic activity of shoulder muscles during wheelchair propulsion by paraplegic persons," Archives of Physical Medicine and Rehabilitation, vol. 77, pp. 187-193, 1996.

[12] de Groot S, Veeger HE, Hollander AP et al, "Short-term adaptations in co-ordination during the initial phase of learning manual wheelchair propulsion," Journal of Electromyography and Kinesiology, vol. 13, pp. 217-228, 2003.

[13] Yang YS, Koontz AM, Triolo RJ et al, "Surface electromyography activity of trunk muscles during wheelchair propulsion," Clinical Biomechanics, vol. 21, pp. 1032-1041, 2006.

[14] Dallmeijer AJ, van der Woude LH, Veeger HE et al, "Effectiveness of force application in manual wheelchair propulsion in persons with spinal cord injuries," American Journal of Physical Medicine and Rehabilitation, vol. 77, pp. 213-221, 1998.

[15] Howarth SJ, Polgar JM, Dickerson CR et al, "Trunk Muscle Activity During Wheelchair Ramp Ascent and the Influence of a Geared Wheel on the Demands of Postural Control," Archives of Physical Medicine and Rehabilitation, vol. 91, pp. 436-442, 2010.

[16] Warren WH, Kay BA, Zosh WD et al, "Optic flow is used to control human walking", Nature Neuroscience, vol. 4, pp. 213-216, 2001.

[17] Keshner EA, "Virtual reality and physical rehabilitation: a new toy or a new research and rehabilitation tool?", Journal of NeuroEngineering and Rehabilitation, vol. 1, pp. 1-2, 2004.

[18] Shafeie M, Zolfaghari N, McConville KMV, "Abdominal muscle behavior and motion sickness during paired visual input with roll motion," Human System Interaction (HSI), 2013 The 6th International Conference, pp.247-251, 2013.

[19] Shafeie M, Zolfaghari N, McConville KMV, "Seated Balance During Pitch Motion with and without Visual Input", Engineering in Medicine and Biology Society (EMBC), 2013 35th Annual International Conference of the IEEE, pp. 6385-6388, 2013.

[20] Carrozzo M, Lacquaniti F, "Virtual reality: a tutorial", Electroencephalogr Clin Neurophysiol, vol. 109, pp. 1-9, 1998.

[21] Reid D, Campbell K, "The Use of Virtual Reality with Children with Cerebral Palsy: A Pilot Randomized Trial", Therapeutic Recreation Journal, vol. 40, pp. 255-268, 2006.

[22] Wilson PN, Foreman N, Stanton D, "Virtual reality, disability and rehabilitation", Disability and Rehabilitation, vol. 19, pp. 213-220, 1997.

[23] Lacour M, Barthelemy J, Borel L et al, "Sensory strategies in human postural control before and after unilateral vestibular neurotomy", Exp. Brain Res, vol. 115, pp. 300-310, 1997. 
[24] Inman DP, Loge K, Cram A, "Learning to drive a wheelchair in virtual reality", Journal of Special Education Technology, vol. 26, pp. 21-34, 2011.

[25] Di Gironimo G, Matrone G, Tarallo A, "A virtual reality approach for usability assessment: case study on a wheelchair-mounted robot manipulator", Engineering with Computers, vol. 29, pp. 359-373, 2013.

[26] Virk S, Valter McConville KMV, "Virtual reality applications in improving postural control and minimizing falls", Proceedings of the 28th IEEE EMBS Annual International Conference, pp. 2694-2697, 2006.

[27] Money KE, "Motion Sickness", Am. Psychol. Soc, vol. 50, pp. 1-39, 1970.

[28] Golding JF, "Motion Sickness Susceptibility", Autonomic Neuroscience: Base and Clinical, vol. 129, pp. 67-76, 2006.

[29] Garg A, Owen B, Beller D et al, "A Biomechanical and Ergonomic Evaluation of Patient Transferring Task: Bed to Wheelchair and Wheelchair to Bed," Ergonomics, vol. 34, pp.289-312, 1991.

[30] Forsland EB, Granström A, Levi R et al, "Transfer from Table to Wheelchair in Men and Women with Spinal Cord Injury: Coordination of Body Movement and Arm Forces," Spinal Cord, vol. 45, pp. 41-84, 2007.

[31] Reeves NP, Everding VQ, Cholewicki J et al, "The effects of trunk stiffness on postural control during unstable seated balance", Experimental Brain Research, vol. 174, pp. 694700, 2006.

[32] Zolfaghari N, Shafeie M, Sirikantharajah S, McConville KMV, "Comparison of PS25015A Dry Electrodes and Two Different $\mathrm{Ag} / \mathrm{AgCl}$ Wet Electrodes for ECG Applications", SENSORDEVICES 2014, The Fifth International Conference on Sensor Device Technologies and Applications, pp. 79-83, 2014.

[33] Zolfaghari N, Sirikantharajah S, Shafeie M, McConville KMV, "Adaptive Filtering Technique and Comparison of PS25015A Dry Electrodes and Two Different $\mathrm{Ag} / \mathrm{AgCl}$ Wet Electrodes for Wearable ECG Applications", Sensors \& Transducers, vol. 184, pp. 84-97, 2015.

[34] Konrad P, The ABC of EMG: A Practical Introduction into Kinesiological Electromyography, Scottsdale: Noraxon U.S.A. Inc., 2005.

[35] Raez MBI, Hussain MS, Mohd-Yasin F, "Techniques of EMG signal analysis: detection, processing, classification and applications," Biological Procedures Online, vol. 8, pp. 11$35,2006$. 
[36] Besio W, Prasad A, "Analysis of Skin-Electrode Impedance Using Concentric Ring Electrode," Engineering in Medicine and Biology Society, 2006. EMBS '06. 28th Annual International Conference of the IEEE , pp. 6414-6417, 2006.

[37] Cleveland Medical Devices Inc., BioRadio® 150 User Guide, Cleveland, U.S.A., 2011.

[38] Shafeie M, "Trunk Muscle EMG in a Specially Designed Virtual Reality Motion Simulator," Toronto, Canada, 2013.

[39] Masani K, Sin VW, Vette AH et al, "Postural reactions of the trunk muscles to multidirectional perturbations in sitting", Clinical Biomechanics, vol. 24, pp. 176-182, 2009.

[40] Szabo M, Kanuka H, "Effects of Violating Screen Design Principles of Balance, Unity and Focus on Recall Learning, Study Time and Completion Rate", Journal of Educational Multimedia and Hypermedia, vol. 8, pp. 23-42, 1999.

[41] Zedka M, Kumar S, Narayan Y, "Electromyographic response of the trunk muscles to postural perturbation in sitting subjects", Journal of Electromyography and Kinesiology, vol. 8, pp. 3-10, 1998.

[42] Cooper RA, Ding D, Simpson R et al, "Virtual reality and computer-enhanced training applied to wheeled mobility: an overview of work in Pittsburgh", Assistive Technology, vol. 17, pp. 159-170, 2005.

[43] Harrisson A, Derwent G, Enticknap A et al, "The role of virtual reality technology in the assessment and training of inexperienced powered wheelchair users", Disability and Rehabilitation, vol. 24, pp. 599-606, 2002.

[44] Mahajan HP, Dicianno BE, Cooper RA et al, "Assessment of wheelchair driving performance in a virtual reality-based simulator", The Journal of Spinal Cord Medicine, vol. 36, pp. 322-332, 2013.

[45] Erren-Wolters CV, van Dijk H, de Kort AC et al, "Virtual reality for mobility devices: training applications and clinical results: a review", International Journal of Rehabilitation Research, vol. 30, pp. 91-96, 2007. 